Prepared for the U.S. Department of Energy

under Contract DE-AC05-76RL01830

\title{
Development of a Hydrodynamic and Transport model of Bellingham Bay in Support of Nearshore Habitat Restoration
}

\author{
TWang \\ Z Yang \\ T Khangaonkar
}

April, 2010

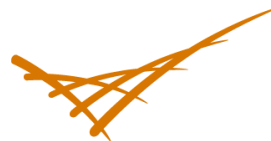

Pacific Northwest

NATIONAL LABORATORY

Proudly Operated by Battelle Since 1965 


\title{
DISCLAIMER
}

This report was prepared as an account of work sponsored by an agency of the United States Government. Neither the United States Government nor any agency thereof, nor Battelle Memorial Institute, nor any of their employees, makes any warranty, express or implied, or assumes any legal liability or responsibility for the accuracy, completeness, or usefulness of any information, apparatus, product, or process disclosed, or represents that its use would not infringe privately owned rights. Reference herein to any specific commercial product, process, or service by trade name, trademark, manufacturer, or otherwise does not necessarily constitute or imply its endorsement, recommendation, or favoring by the United States Government or any agency thereof, or Battelle Memorial Institute. The views and opinions of authors expressed herein do not necessarily state or reflect those of the United States Government or any agency thereof.

\author{
PACIFIC NORTHWEST NATIONAL LABORATORY \\ operated by \\ BATTELLE \\ for the \\ UNITED STATES DEPARTMENT OF ENERGY \\ under Contract DE-ACO5-76RL01830
}

Printed in the United States of America

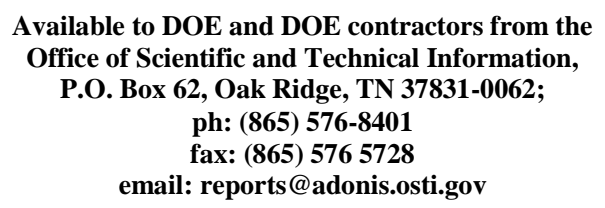

email: reports@adonis.osti.gov

\author{
Available to the public from the National Technical Information Service, \\ U.S. Department of Commerce, 5285 Port Royal Rd., Springfield, VA 22161 \\ ph: (800) 553-6847$$
\text { fax: }(703) 605-6900
$$ \\ email: orders@nits.fedworld.gov \\ online ordering: http://www.ntis.gov/ordering.htm
}




\section{Development of a Hydrodynamic and Transport Model of Bellingham Bay in Support of Nearshore Habitat Restoration}

T Wang

Z Yang

T Khangaonkar

April, 2010

Prepared for

Washington State Department of Ecology

Contract \# DE-AC05-76RL01830

Pacific Northwest National Laboratory

Richland, Washington 99352 



\section{Executive Summary}

In this study, a hydrodynamic model based on the unstructured-grid finite volume coastal ocean model (FVCOM) was developed for Bellingham Bay, Washington. The model simulates water surface elevation, velocity, temperature, and salinity in a three-dimensional domain that covers the entire Bellingham Bay and adjacent water bodies, including Lummi Bay, Samish Bay, Padilla Bay, and Rosario Strait. The model was developed using Pacific Northwest National Laboratory's high-resolution Puget Sound and Northwest Straits circulation and transport model. A sub-model grid for Bellingham Bay and adjacent coastal waters was extracted from the Puget Sound model and refined in Bellingham Bay using bathymetric light detection and ranging (LIDAR) and river channel cross-section data. The model uses tides, river inflows, and meteorological inputs to predict water surface elevations, currents, salinity, and temperature. A tidal open boundary condition was specified using standard National Oceanic and Atmospheric Administration (NOAA) predictions. Temperature and salinity open boundary conditions were specified based on observed data. Meteorological forcing (wind, solar radiation, and net surface heat flux) was obtained from NOAA real observations and National Center for Environmental Prediction North American Regional Analysis outputs. The model was run in parallel with 48 cores using a time step of 2.5 seconds. It took 18 hours of cpu time to complete 26 days of simulation. The model was calibrated with oceanographic field data for the period of 6/10/2009 to 6/25/2009. These data were collected specifically for the purpose of model development and calibration. They include time series of water-surface elevation, currents, temperature, and salinity as well as temperature and salinity profiles during instrument deployment and retrieval. Comparisons between model predictions and field observations show an overall reasonable agreement in both temporal and spatial scales. Comparisons of root mean square error values for surface water elevation, velocity, temperature, and salinity time series are $0.11 \mathrm{~m}, 0.10 \mathrm{~m} / \mathrm{s}, 1.28^{\circ} \mathrm{C}$, and $1.91 \mathrm{ppt}$, respectively. The model was able to reproduce the salinity and temperature stratifications inside Bellingham Bay. Wetting and drying processes in tidal flats in Bellingham Bay, Samish Bay, and Padilla Bay were also successfully simulated.

Both model results and observed data indicated that water surface elevations inside Bellingham Bay are highly correlated to tides. Circulation inside the bay is weak and complex and is affected by various forcing mechanisms, including tides, winds, freshwater inflows, and other local forcing factors. The Bellingham Bay model solution was successfully linked to the NOAA oil spill trajectory simulation model "General NOAA Operational Modeling Environment (GNOME)." Overall, the Bellingham Bay model has been calibrated reasonably well and can be used to provide detailed hydrodynamic information in the bay and adjacent water bodies. While there is room for further improvement with more available data, the calibrated hydrodynamic model provides useful hydrodynamic information in Bellingham Bay and can be used to support sediment transport and water quality modeling as well as assist in the design of nearshore restoration scenarios. 



\section{Acronyms and Abbreviations}

2-D

3-D

ADCP

BBAT

CE-QUAL-ICM

CTD

DFO

DNR

Ecology

EFDC

FVCOM

GIS

GNOME

HAZMAT

LIDAR

MAE

ME

NAD83

NARR

NCEP

NOAA

PNNL

POM

PSDEM

PSLC

RMSE

USGS

UTM

UW

XTide two-dimensional

three-dimensional

Acoustic Doppler Current Profiler

Bellingham Bay Action Team

The Corps of Engineers Integrated Compartment Water Quality Model

Conductivity, Temperature, and Depth

Department of Fisheries and Oceans Canada

Washington State Department of Natural Resources

Washington State Department of Ecology

Environmental Fluid Dynamics Code

Finite Volume Coastal Ocean Model

Geographic Information System

the General NOAA Oil Modeling Environment

Hazardous Materials Response Division

Light Detection and Ranging

Mean Absolute Error

Mean Error

North American Datum of 1983

North American Regional Analysis

National Center for Environmental Prediction

National Oceanic and Atmospheric Administration

Pacific Northwest National Laboratory

Princeton Ocean Model

Puget Sound Digital Elevation Model

Puget Sound LIDAR Consortium

Root Mean Square Error

U.S. Geological Survey

Universal Transverse Mercator

University of Washington

Harmonic tide clock and tide predictor 



\section{Contents}

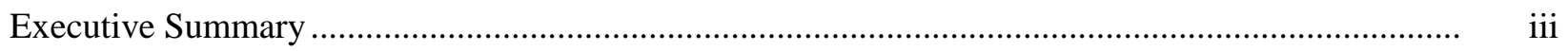

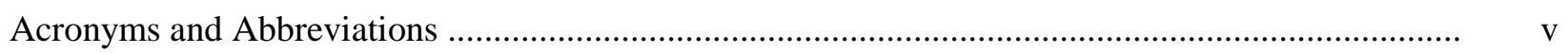

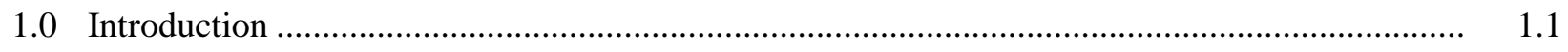

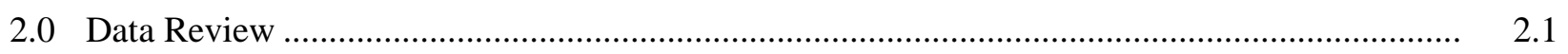

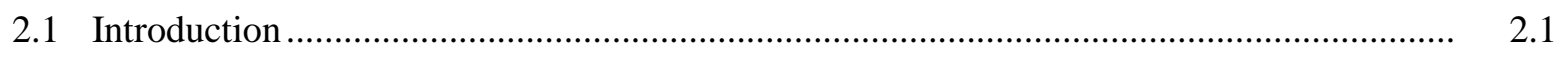

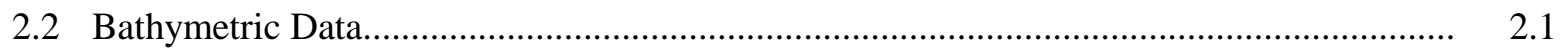

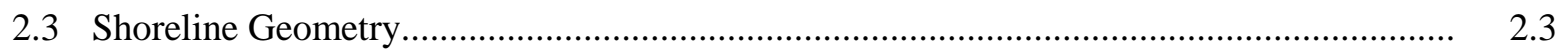

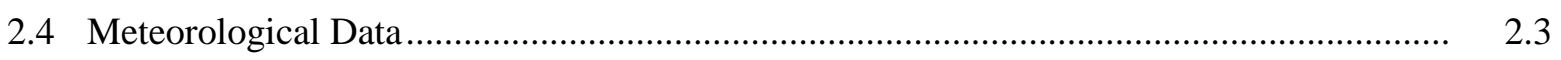

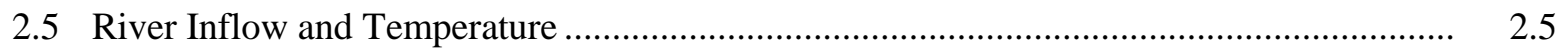

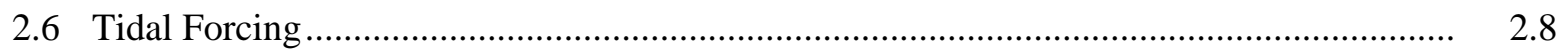

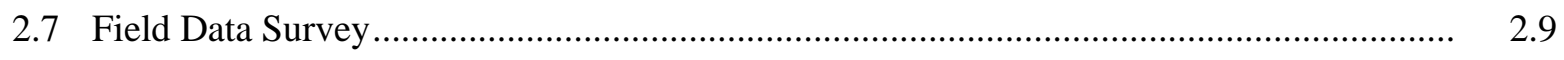

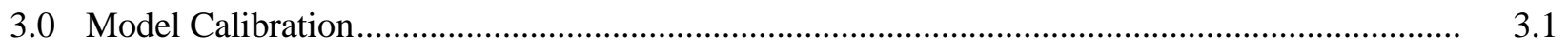

3.1 The Hydrodynamic Model ….............................................................................

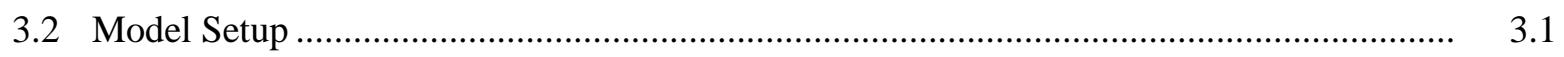

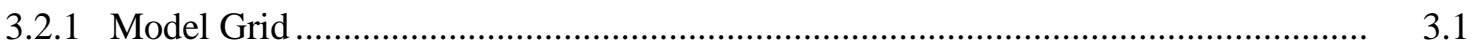

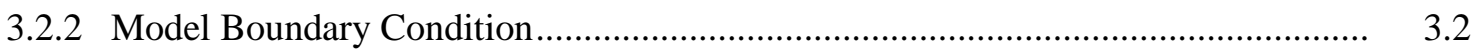

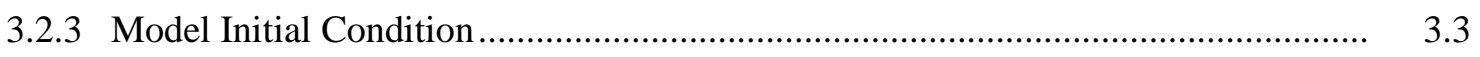

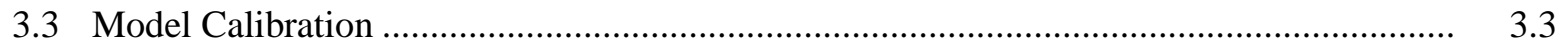

3.3.1 Model Calibration-Water-Surface Elevation .................................................... 3.4

3.3.2 Model Calibration —Velocity ................................................................... 3.8

3.3.3 Model Calibration —-Temperature and Salinity …............................................. 3.15

3.4 Hydrodynamics in Bellingham Bay .................................................................... 3.28

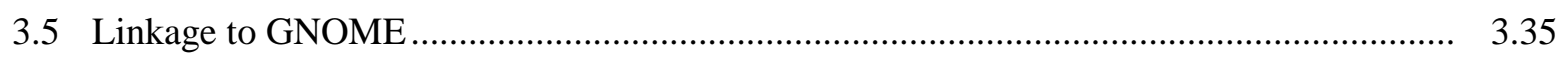

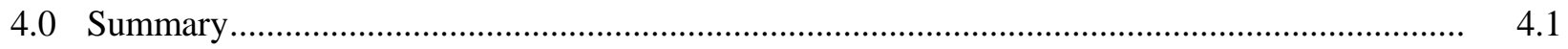

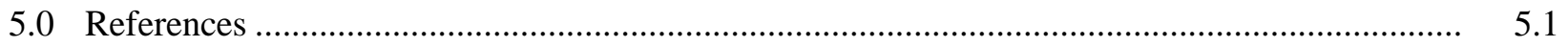




\section{Figures}

1.1. Bellingham Bay and the Northern Puget Sound............................................................... 1.1

2.1. LIDAR Data Coverage at Nooksack River Delta............................................................. 2.2

2.2. Bathymetric Cross-Sections at Nooksack River Delta ....................................................... 2.2

2.3. Model Forcing Stations Used in this Study .................................................................... 2.4

2.4. Wind Stick Plot of Hourly Wind Data at NOAA Cherry Point Station ................................... 2.4

2.5. Downward Shortwave Solar Radiation from NARR Dataset.................................................. 2.5

2.6. Net Surface Heat Flux Calculated from NARR Dataset ....................................................... 2.5

2.7. Flow Rates for Nooksack River (left Y-axis) and Samish River (right Y-axis) in June 2009 ... 2.6

2.8. Rivers Discharge into Bellingham Bay and Adjacent Coastal Waters ................................... 2.7

2.9. Washington State Gauged River Flow Rates for Tenmile Creek (left Y-axis) and Silver

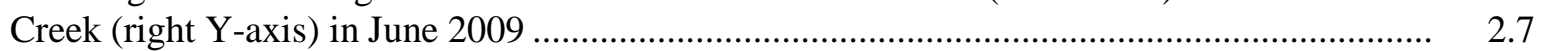

2.10. Washington State Gauged River Temperature for Tenmile Creek and Silver Creek in June 2009.

2.11. Time Series Plot of Open Boundary Tides at Cherry Point, Washington .............................. 2.8

2.12. Time Series Plot of Open Boundary Tides at Aleck Bay ..................................................... 2.9

2.13. Time Series Plot of Open Boundary Tides at Bowman Bay .................................................. 2.9

2.14. Locations for Field Data Collection Conducted by Hart Crowser, Inc. ................................. 2.10

3.1. Bellingham Bay Hydrodynamic Model Domain and Grid................................................. 3.2

3.2. Comparisons of Predicted and Observed Water Levels at Stations T1, T2, and T3 ................ 3.5

3.3. Comparisons of Predicted and Observed Water Levels at Stations T4, T5, and T6 ............... 3.6

3.4. Comparisons of Predicted and Observed Water Levels at Stations T7, C1, and C4 ............... 3.7

3.5. Comparisons of Predicted and Observed Velocity at Station C3 …....................................... 3.9

3.6. Comparisons of Predicted and Observed Velocity at Station C4 ......................................... 3.10

3.7. Comparisons of Predicted and Observed Velocity at Station C2 …..................................... 3.11

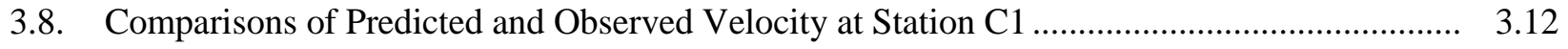

3.9. Harmonic Analysis Result of Surface Layer East Component Velocity at Station C3 ............. 3.14

3.10. Harmonic Analysis Result of Surface Layer East Component Velocity at Station C1 ............ 3.15

3.11. Comparisons of Predicted and Observed Water Temperature at Stations T1, T2, and T3 ........ 3.17

3.12. Comparisons of Predicted and Observed Water Level at Stations T4, T5, and T6 ................. 3.18

3.13. Comparisons of Predicted and Observed Water Level at Stations T7, C1, and C4................. 3.19

3.14. Comparisons of Predicted and Observed Salinity at Stations T1, T2, and T3 ....................... 3.20

3.15. Comparisons of Predicted and Observed Salinity at Stations T4, T5, and T6 ....................... 3.21

3.16. Comparisons of Predicted and Observed Salinity at Stations T7, C1, and C4 ....................... 3.22

3.17. Comparisons of Predicted and Observed Water Temperature Vertical Profiles During the Deployment Period on June 10 and 11, 2009.

3.18. Comparisons of Predicted and Observed Water Temperature Vertical Profiles During Retrieval Period on June 25, 2009 
3.19. Comparisons of Predicted and Observed Salinity Vertical Profiles During Deployment Period on June 10 and 11, 2009.

3.20. Comparisons of Predicted and Observed Salinity Vertical Profiles During Retrieval Period on June 25, 2009

3.21. Snapshot of Surface Velocity During Ebb (6/24/2009 9:30 AM) ........................................ 3.30

3.22. A Snapshot of Surface Velocity During Low Tide (6/24/2009 12:00 PM) ............................ 3.31

3.23. A Snapshot of Surface Velocity During Flood (6/24/2009 5:00 PM) .................................... 3.32

3.24. A Snapshot of Surface Velocity During High Tide (6/24/2009 8:30 PM) .............................. 3.33

3.25. A Snapshot of Surface Salinity During Low Tide (6/24/2009 12:00 PM) ............................ 3.34

3.26. A Snapshot of Surface Salinity During High Tide (6/24/2009 8:30 PM) ............................. 3.35

3.27. Initial Distribution of Released Particles (pointed by arrow) in Bellingham Bay .................... 3.36

3.28. A Snapshot of Particle Distribution After 5 Days Simulation............................................... 3.37 


\section{Tables}

2.1. Summary of Field Data Used for Hydrodynamic Model Calibration .................................... 2.11

3.1. Key Hydrodynamic Model Parameters and Configuration ................................................... 3.4

3.2. Model Calibration Error Statistics for Water-Surface Elevation............................................... 3.7

3.3. Model Calibration Error Statistics for East Direction Current Velocity ................................. 3.13

3.4. Model Calibration Error Statistics for Water-Temperature Time Series ................................ 3.19

3.5. Model Calibration Error Statistics for Salinity Time Series .................................................. 3.22

3.6. Model Calibration Error Statistics for Temperature Vertical Profiles..................................... 3.25

3.7. Model Calibration Error Statistics for Salinity Vertical Profiles............................................ 3.28

4.1. Summary of Model Calibration Error Statistics ...................................................................... 


\subsection{Introduction}

Bellingham Bay is located in the Northern Puget Sound, Washington. It is separated from the Strait of Georgia on the west by the Lummi Peninsula and Lummi Island and is bordered on the east by the City of Bellingham and to the south by Samish Bay (Figure 1.1). Historically, Bellingham Bay was exposed to a series of marine environment problems, including habitat loss and sediment contamination. In 1996, the Bellingham Bay Habitat Action Team (BBAT) was formed with the mission of using a new cooperative approach to expedite source control, sediment cleanup, and associated habitat restoration in Bellingham Bay. Since 1998, BBAT has identified a number of potential habitat restoration and protection opportunities and has worked to implement them. Using a bay-wide ecosystem approach, BBAT has focused on a number of issues, such as recovery of eelgrass beds, recovery of estuaries at the creek mouths (Squalicum Creek, Whatcom Creek, and Padden Creek), creation of intertidal and shallow subtidal migration corridors, and removal of overwater structures.

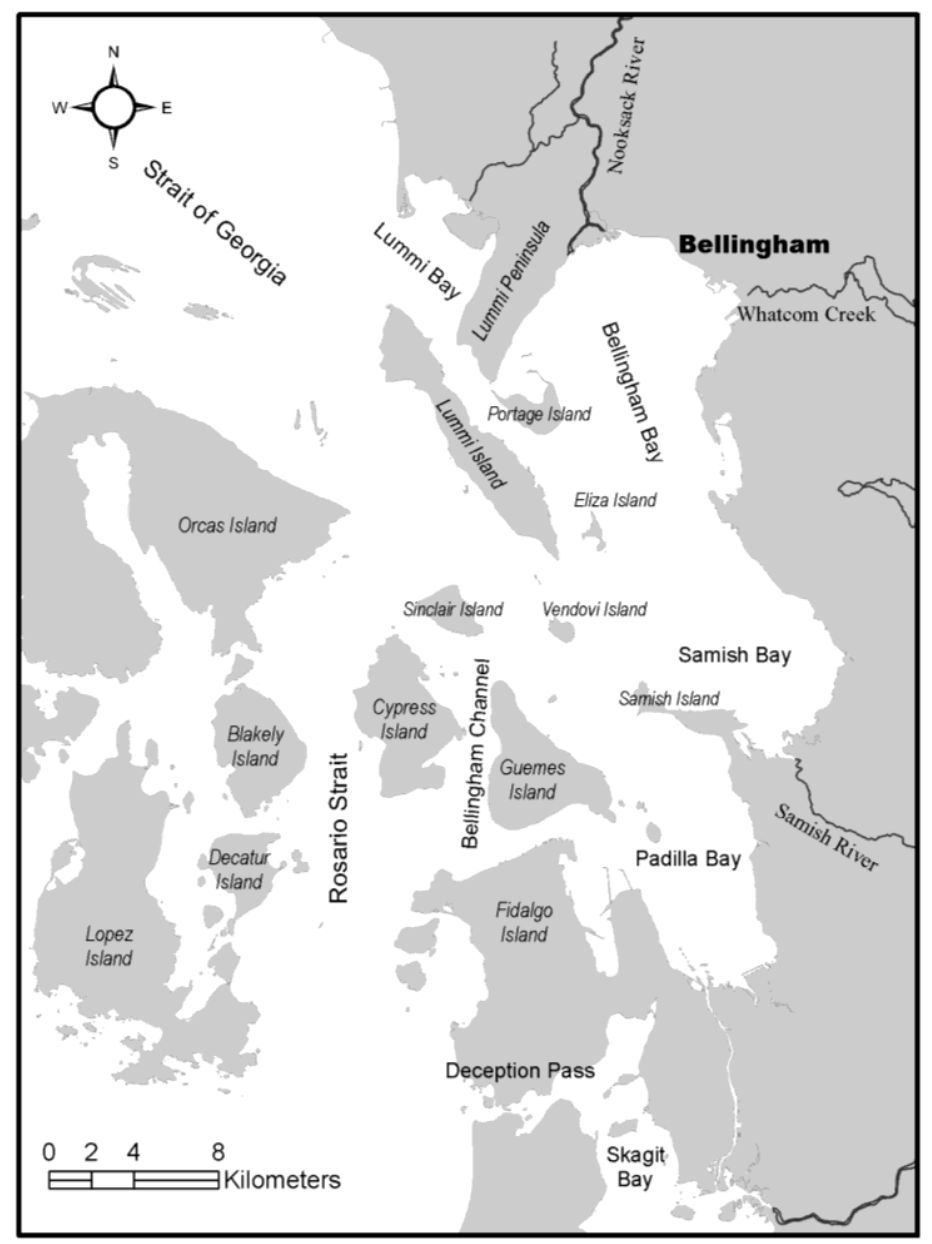

Figure 1.1. Bellingham Bay and the Northern Puget Sound (shoreline and river vector data obtained from Ecology online Geographic Information System [GIS] database) 
Due to site-specific conditions in Bellingham Bay, such as historic and current land use, oceanographic conditions, sediment supply, and availability of freshwater, there is a need to develop a better understanding of the feasibility of achieving restoration goals. These include the recovery of tidal exchange, a supply of sediment and nutrients, and the establishment of fish-migration pathways. Many of the proposed restoration actions can be potentially influenced by the hydrodynamic circulation in Bellingham Bay, large loads of suspended sediment delivered by the Nooksack River, and existing nearshore mudflat and marshland habitat distribution. There is considerable interest in developing a better understanding of the fish-migration pathways and how they may be improved or affected by the proposed restoration actions. In addition, there is interest in verifying that proposed actions take into account the future effect of climate change and the effect of sea level rise in the planning effort. BBAT therefore concluded that there was a need for a high-resolution circulation model of the Bellingham Bay with the capability to simulate nearshore processes of interest, such as circulation in complex marshlands with multiple tidal channels, wetting and drying of mudflats, and water quality kinetics and sediment transport processes.

Pacific Northwest National Laboratory's (PNNL's) Marine Science Laboratory has been actively supporting a number of nearshore restoration projects in the Puget Sound, including restoration at Nisqually National Wildlife Refuge, Dungeness River Delta, multiple projects in the Snohomish Estuary, Port Susan and Leque Island restoration projects on the Stillaguamish River, and various projects on the Skagit River estuary (Yang and Khangaonkar 2008; Yang et al. 2009a, 2010; Khangaonkar and Yang 2010). Through these studies, PNNL has developed detailed models for the associated sub-basins (e.g., the Whidbey Basin) and hydrodynamic and transport models covering the entire Puget Sound in intermediate and fine scales in supporting decision makers (Yang and Khangaonkar 2007; Yang et al. 2009b).

The BBAT is interested in developing a better understanding of fish migration pathways and how they may be improved or affected by the restoration actions identified in the Bellingham Bay Comprehensive Strategy final environmental impact statement, a guidance document integrating sediment cleanup, control of pollution sources, habitat restoration, and shoreline land use on a bay-wide scale. As a first step to achieve this goal, the Washington State Department of Ecology (Ecology) has contracted PNNL to develop a hydrodynamic model for Bellingham Bay.

The overall objective of this study is to develop a high-resolution hydrodynamic model of Bellingham Bay. An efficient approach to achieve this objective is to use the existing Puget Sound wide hydrodynamic model developed by PNNL. Specifically, the modeling tasks are as follows:

- Extract and refine a model grid for Bellingham Bay from the Puget Sound model.

- Set up a circulation model for Bellingham Bay with available data, including bathymetric light detection and ranging (LIDAR) data, river cross-sections, tides, river inflows, and meteorological data.

- Calibrate the model with field survey data collected by Ecology for water level, velocity, salinity, and temperature.

- Link the hydrodynamic model to the National Oceanic and Atmospheric Administration's (NOAA's) particle tracking model (General NOAA Oil Modeling Environment [GNOME]) for analysis of fishmigration pathways. 
This report summarizes the modeling effort and results in the development of a hydrodynamic model of Bellingham Bay. 



\subsection{Data Review}

\subsection{Introduction}

The Pacific Northwest coast is characterized with high tidal energy. Circulation in Bellingham Bay is primarily controlled by tides, which propagate from the Strait of Juan de Fuca and through Rosario Strait into Bellingham Bay. The circulation is also affected by Nooksack River inflow, wind, bathymetry, and shoreline geometry. To set up a hydrodynamic model for Bellingham Bay, several types of data are required. They include shoreline geometry, bathymetry, river inflow, meteorological forcing, and tides at open boundaries of the model domain. In addition, field observations are required for the hydrodynamic model calibration. They may include water surface elevation, velocity, salinity, and temperature.

\subsection{Bathymetric Data}

Bathymetric data are one of the most important datasets in model setup because they define the shape and geometry of the model domain. The bathymetric data used in the Bellingham Bay hydrodynamic model mainly come from the following sources:

1. The University of Washington's (UW's) Puget Sound Digital Elevation Model (PSDEM)

2. Bathymetric data in the Strait of Juan de Fuca and the Strait of Georgia from the Department of Fisheries and Oceans Canada (DFO)

3. LIDAR data obtained from Puget Sound LIDAR Consortium (PSLC)

4. Bathymetric data collected by Ecology through Hart Crowser, Inc. at Nooksack River Delta.

The UW PSDEM bathymetric data cover almost the entire Puget Sound and adjacent Washington state coastal waters. These data are at $30-\mathrm{m}$ by $30-\mathrm{m}$ horizontal resolution. The vertical resolution is 0.1 meter. Detailed information on the PSDEM data of Puget Sound can be found in Finlayson et al. (2000). These data are the primary source of bathymetry for this study. For regions that are missing in the UW PSDEM dataset (e.g., the area around Orcas Island), the DFO bathymetric data were used. Although these data have a coarser resolution than the UW PSDEM data, they are considered sufficient for Bellingham Bay model development as they are only used for regions outside the Bay.

Tidal flats and marshland near the Nooksack River Delta, which can be represented reasonably well by LIDAR elevation data, are of special interest to this study. The LIDAR data downloaded from the PSLC website have a horizontal resolution of $2 \mathrm{~m}$ by $2 \mathrm{~m}$ and a vertical resolution of 0.001 meter. However, the absolute vertical accuracy can vary between $\pm 20-60 \mathrm{~cm}$, depending on the terrain type and vegetation cover (PSLC 2005). A detailed description can be obtained from the PSLC website (http://pugetsoundlidar.ess.washington.edu). Figure 2.1 shows an example plot of the LIDAR data coverage at the Nooksack River Delta. 


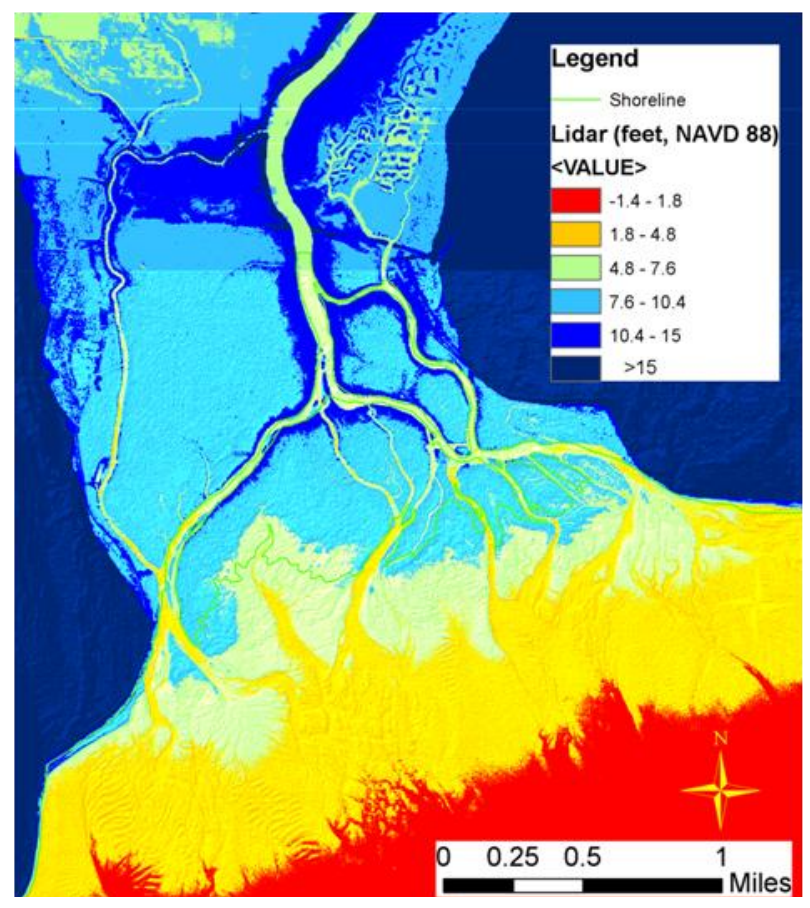

Figure 2.1. LIDAR Data Coverage at Nooksack River Delta (positive values denote the elevation above NAVD 88)

Additional cross-sectional bathymetric data collected by Hart Crowser in the Nooksack River Delta and the lower portion of the river are used to verify the bathymetry for river channels and selected portions of the mudflat. The data are shown in Figure 2.2. All bathymetric data used in the model development are referenced to the North American Vertical Datum of 1988 (NAVD 88).

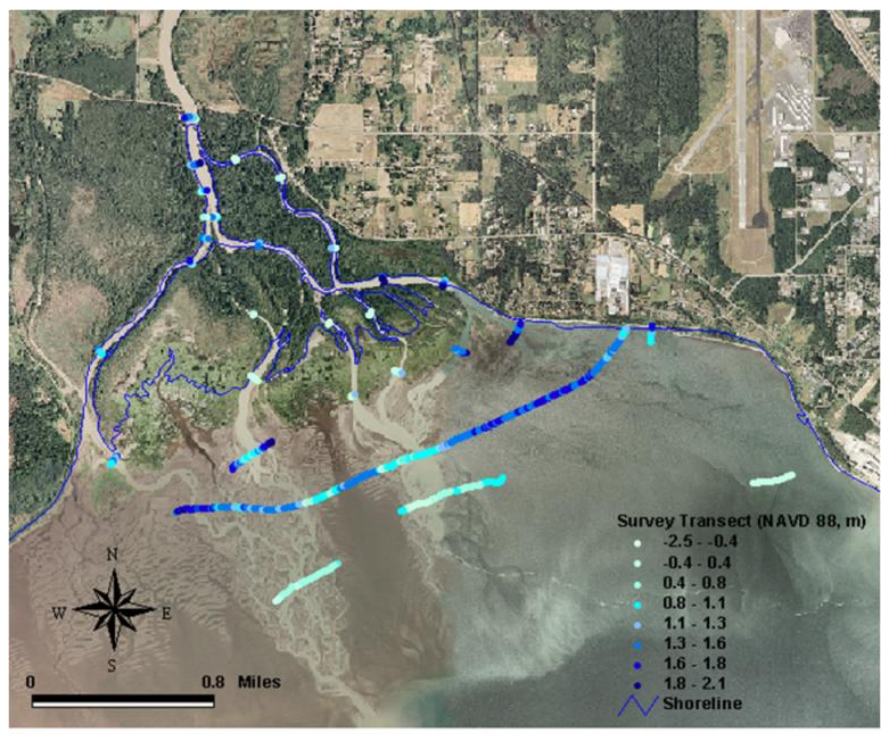

Figure 2.2. Bathymetric Cross-Sections at Nooksack River Delta (positive values denote the elevation above NAVD 88) 


\subsection{Shoreline Geometry}

In addition to bathymetry, shoreline geometry data provide an important spatial reference to define the hydrodynamic model land boundaries. For this project, shoreline data downloaded from the Ecology online GIS database were used as the primary reference. Supplemental GIS layers, such as overwater marine structures downloaded from Washington State Department of Natural Resources (DNR), were also used to verify that important marine features are also properly incorporated into the model grid.

\subsection{Meteorological Data}

Meteorological forcing, such as wind and solar radiation, can affect both physical and biological processes in Bellingham Bay. Observational data close to the model domain are warranted for the most part because meteorology is highly variable in both temporal and spatial scales. To simulate windinduced circulation and mixing processes, hourly wind data from the NOAA real-time observational station at Cherry Point, Washington (NOAA 2009) were used in the hydrodynamic model. For temperature simulation, the North American Regional Reanalysis (NARR) datasets were used in this study because of the lack of high-quality observational data (e.g., solar radiation) in Bellingham Bay. The NARR data are generated by the NOAA National Center for Environmental Prediction (NCEP) based on the regional meteorological model (Eta Model) at a 32-km resolution (Mesinger et al. 2006). NARR data provide all the meteorological parameters, such as surface heat flux and solar radiation, which are required for the hydrodynamic model at a reasonable temporal resolution (3-hours).

The locations of meteorological stations are shown in Figure 2.3. The wind stick plot for the modeling period of interest at Cherry Point is presented in Figure 2.4. Downward shortwave solar radiation and net heat flux calculated from NARR data are shown in Figure 2.5 and Figure 2.6, respectively. As can be seen from Figure 2.4, the wind is generally less than $10 \mathrm{~m} / \mathrm{s}$ and primarily from the south. The daily peak of net surface flux can vary from $150 \mathrm{~W} / \mathrm{m}^{2}$ to $950 \mathrm{~W} / \mathrm{m}^{2}$. The daily peak of solar radiation varies from $350 \mathrm{~W} / \mathrm{m}^{2}$ to $1000 \mathrm{~W} / \mathrm{m}^{2}$, depending on cloud cover. As expected, the peak solar radiation and net heat flux normally occur around noon each day. 


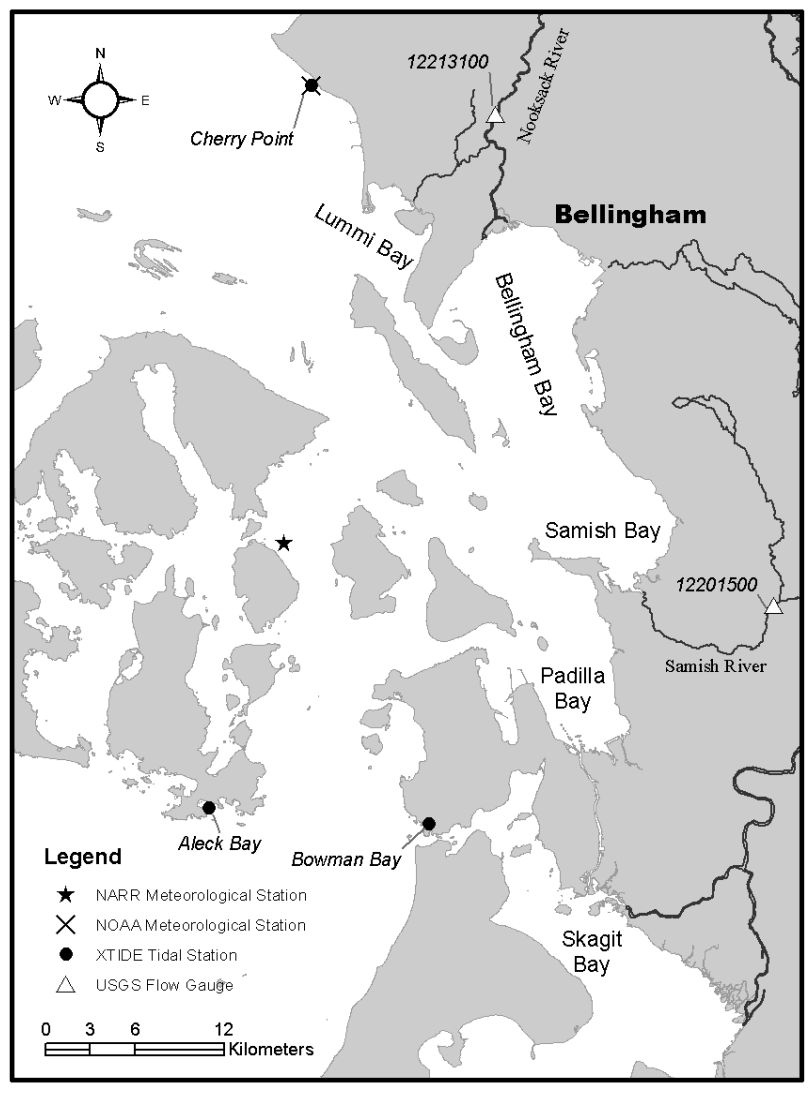

Figure 2.3. Model Forcing Stations Used in this Study

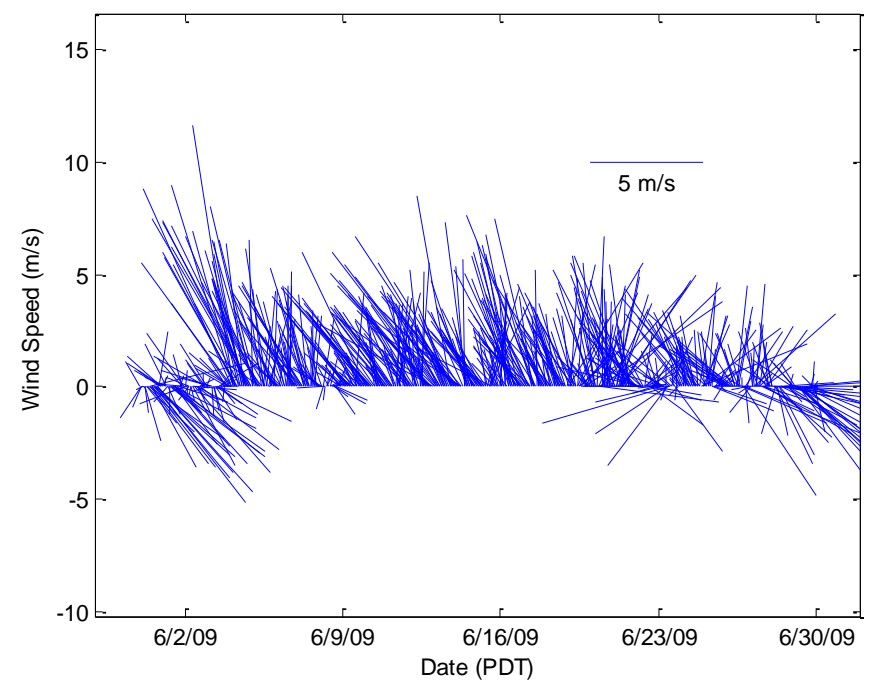

Figure 2.4. Wind Stick Plot of Hourly Wind Data at NOAA Cherry Point Station 


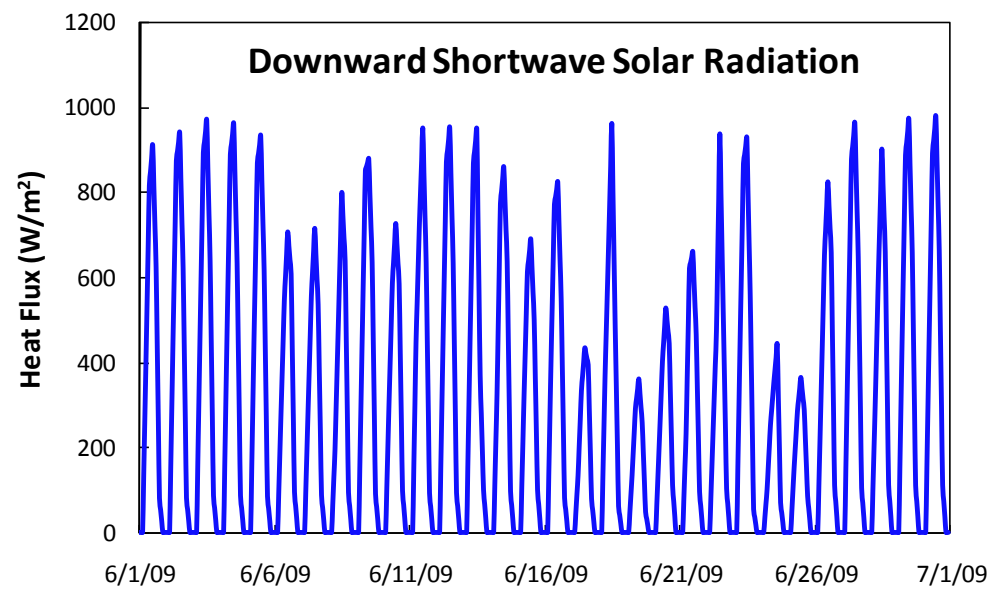

Figure 2.5. Downward Shortwave Solar Radiation from NARR Dataset

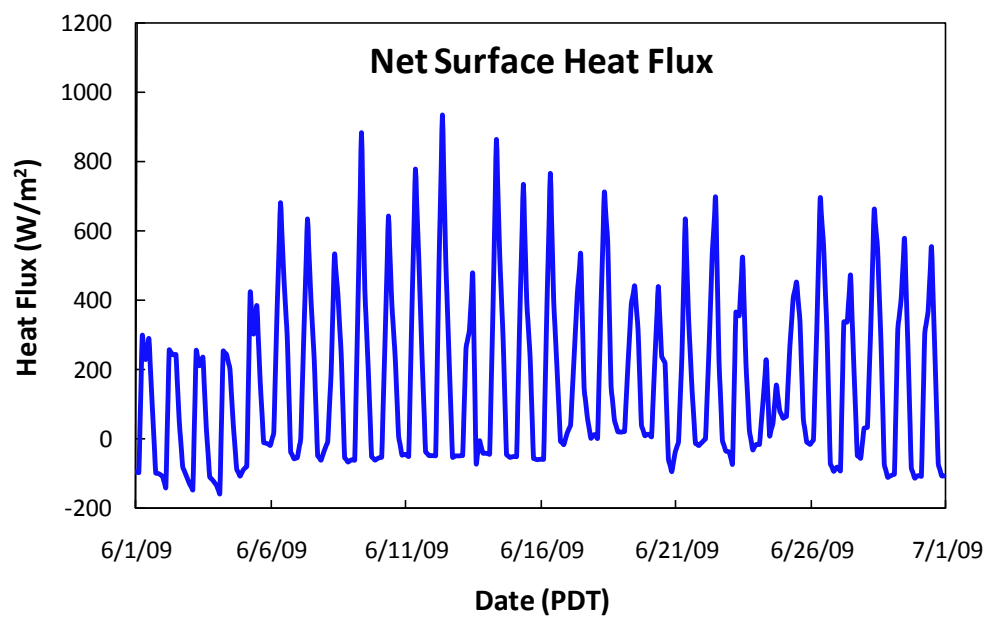

Figure 2.6. Net Surface Heat Flux Calculated from NARR Dataset (positive values denote flux from air to water)

\subsection{River Inflow and Temperature}

The Nooksack River is the major river emptying into Bellingham Bay. It has been gauged continuously by the U.S. Geological Survey (USGS) at Gauge 12213100 (see Figure 2.3). Because the hydrodynamic model domain covers Samish Bay, discharge from the Samish River (USGS Gauge 12201500 in Figure 2.3) is included in the model as well. The hourly flow rates for both rivers are obtained from USGS gauges. In general, the discharge rates for both rivers show a decreasing trend in June of 2009 (Figure 2.7). The Samish River provides roughly $2 \%$ of the flow of the Nooksack River. 


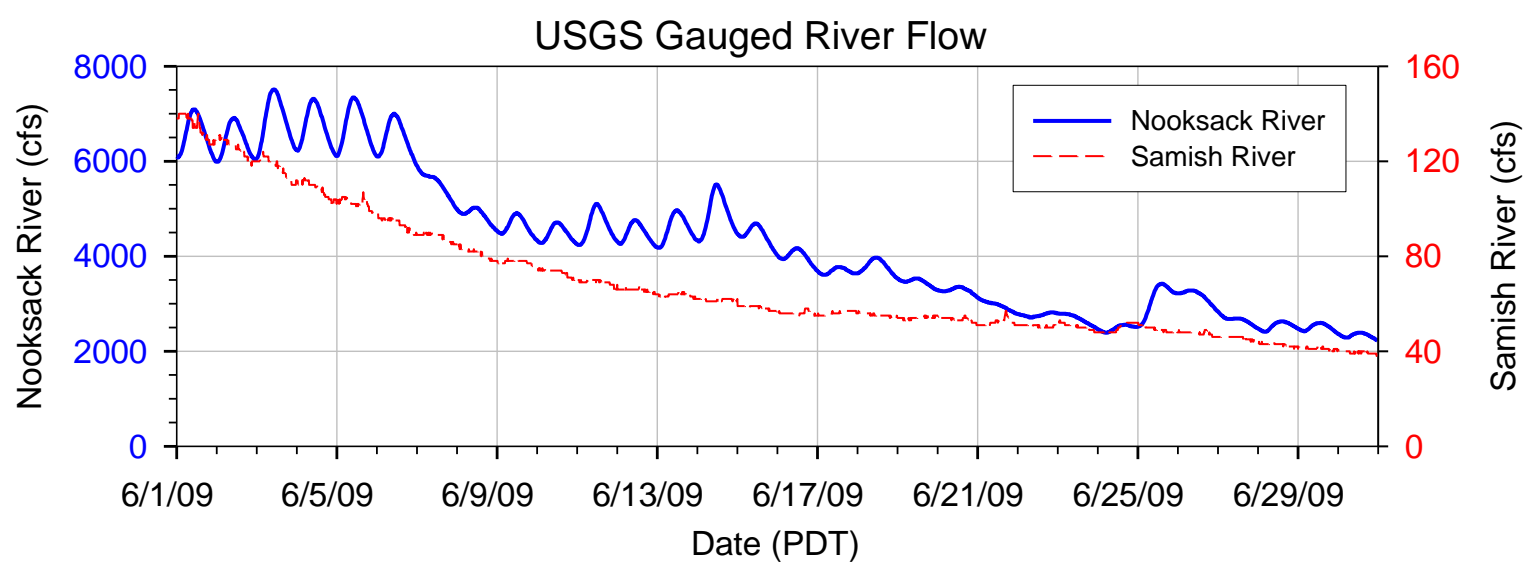

Figure 2.7. Flow Rates for Nooksack River (left Y-axis) and Samish River (right Y-axis) in June 2009 (raw data courtesy of Mr. John Clemens, USGS Washington Water Science Center)

Besides the two major rivers, a number of small streams, such as Squalicum Creek and Whatcom Creek, discharge directly into Bellingham Bay and Samish Bay (Figure 2.8). Although these small streams have much lower flow rates than major ones, they can be locally important and can influence circulation and water quality near the discharge locations. These streams are also included in the model for completeness. In addition, incorporating small streams at the current stage can facilitate the future model refinement process when special interests arise. Unlike major rivers, observational data for small streams are usually unavailable through USGS. To estimate their flow rates, a simple drainage areaweighted method was applied in this study based on available flows measured by the Ecology Flow Monitoring Network at two gauges, Tenmile Creek above Barrett Lake (Station ID 01P080) and Silver Creek near Alger (Station ID 03K070). The corresponding flow rates and water temperature time series are plotted in Figure 2.9 and Figure 2.10, respectively. The flow patterns are similar to those of the Nooksack and Samish Rivers, except the magnitude is much smaller. For river temperatures, both rivers show apparent diurnal variations. In general, Tenmile Creek is about 2 to $3{ }^{\circ} \mathrm{C}$ warmer than Silver Creek.

The hourly flows of Tenmile Creek and Silver Creek are first normalized by individual drainage areas to obtain the unit area flow rates, which are subsequently averaged to obtain the mean flow rates for hourly unit areas. The mean flow rates for hourly unit areas are then applied universally for the remaining small streams discharging into the model domain. Thus, the hourly flow rates for a given stream can be easily obtained by multiplying its drainage area and previously calculated mean flow rates for hourly unit areas.

For river temperatures, the averaged hourly measurements at Tenmile Creek and Silver Creek are applied universally for all the rivers. Because no observational temperature data are available from USGS for Nooksack River and the Samish River, the averaged hourly temperatures from Tenmile Creek and Silver Creek were applied to Nooksack and Samish as an approximation. The discharge locations for all the rivers discharging into the model domain are shown in Figure 2.8. 


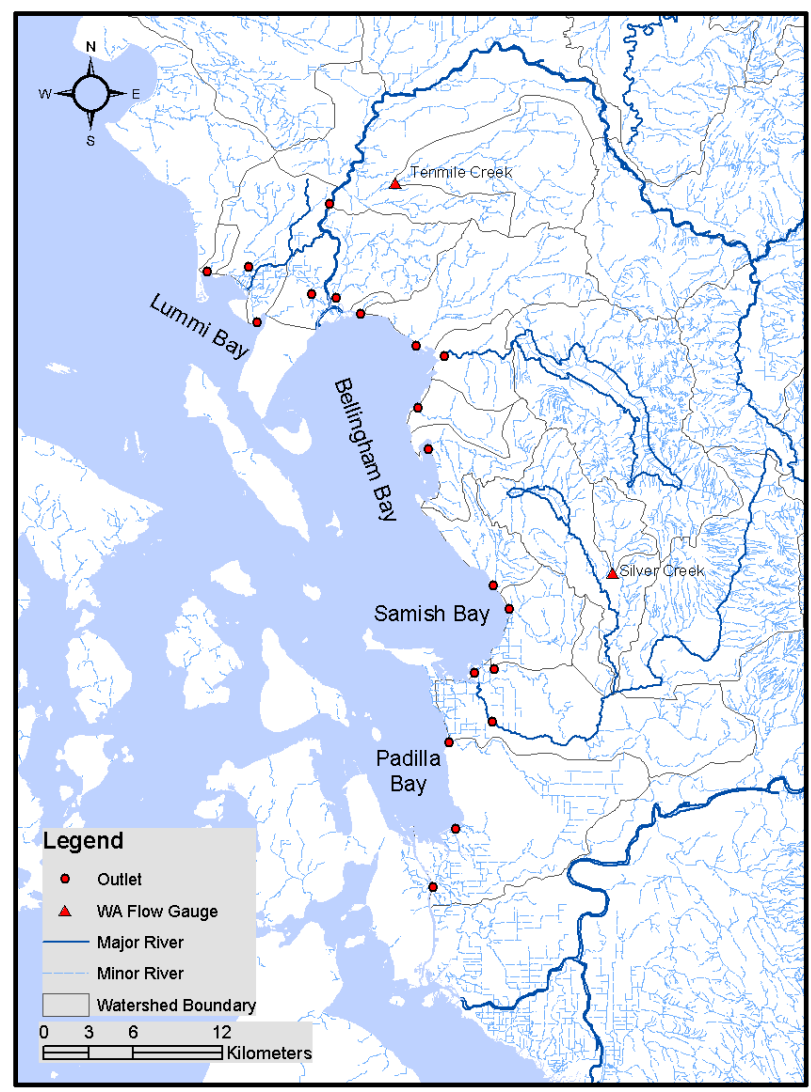

Figure 2.8. Rivers Discharge into Bellingham Bay and Adjacent Coastal Waters (GIS data for rivers obtained from Ecology and DNR online GIS database)

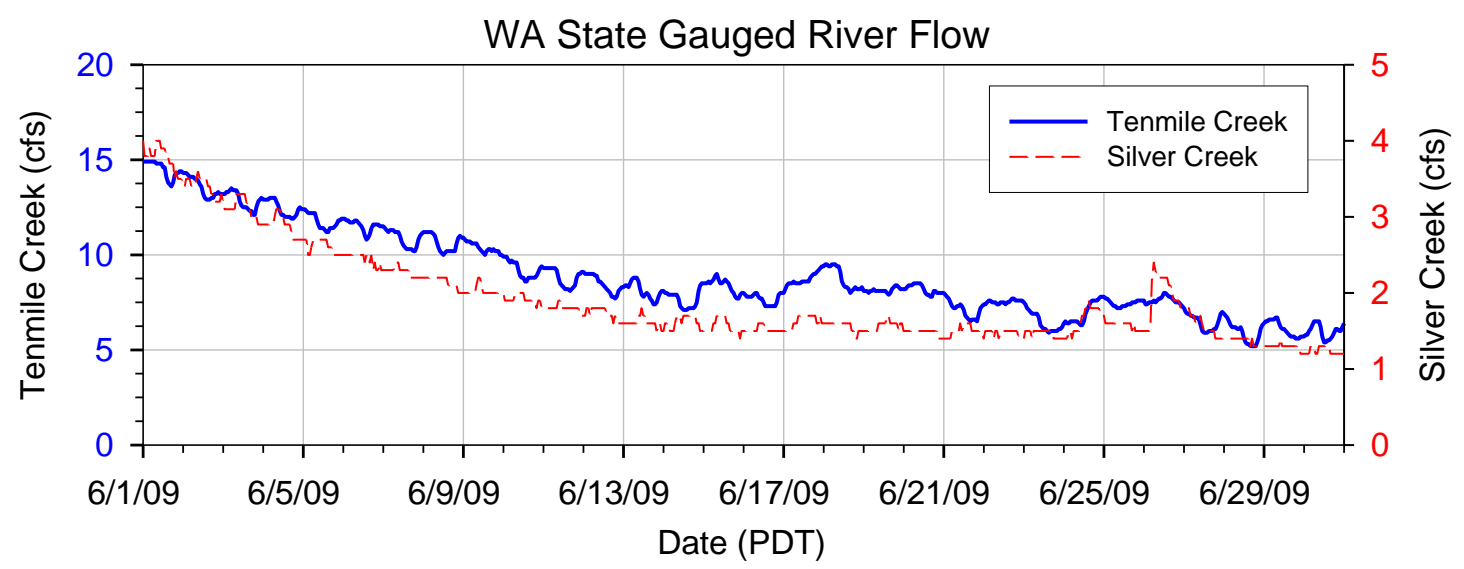

Figure 2.9. Washington State Gauged River Flow Rates for Tenmile Creek (left Y-axis) and Silver Creek (right Y-axis) in June 2009 (raw data courtesy of Mr. Chuck Springer, Ecology) 


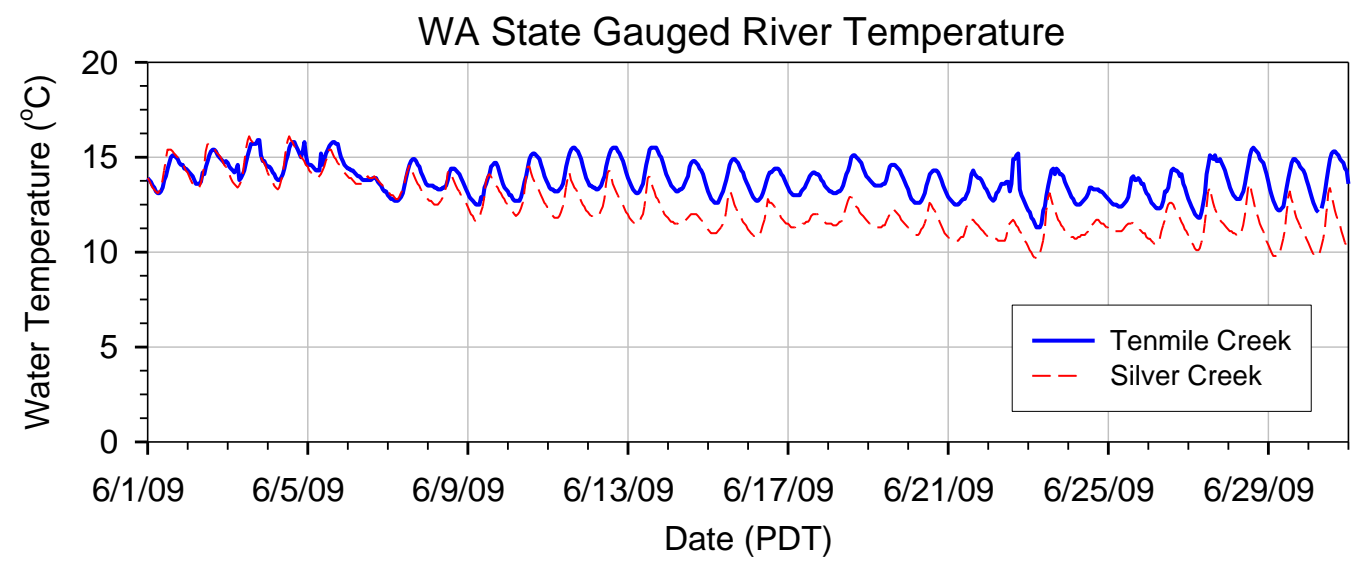

Figure 2.10. Washington State Gauged River Temperature for Tenmile Creek and Silver Creek in June 2009 (raw data courtesy of Mr. Chuck Springer, Ecology)

\subsection{Tidal Forcing}

Tides are the primary driving force for the circulation in Bellingham Bay. Although real-time water level observations that include both tides and non-tidal fluctuations are more preferred as the open boundary conditions, harmonic tides are also sufficient in most situations. Around Bellingham Bay, there is only one water level observational station (Cherry Point, Washington) maintained by NOAA. Because of the complexity of the circulation pattern around the model domain, it is not sufficient to use the Cherry Point data for hydrodynamic model setup. Therefore, harmonic tides provided by the harmonic tide clock and tide predictor (XTide) (Flater 1996) are used as the surrogate in this study. The 1-month time series of tidal elevations at three XTide stations are plotted in Figure 2.11 to Figure 2.13, respectively. The corresponding station locations are provided in Figure 2.3. A strong spring-neap cycle can be seen at all three stations.

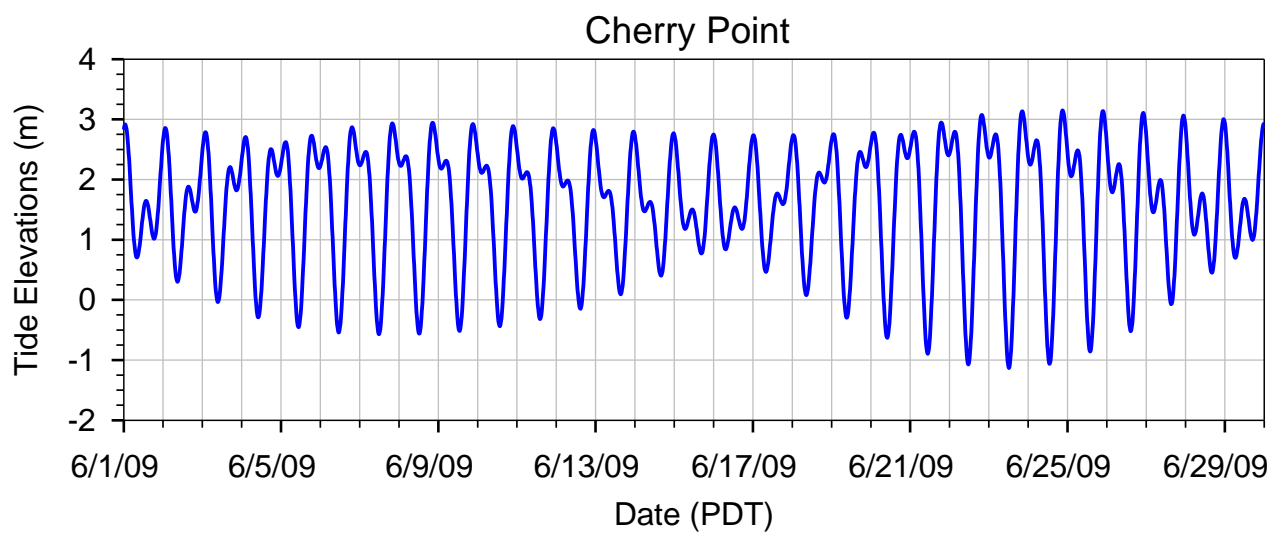

Figure 2.11. Time Series Plot of Open Boundary Tides at Cherry Point, Washington 


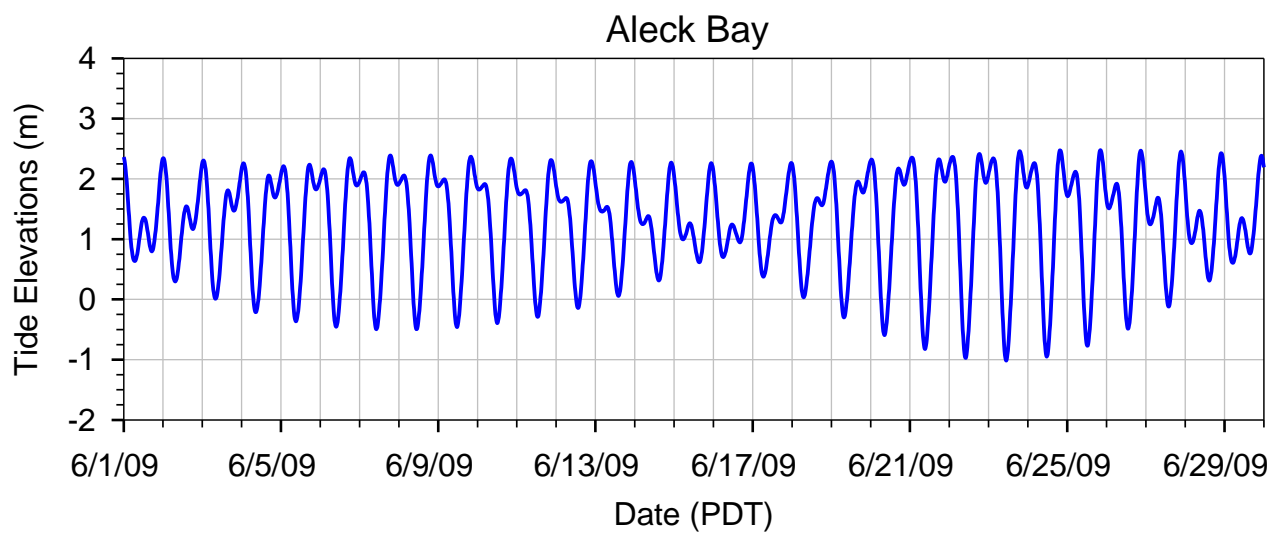

Figure 2.12. Time Series Plot of Open Boundary Tides at Aleck Bay

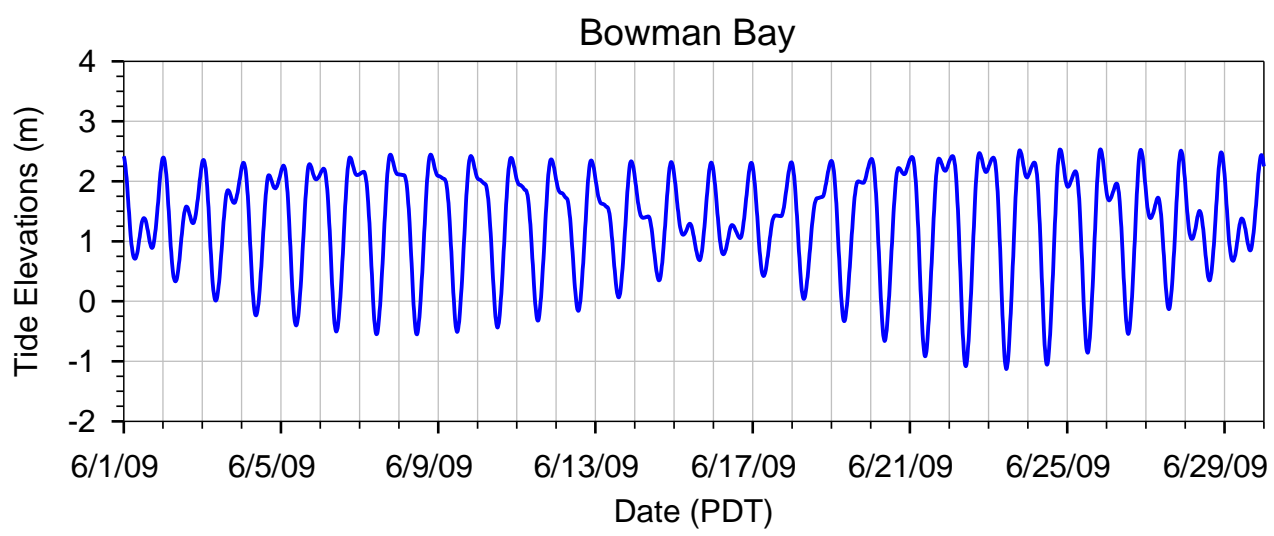

Figure 2.13. Time Series Plot of Open Boundary Tides at Bowman Bay

\subsection{Field Data Survey}

In conjunction with hydrodynamic model development, field surveys were conducted by Hart Crowser, Inc. in June 2009. In addition to the aforementioned Nooksack River Delta bathymetry, oceanographic data on water surface elevation, velocity, salinity, and temperature were also collected at selected locations in and around Bellingham Bay. Detailed descriptions on data-collection methods and quality assurance/quality control were provided in the field data report (Hart Crowser Inc. 2009). The stations for field data collection are shown in Figure 2.14, and the corresponding data availability at each station is summarized in Table 2.1. 


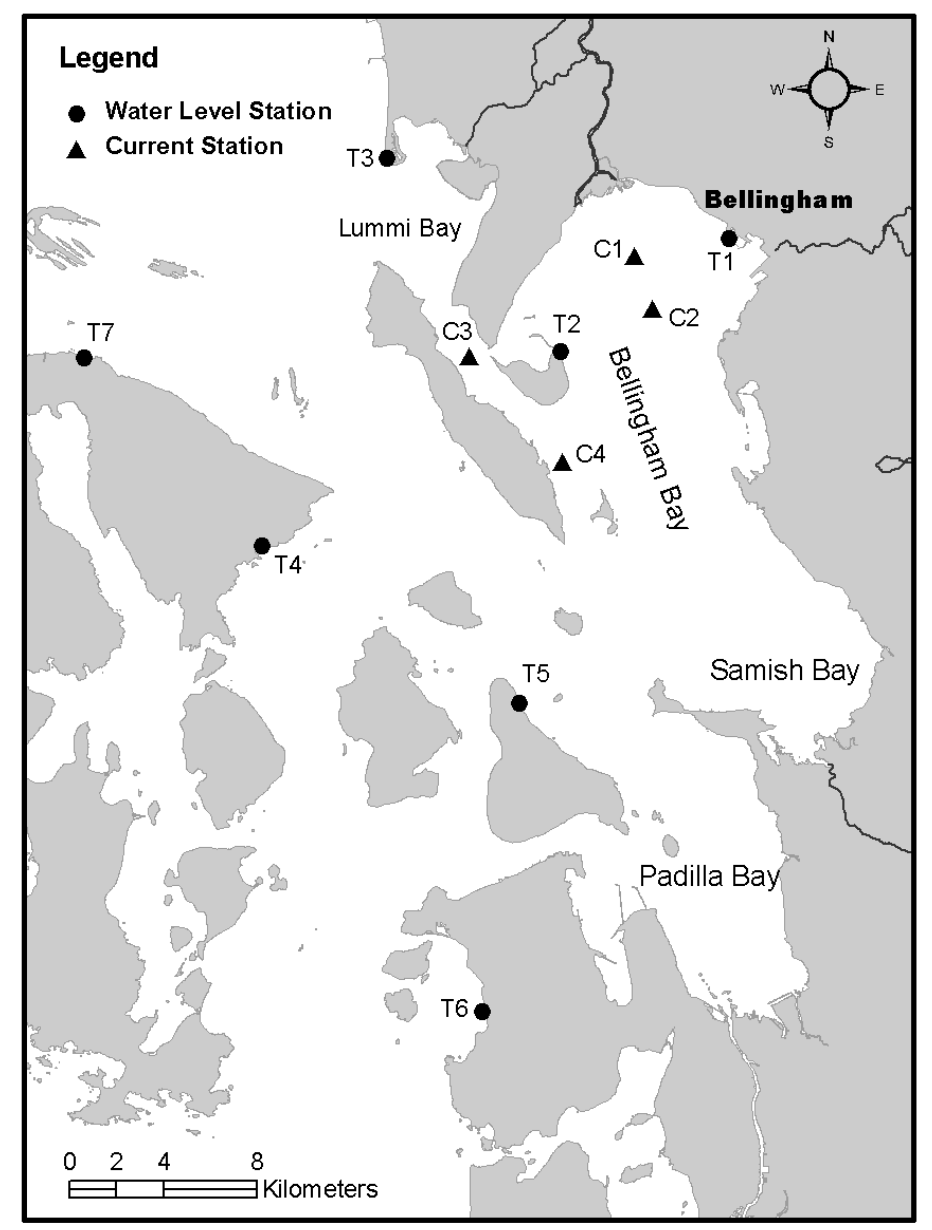

Figure 2.14. Locations for Field Data Collection Conducted by Hart Crowser, Inc.

There are seven tidal (water level) stations (T1-T7) and four current stations (C1-C4). Time series records of water surface elevation, temperature, and salinity are available at all seven tidal stations. Besides, water depth measurements were collected in conjunction with velocity measurements at four current stations using Acoustic Doppler Current Profilers (ADCP). However, temperature and salinity are only available at selected current stations as shown in Table 2.1 because of instrument malfunction or other operational issues (Hart Crowser Inc. 2009). Conductivity/salinity, temperature, and depth (CTD) profiles through the water column were collected during instrument deployment and retrieval at all stations. 
Table 2.1. Summary of Field Data Used for Hydrodynamic Model Calibration

\begin{tabular}{cccccc}
\hline Station & $\begin{array}{c}\text { Water Level/Depth } \\
\text { Time Series }\end{array}$ & $\begin{array}{c}\text { Temperature } \\
\text { Time Series }\end{array}$ & $\begin{array}{c}\text { Salinity } \\
\text { Time Series }\end{array}$ & $\begin{array}{c}\text { Current Velocity } \\
\text { Time Series }\end{array}$ & $\begin{array}{c}\text { CTD } \\
\text { Profiles }\end{array}$ \\
\hline T1 & $\mathrm{A}$ & $\mathrm{A}$ & $\mathrm{A}$ & $\mathrm{U}$ & $\mathrm{A}$ \\
$\mathrm{T} 2$ & $\mathrm{P}$ & $\mathrm{P}$ & $\mathrm{P}$ & $\mathrm{U}$ & $\mathrm{P}$ \\
$\mathrm{T} 3$ & $\mathrm{~A}$ & $\mathrm{~A}$ & $\mathrm{~A}$ & $\mathrm{U}$ & $\mathrm{A}$ \\
$\mathrm{T} 4$ & $\mathrm{P}$ & $\mathrm{P}$ & $\mathrm{P}$ & $\mathrm{U}$ & $\mathrm{A}$ \\
$\mathrm{T} 5$ & $\mathrm{P}$ & $\mathrm{P}$ & $\mathrm{P}$ & $\mathrm{U}$ & $\mathrm{A}$ \\
T6 & $\mathrm{P}$ & $\mathrm{P}$ & $\mathrm{P}$ & $\mathrm{U}$ & $\mathrm{A}$ \\
T7 & $\mathrm{P}$ & $\mathrm{P}$ & $\mathrm{P}$ & $\mathrm{U}$ & $\mathrm{A}$ \\
$\mathrm{C} 1$ & $\mathrm{~A}$ & $\mathrm{~A}$ & $\mathrm{~A}$ & $\mathrm{~A}$ & $\mathrm{~A}$ \\
C2 & $\mathrm{M}$ & $\mathrm{M}$ & $\mathrm{M}$ & $\mathrm{A}$ & $\mathrm{A}$ \\
C3 & $\mathrm{M}$ & $\mathrm{M}$ & $\mathrm{M}$ & $\mathrm{A}$ & $\mathrm{A}$ \\
C4 & $\mathrm{A}$ & $\mathrm{A}$ & $\mathrm{A}$ & $\mathrm{A}$ & $\mathrm{A}$ \\
\hline A: Data available & & & & \\
U: Data not collected & & & & \\
M: Data not available & & & & \\
P: Data partially available & & & & \\
\hline
\end{tabular}





\subsection{Model Calibration}

\subsection{The Hydrodynamic Model}

The model selected for this study is the Finite Volume Coastal Ocean Model (FVCOM) developed by the University of Massachusetts (Chen et al. 2003). FVCOM is a three-dimensional (3-D) hydrodynamic model that can simulate wetting-drying and tide- and density-driven circulation in an unstructured, finite element framework. Compared with structured grid models, such as the Princeton Ocean Model (POM) (Blumberg and Mellor 1987) and the Environmental Fluid Dynamics Code (EFDC) (Hamrick 1992), the unstructured grid model framework of FVCOM is especially suited to Bellingham Bay and adjacent waters, which have complex shoreline geometry and dynamic physical processes in the intertidal zone. FVCOM solves the 3-D momentum, continuity, temperature, salinity, and density equations in an integral form (finite volume method) and thus allows mass conservation to be strictly maintained. A sigmastretched coordinate system was used in the vertical plane to better represent the irregular bathymetry. The model employs the Mellor Yamada level 2.5 turbulence closure scheme (Mellor and Yamada 1982; Galperin et al. 1988; Kantha and Clayson 1994; Mellor and Blumberg 2004) for vertical mixing and the Smagorinsky scheme for horizontal mixing. It has been successfully applied to simulate hydrodynamics and transport processes in many estuaries and coastal waters (Zheng et al. 2003; Chen and Rawson 2005; Zhao et al. 2006; Weisberg and Zheng 2006; Aoki and Isobe 2007; Chen et al. 2008). In Puget Sound, PNNL has applied the model with great success to a number of water bodies, including Skagit Bay, the Snohomish River, Port Susan Bay, the Nisqually Delta, and the entire Puget Sound (Yang and Khangaonkar 2008; Yang et al. 2009a, b, 2010; Khangaonkar and Yang 2010). In addition to its capability of simulating hydrodynamics, FVCOM includes sub-models for sediment and water quality processes and is also being coupled to other models, e.g., the Corps of Engineers Integrated Compartment Water Quality model (CE-QUAL-ICM) and the GNOME oil-spill-trajectory model. Thus, FVCOM is not only suitable for simulating the hydrodynamics of Bellingham Bay, but also has a strong potential for future applications on sediment and water quality in the Bay.

\subsection{Model Setup}

\subsubsection{Model Grid}

The hydrodynamic model grid of Bellingham Bay was developed by refining the existing PNNL Puget Sound Model around Bellingham Bay. Although Bellingham Bay is the primary region of most interest, the model domain was expanded to include Samish Bay, Padilla Bay, and Lummi Bay to allow for exchanges among the neighboring basins. The refinement of the model grid was based on all the available bathymetry and shoreline data described in Sections 2.2 and 2.3. Figure 3.1 shows the model grid for the entire domain and the portion inside Bellingham Bay. As seen from the figure, the grid resolution around the Nooksack River Delta is especially high, with an average cell size of 30 meters.

The Bellingham Bay model grid consists of 35,458 elements and 19,301 nodes in the horizontal plane. To simulate salinity stratification accurately, 25 uniform vertical layers were specified in the water column in a sigma-stretched coordinate system. The model was set up in Universal Transverse Mercator (UTM) North American Datum (NAD) 83 (Zone 10) coordinates in the horizontal plane with reference to North American Vertical Datum 88 (NAVD 88) in the vertical direction. 


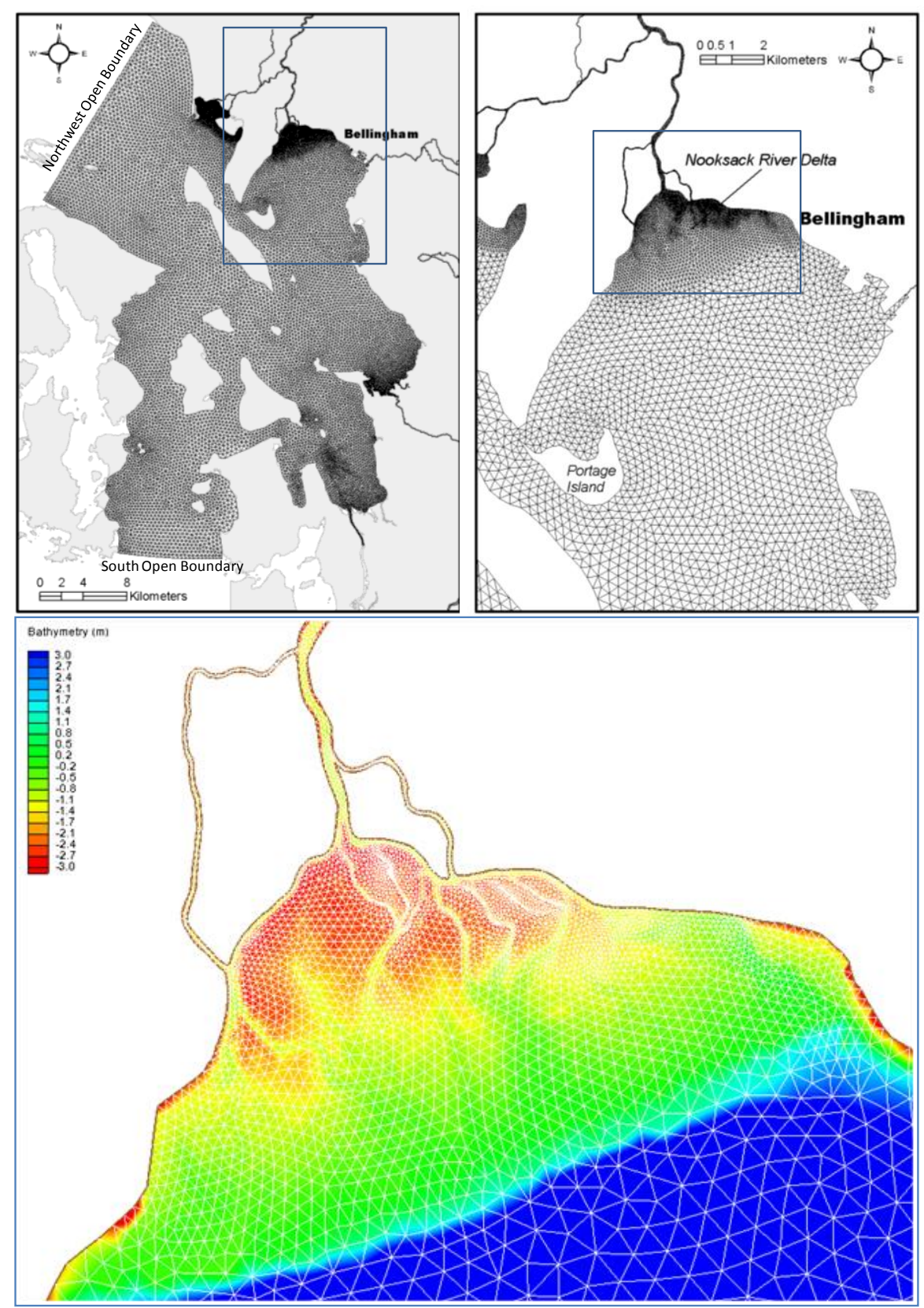

Figure 3.1. Bellingham Bay Hydrodynamic Model Domain and Grid (positive bathymetry value denotes water depth below NAVD 88)

\subsubsection{Model Boundary Condition}

The open boundary conditions for water level were specified using tidal elevations predicted by XTide software. There are two open boundaries for the Bellingham Bay hydrodynamic model: 1) the northwest open boundary between Cherry Point and Orcas Island and 2) the south open boundary 
between Aleck Bay and Bowman Bay. As an approximation, small waterways connected to San Juan Islands are not considered and were treated as a solid boundary. For the northwest open boundary, tidal elevations produced by XTide at Cherry Point station are applied uniformly to all the boundary nodes. At the south open boundary, tidal elevations predicted by XTide at Aleck Bay and Bowman Bay are linearly interpolated to each boundary node. For salinity and temperature, observed time series of salinity and temperature at stations T3, T7, and T6 in Figure 2.14 were applied to corresponding open boundary nodes. During the model "spin-up" period (6/1/2009 - 6/10/2009) when observational data were unavailable, constant salinity (33 ppt) and temperature $\left(10^{\circ} \mathrm{C}\right)$ were applied at both open boundaries. At the water surface, hourly wind speed and direction obtained from the NOAA Cherry Point station were applied uniformly to the entire model domain. To simulate temperature, hourly values of downward solar radiation and net surface heat flux from NARR dataset were applied uniformly to the entire model domain. At river boundaries, hourly values of river inflow and temperature as described in Section 2.5 were specified.

\subsubsection{Model Initial Condition}

The primary goal of this study is to develop and calibrate the Bellingham Bay hydrodynamic model against the field survey data collected by Hart Crowser during 6/10/2009 to 6/25/2009. One of the major challenges in model calibration is to obtain proper initial conditions, especially for salinity and temperature throughout the model domain. Ideally, a spatially variable initial condition should be specified based on data from an intense survey throughout the system. However, this type of information is usually unavailable. A simulation period from 6/1/2009 to 6/26/2009 was selected to allow sufficient model spin-up time to eliminate the uncertainty in initial conditions. The model was first cold-started with a uniform condition for salinity $(30 \mathrm{ppt})$ and temperature $\left(10{ }^{\circ} \mathrm{C}\right)$. The model was then run cyclically from 6/1/2009 to 6/26/2009 using end results as initial conditions. After two to three cycles, the salinity and temperature field inside the model domain reached a reasonable distribution that was well defined by river input and salinity as well as temperature open boundary conditions.

\subsection{Model Calibration}

The hydrodynamic model calibration run was conducted for the period of $6 / 1 / 2009$ to $6 / 26 / 2009$. The period of 6/10/2009 to 6/25/2009 was selected for model and data comparisons. The final calibration was achieved through matching predicted water level, current velocity, salinity, and temperature to observed

data by adjusting key model parameters. Key model parameters used in this calibration effort are listed in Table 3.1.

Comparisons of model results and observed data for water level and velocity are provided in Figure 3.2 to Figure 3.8. The corresponding error statistics are listed in Table 3.2 and Table 3.3. Comparisons for temperature and salinity are given in Figure 3.11 to Figure 3.20, and the corresponding error statistics are provided in Table 3.4 to Table 3.7. The following sections summarize the calibration results for individual variables. 
Table 3.1. Key Hydrodynamic Model Parameters and Configuration

\begin{tabular}{ccc}
\hline Model Parameter & Value & Comment \\
\hline Model Time Step & $2.5(\mathrm{sec})$ & \\
Bottom Friction Coefficient & 0.005 & \\
\hline Bottom Roughness & $0.005(\mathrm{~m})$ & Log Boundary Layer Theory \\
\hline Horizontal Diffusion & Smagorinsky Scheme & Multiplicative Coefficient $=0.2$ \\
Vertical Eddy Viscosity & MY 2.5 Turbulent Closure & \\
Vertical Layer & 25 & Uniform Sigma Layers \\
Tidal Open Boundary Condition & Water Level Time Series & Radiative Boundary Condition \\
Salinity and Temperature Open & Constant and Time Series & Adjusted based on Survey Data \\
Boundary Conditions & Wind Speed/Direction, Net & NOAA Observations and NCEP \\
Meteorological Forcing & Heat Flux and Solar Radiation & NARR Outputs \\
\hline
\end{tabular}

\subsubsection{Model Calibration-Water Surface Elevation}

Comparisons of predicted water surface elevation and field observations at seven tidal stations ( $\mathrm{T} 1$ to T7) and two current stations (C1 and C4) are presented in Figure 3.2 to Figure 3.4. The spring-neap tidal cycle and the diurnal inequality were successfully reproduced in the model simulations. Predicted tidal phases were also in good agreement with observed data. In general, tides in Bellingham Bay are primarily controlled by tidal elevations prescribed at the two open boundaries. Due to the relatively small size of the model domain, no substantial differences in tidal amplitudes and phases were found at all the stations. However, as tides propagate from Strait of Juan de Fuca into the Bay, the tidal amplitude increases gradually towards the north, e.g., the tidal amplitude at Station T3 is slightly larger than Station T6. Meanwhile, tidal phases lag behind towards the north. Inside Bellingham Bay, the same pattern still holds, but the differences in amplitudes and phases are minimal.

The error statistics for mean error (ME), mean absolute error (MAE), and root mean square error (RMSE) between model predictions and field observations are listed in Table 3.2. As can be seen, the ME, MAE, and RMSE for most stations are less than $0.1 \mathrm{~m}$ except for Station T2. It should be noted that the instrument at T2 malfunctioned in the initial period of the survey, and the data quality needs further review. 

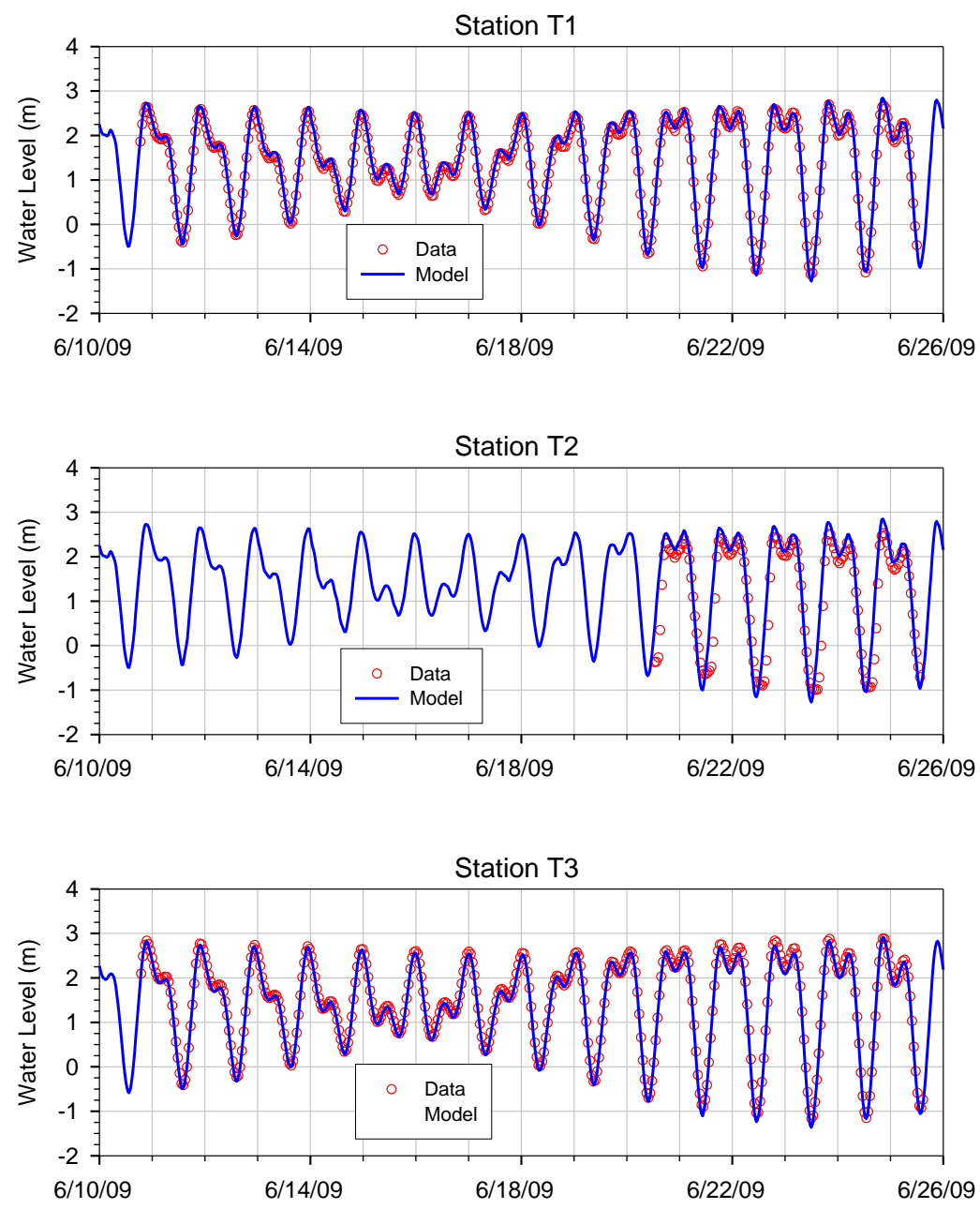

Figure 3.2. Comparisons of Predicted and Observed Water Levels at Stations T1, T2, and T3 

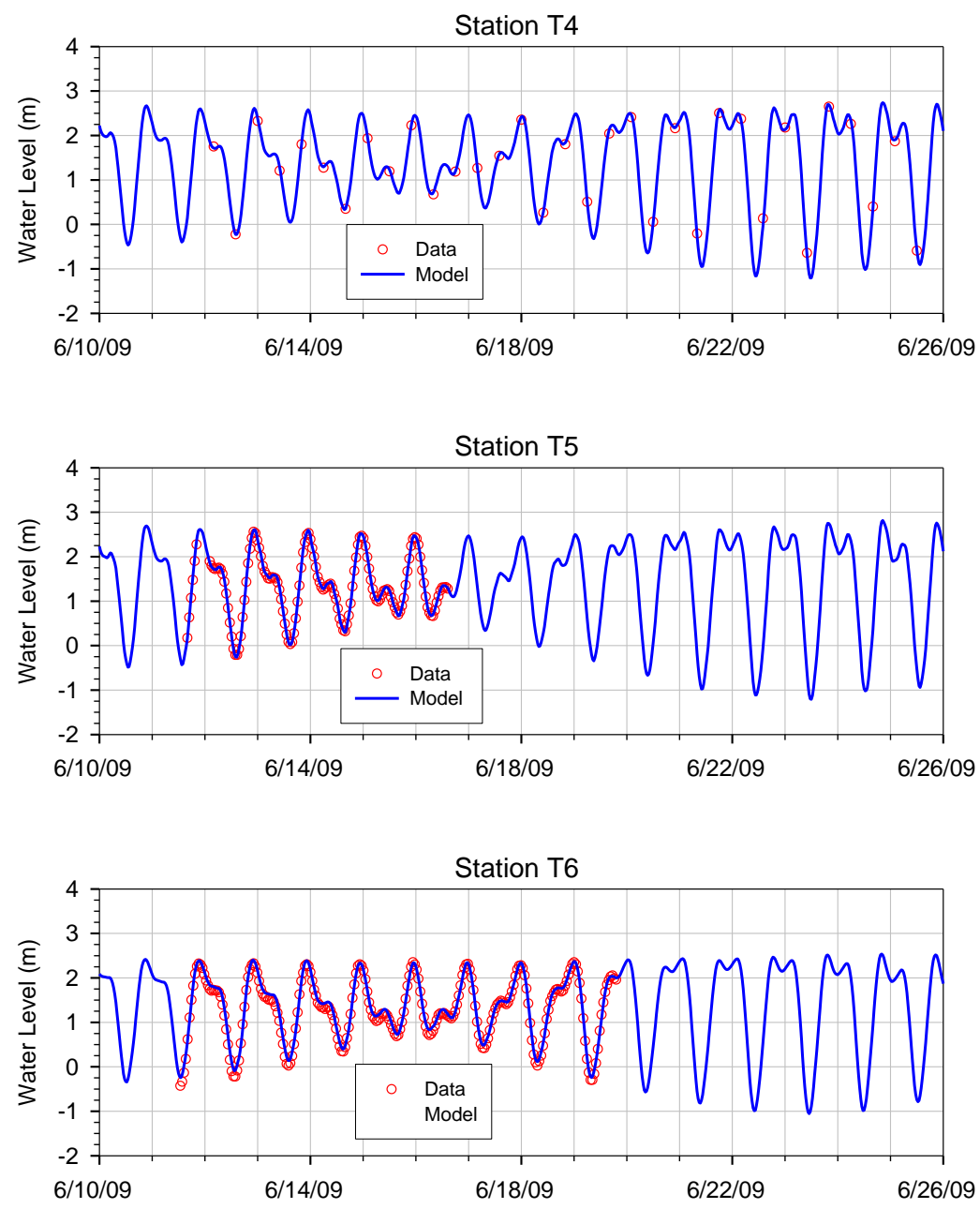

Figure 3.3. Comparisons of Predicted and Observed Water Levels at Stations T4, T5, and T6 

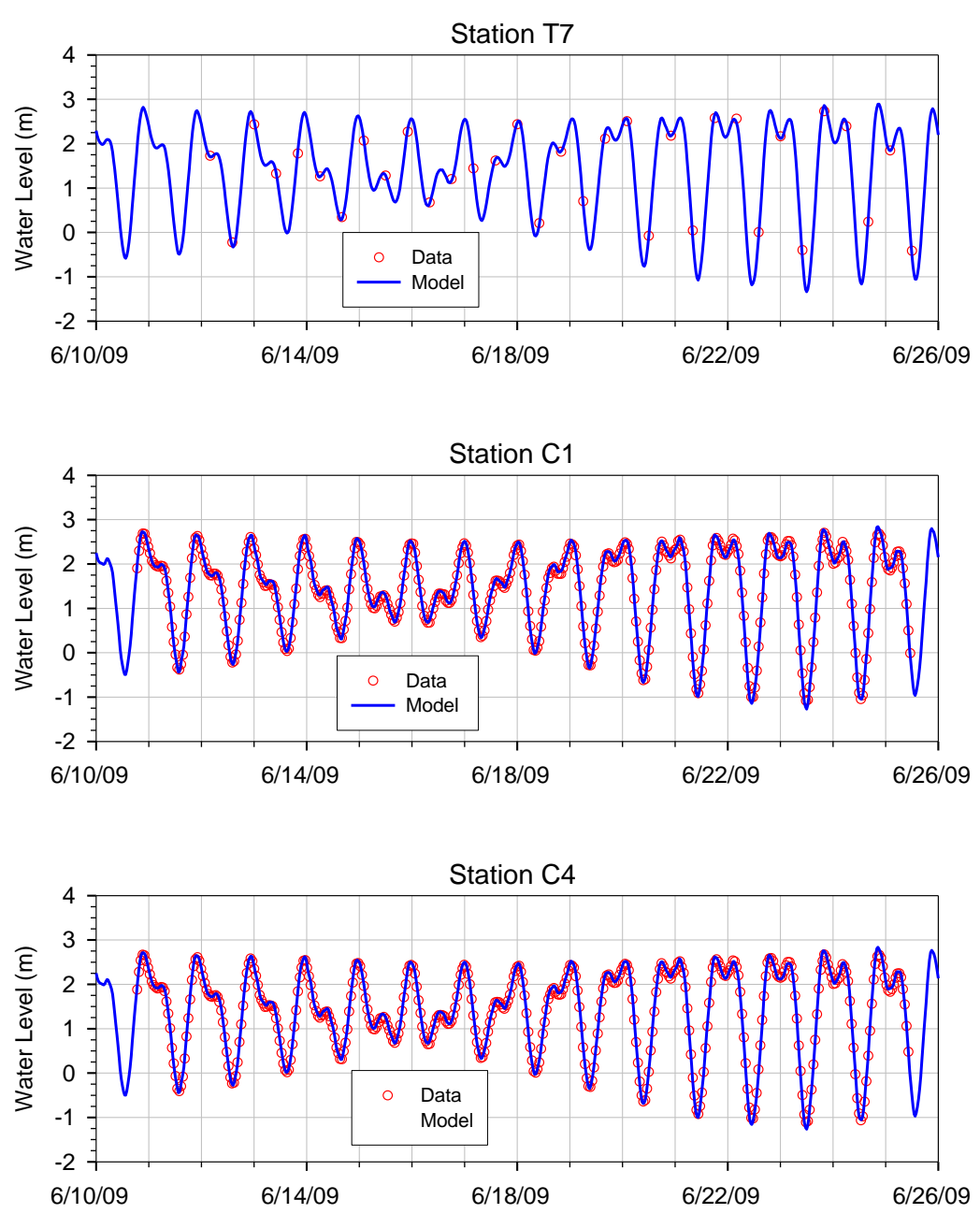

Figure 3.4. Comparisons of Predicted and Observed Water Levels at Stations T7, C1, and C4

Table 3.2. Model Calibration Error Statistics for Water Surface Elevation

\begin{tabular}{cccc}
\hline Station & ME $(\mathrm{m})$ & MAE $(\mathrm{m})$ & RMSE $(\mathrm{m})$ \\
\hline T1 & 0.04 & 0.06 & 0.07 \\
T2 & 0.23 & 0.34 & 0.49 \\
T3 & -0.04 & 0.04 & 0.06 \\
T4 & 0.02 & 0.04 & 0.05 \\
T5 & 0.02 & 0.03 & 0.04 \\
T6 & 0.04 & 0.04 & 0.07 \\
T7 & 0.00 & 0.06 & 0.07 \\
C1 & 0.02 & 0.04 & 0.06 \\
C4 & 0.03 & 0.04 & 0.05 \\
\hline Mean & 0.04 & 0.08 & 0.11 \\
\hline
\end{tabular}




\subsubsection{Model Calibration-Velocity}

There are four velocity stations inside the model domain (Figure 2.14). Stations C1 and C2 are inside Bellingham Bay and the other two (C3 and $\mathrm{C} 4)$ are located in the channel between Lummi Island and Lummi Peninsula. Model predictions at all four stations are compared against field observations. The comparisons are conducted at surface, middle, and bottom layers, respectively. To better illustrate the comparison, velocities are decomposed into East and North components and provided in Figure 3.5 to Figure 3.8. The corresponding error statistics are summarized in Table 3.3 and Table 3.4.

Unlike many other estuaries and bays where tidal currents become stronger as tides propagate into the estuaries and bays, currents inside Bellingham Bay are much smaller at $\mathrm{C} 1$ and $\mathrm{C} 2$ compared to the outside stations $\mathrm{C} 3$ and $\mathrm{C} 4$, as shown in the model results and observed data. It is noted that both model predictions and field observations showed no clear tidal signals in velocities inside Bellingham Bay stations. This is likely caused by the presence of multiple islands near the mouth of Bellingham Bay, i.e., Lummi Island, Portage Island, Sinclair Island, Guemes Island, and Cypress Island (see Figure 1.1), which dissipate the tidal energy as tides propagate into Bellingham Bay. Comparisons of the model results and observed data at $\mathrm{C} 1$ and $\mathrm{C} 2$ indicated that the model under-predicted velocity magnitudes. Although the model under-predicted the velocities at $\mathrm{C} 1$ and $\mathrm{C} 2$, the corresponding error statistics are still quite small as shown in Table 3.3 because of the overall small velocity magnitudes in these stations.

The forcing mechanisms that are responsible for the irregular variations in velocity distributions observed at $\mathrm{C} 1$ and $\mathrm{C} 2$ are not clearly understood. To further investigate this, a harmonic analysis of observed velocity data was conducted at selected stations. Nine major tidal constituents, K1, O1, P1, Q1, $\mathrm{M} 2, \mathrm{~N} 2, \mathrm{~S} 2$, K2, and M4, are included in the harmonic analysis. By using the harmonic analysis technique, the effect of tides on velocities may be quantified. Figure 3.9 shows the comparison of harmonic fit and the observed data for the east velocity component at Station C3 (upper panel) and the residual velocities (the differences between observed data and the harmonic fit) (bottom panel). The predicted east velocity component based on harmonic analysis at $\mathrm{C} 3$ matched the observed data very well with $\mathrm{R}^{2}=0.9$. The corresponding residuals were small compared to the observed data. This indicated that tides account for $90 \%$ of the variability in the velocity data, or in the other words, the velocity at $\mathrm{C} 3$ was dominated by tidal components. In contrast, the harmonic fit to the observed data at Station $\mathrm{C} 1$ was very poor with $\mathrm{R}^{2}=0.26$, and the non-tidal residuals were very large (Figure 3.10). This indicated that the observed velocities at $\mathrm{C} 1$ were not dominated by tidal constituents but other factors, such as local winds. Because velocity magnitudes at $\mathrm{C} 1$ and $\mathrm{C} 2$ are small, data noises may also contribute to the tidal residuals. 

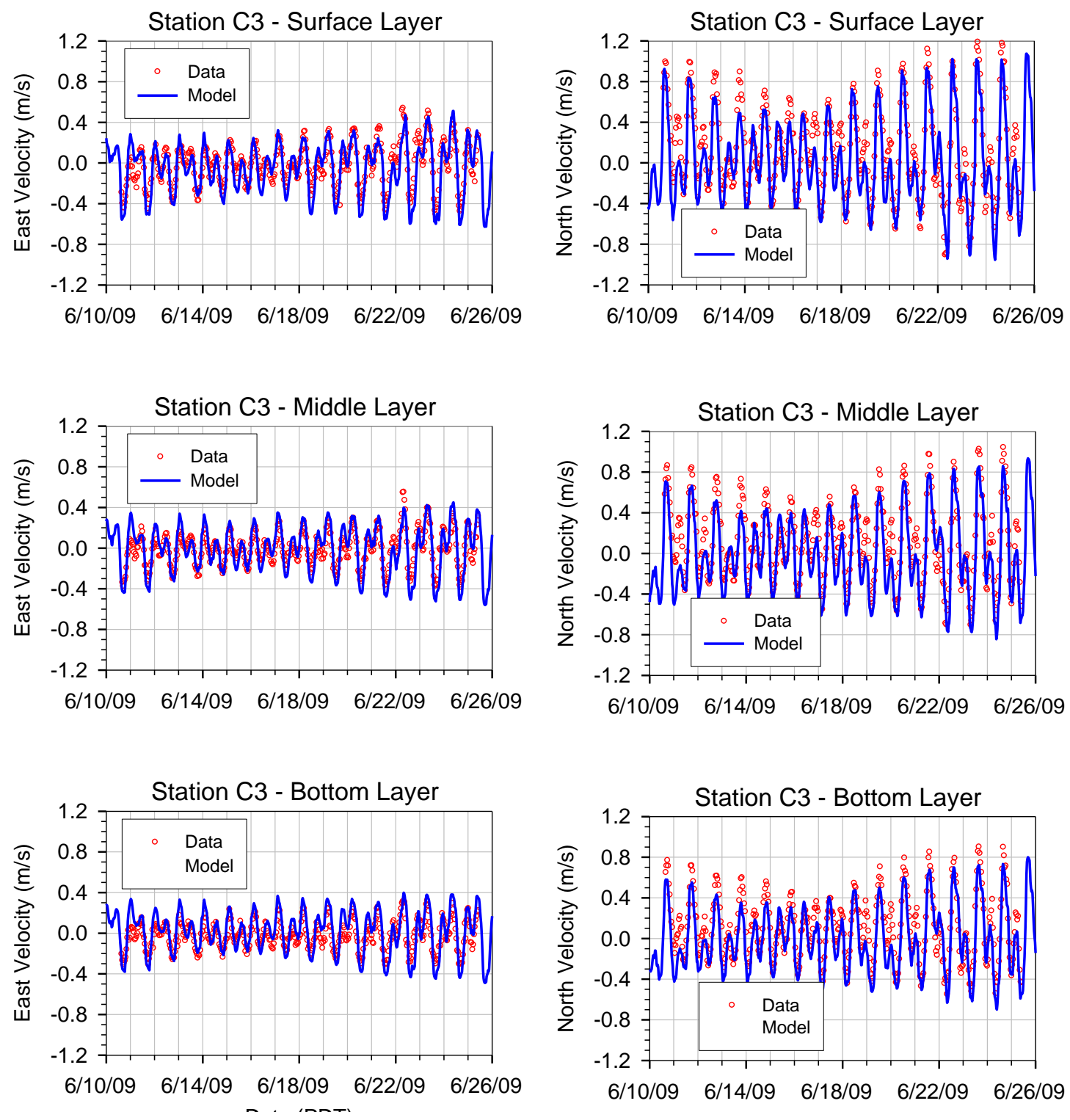

Figure 3.5. Comparisons of Predicted and Observed Velocity at Station C3 

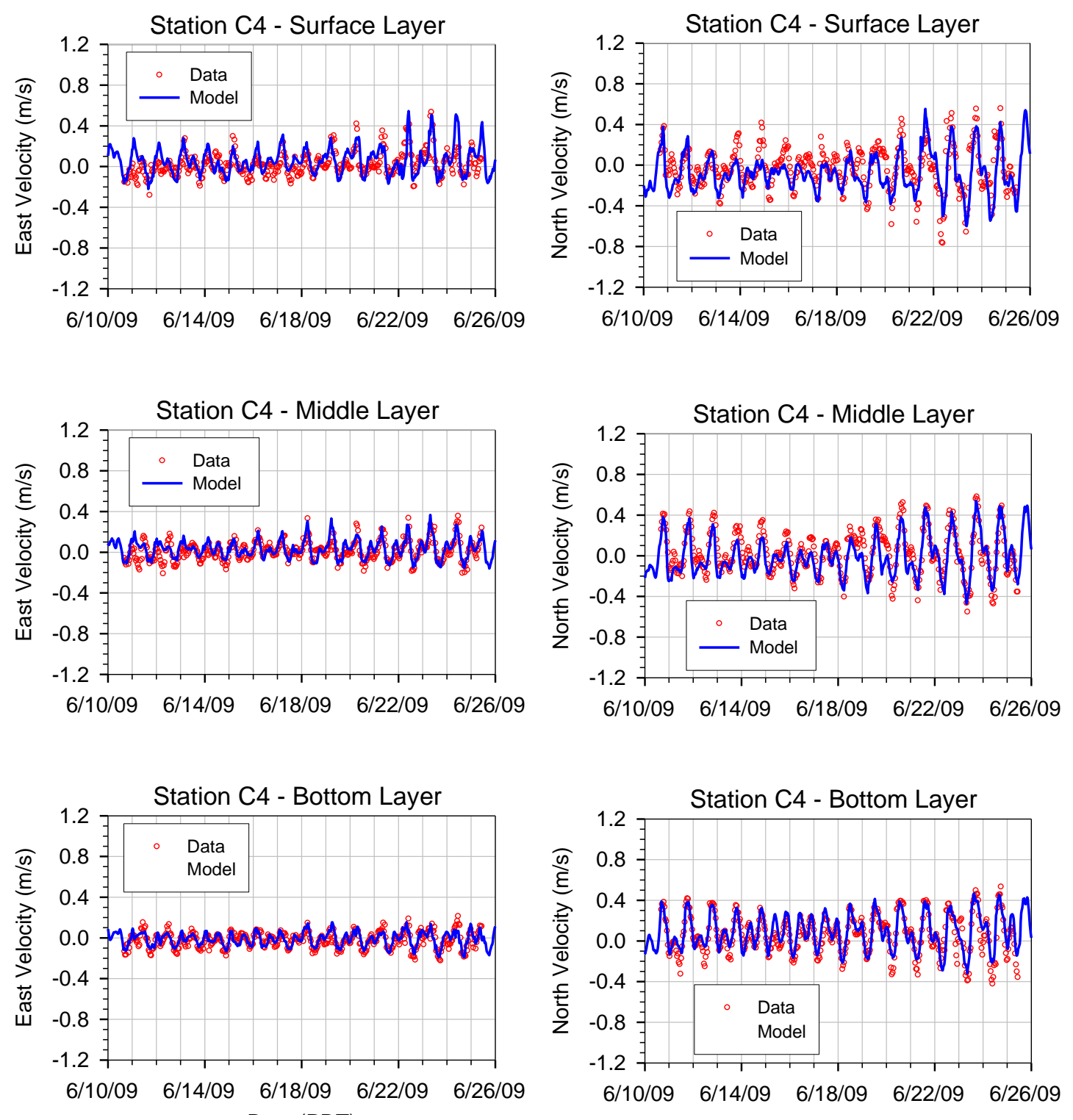

Figure 3.6. Comparisons of Predicted and Observed Velocity at Station C4 

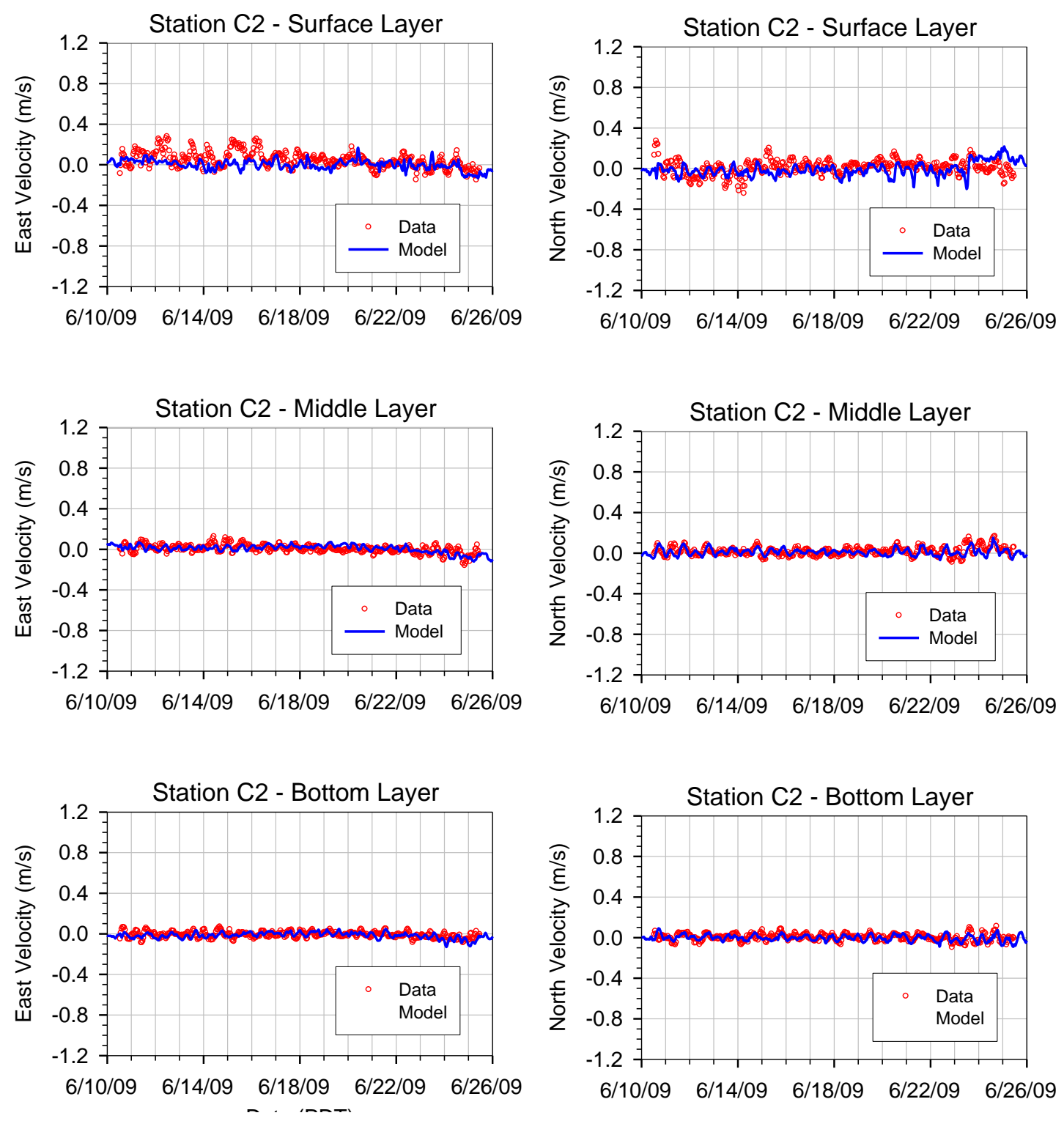

Figure 3.7. Comparisons of Predicted and Observed Velocity at Station C2 

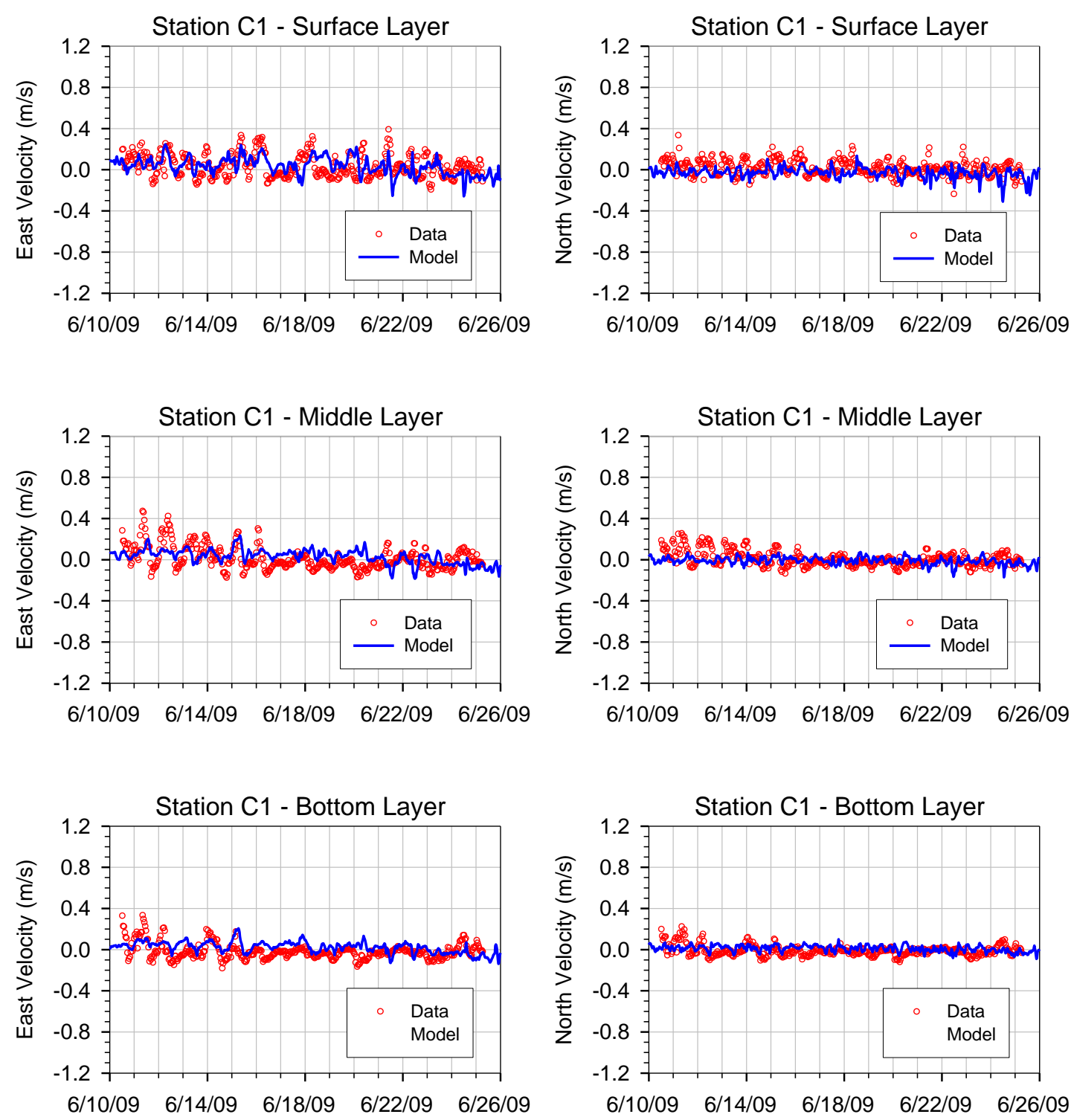

Figure 3.8. Comparisons of Predicted and Observed Velocity at Station C1 
Table 3.3. Model Calibration Error Statistics for East Direction Current Velocity

\begin{tabular}{|c|c|c|c|c|c|c|}
\hline & & Station & $\mathrm{C} 1$ & $\mathrm{C} 2$ & $\mathrm{C} 3$ & $\mathrm{C} 4$ \\
\hline \multirow{12}{*}{$\begin{array}{c}\text { East } \\
\text { Velocity } \\
\text { Component }\end{array}$} & \multirow{4}{*}{$\operatorname{ME}(\mathrm{m} / \mathrm{s})$} & Surface & 0.00 & -0.05 & -0.02 & 0.04 \\
\hline & & Middle & 0.02 & 0.01 & 0.01 & 0.02 \\
\hline & & Bottom & 0.02 & 0.00 & 0.05 & 0.01 \\
\hline & & Mean & 0.01 & -0.01 & 0.01 & 0.02 \\
\hline & \multirow{4}{*}{$\operatorname{MAE}(\mathrm{m} / \mathrm{s})$} & Surface & 0.10 & 0.07 & 0.10 & 0.09 \\
\hline & & Middle & 0.09 & 0.03 & 0.09 & 0.06 \\
\hline & & Bottom & 0.06 & 0.03 & 0.09 & 0.04 \\
\hline & & Mean & 0.08 & 0.04 & 0.09 & 0.06 \\
\hline & \multirow{4}{*}{$\begin{array}{l}\text { RMSE } \\
(\mathrm{m} / \mathrm{s})\end{array}$} & Surface & 0.12 & 0.09 & 0.12 & 0.11 \\
\hline & & Middle & 0.11 & 0.04 & 0.11 & 0.07 \\
\hline & & Bottom & 0.08 & 0.03 & 0.11 & 0.05 \\
\hline & & Mean & 0.10 & 0.06 & 0.11 & 0.08 \\
\hline \multirow{12}{*}{$\begin{array}{c}\text { North } \\
\text { Velocity } \\
\text { Component }\end{array}$} & \multirow{4}{*}{$\mathrm{ME}(\mathrm{m} / \mathrm{s})$} & Surface & -0.04 & -0.02 & -0.11 & -0.05 \\
\hline & & Middle & -0.01 & 0.00 & -0.12 & -0.04 \\
\hline & & Bottom & 0.02 & 0.00 & -0.11 & 0.03 \\
\hline & & Mean & -0.01 & -0.01 & -0.11 & -0.02 \\
\hline & \multirow{4}{*}{$\operatorname{MAE}(\mathrm{m} / \mathrm{s})$} & Surface & 0.08 & 0.07 & 0.16 & 0.13 \\
\hline & & Middle & 0.03 & 0.03 & 0.16 & 0.09 \\
\hline & & Bottom & 0.02 & 0.02 & 0.14 & 0.07 \\
\hline & & Mean & 0.04 & 0.04 & 0.15 & 0.10 \\
\hline & \multirow{4}{*}{$\begin{array}{l}\text { RMSE } \\
(\mathrm{m} / \mathrm{s})\end{array}$} & Surface & 0.09 & 0.09 & 0.20 & 0.16 \\
\hline & & Middle & 0.08 & 0.04 & 0.19 & 0.12 \\
\hline & & Bottom & 0.06 & 0.03 & 0.17 & 0.09 \\
\hline & & Mean & 0.08 & 0.05 & 0.19 & 0.12 \\
\hline
\end{tabular}




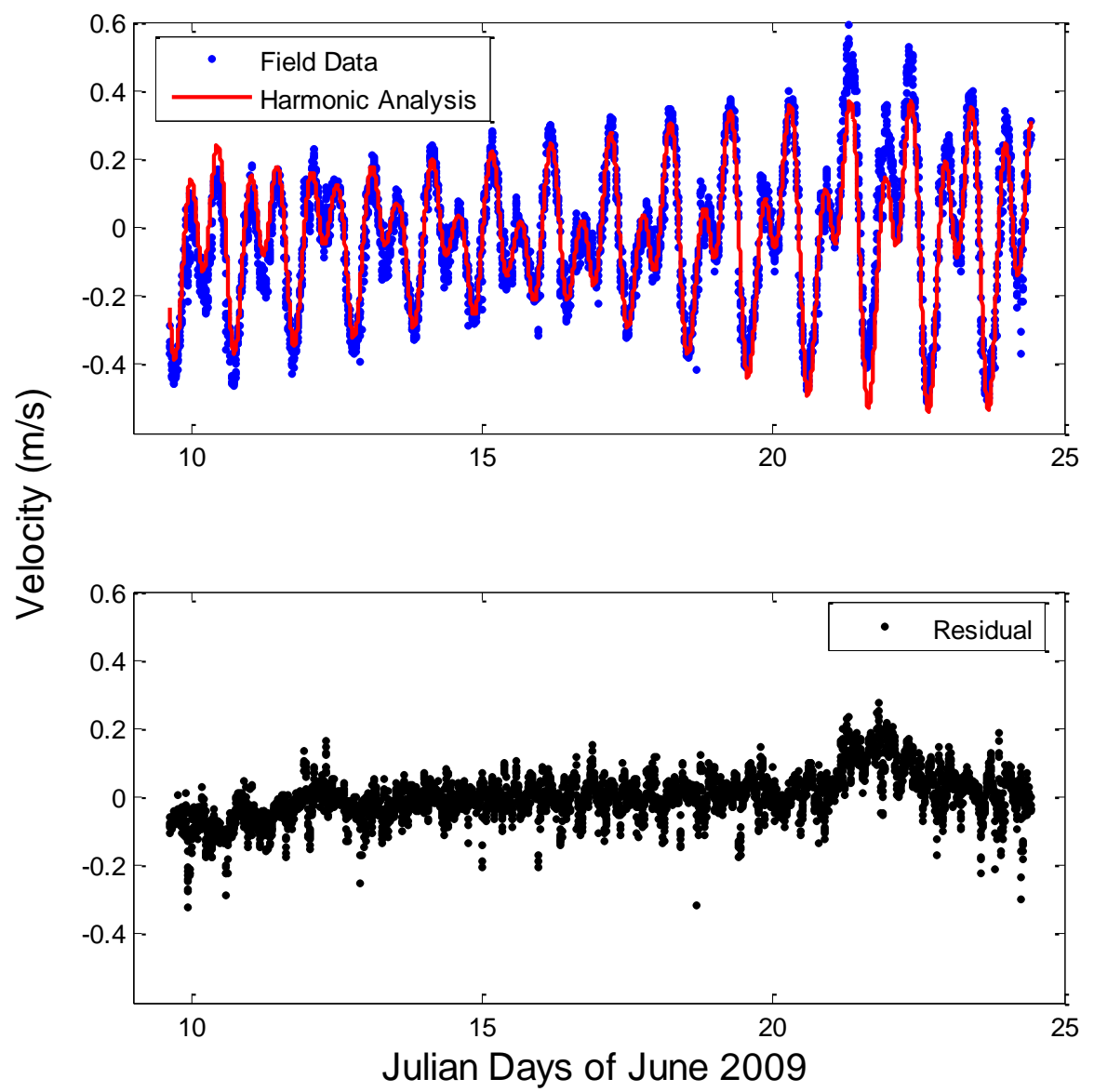

Figure 3.9. Harmonic Analysis Result of Surface Layer East Component Velocity at Station C3 


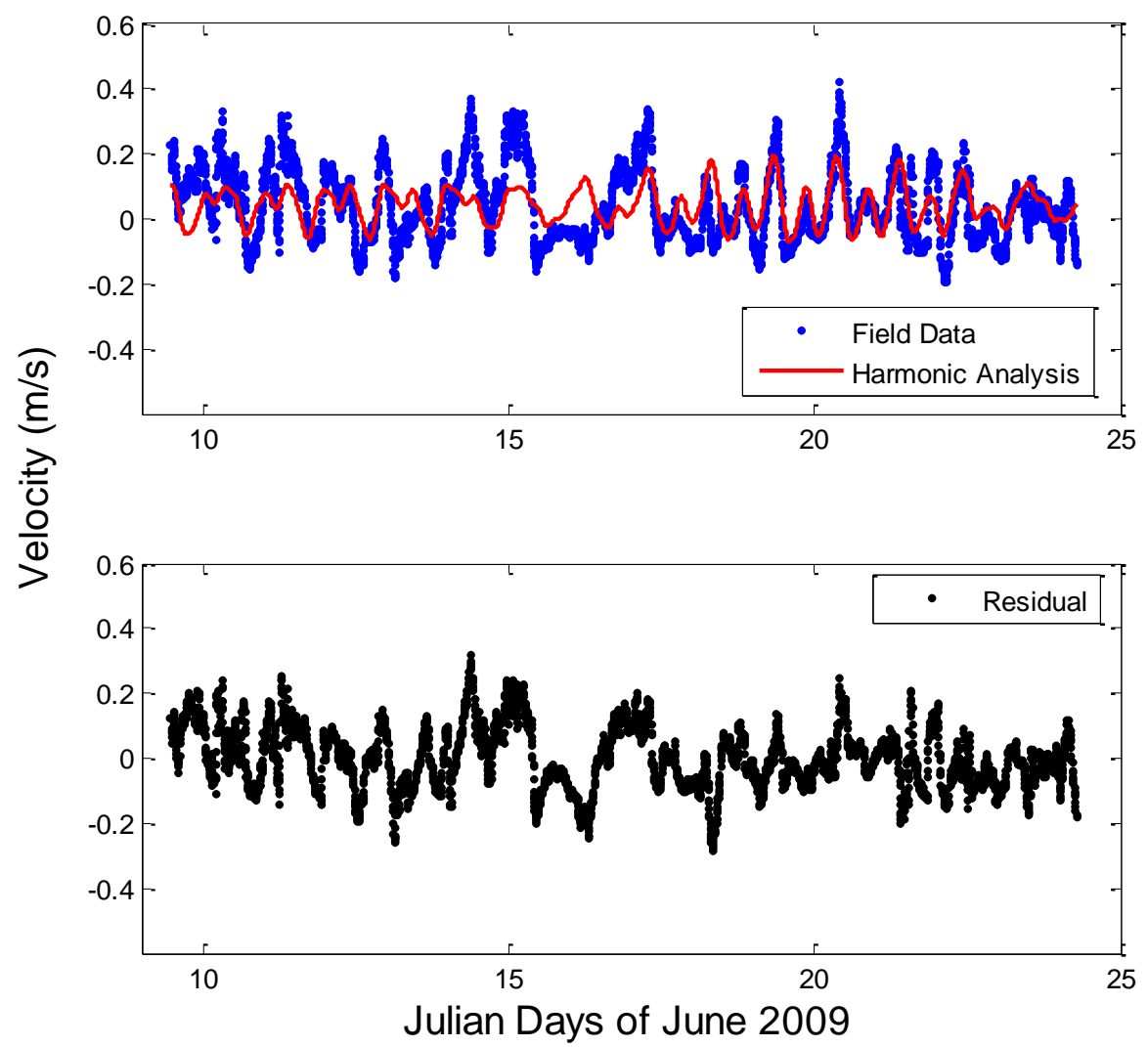

Figure 3.10. Harmonic Analysis Result of Surface Layer East Component Velocity at Station C1

\subsubsection{Model Calibration-Temperature and Salinity}

Two types of temperature and salinity data are available for Bellingham Bay hydrodynamic model calibration: temperature and salinity time series collected continuously at fixed stations through the twoweek sampling period and instantaneous temperature and salinity vertical profiles collected twice during deployment and retrieval in conjunction with the continuous measurement (Table 2.1). The time series data at fixed water depths are useful in evaluating the model's performance in temporal variations while the instantaneous vertical profiles provide detailed information on the vertical stratification and mixing processes.

Simulating temperature and salinity distributions in Bellingham Bay is highly challenging. Temperature and salinity distributions are not only controlled by physical exchanges driven by tides, but also by river discharge and meteorological forcing, which is generally of much higher uncertainty than open-boundary tidal forcing. Time-series comparisons of temperature between model predictions and field observations are presented in Figure 3.11 to Figure 3.14. Stations T1 and T2 are within Bellingham Bay, and Station T3 is located at the mouth of Lummi Bay near the open boundary of the model. Temperature variations as much as to $5^{\circ} \mathrm{C}$ were observed in the field data at $\mathrm{T} 1$ and $\mathrm{T} 2$, but daily variations due to meteorological forcing were not very clear as shown in the model results (Figure 3.11). Strong daily temperature variations were observed in the data at T3, and the model under-predicted the range of the temperature variations, probably because of the open boundary effect. For stations located outside Bellingham Bay, e.g., Stations T4 to T7, temperature variations were very small during the period 
of model simulation (Figure 3.12 and Figure 3.13). Temperature distributions at these stations are mainly controlled by tidal circulations driven by the open boundary conditions. Temperature data were also available at the bottom of the water column at the two ADCP stations $\mathrm{C} 1$ and $\mathrm{C} 4$ in Bellingham Bay. Comparisons of predicted and observed temperatures at $\mathrm{C} 1$ and $\mathrm{C} 4$ are presented in Figure 3.13. Model results showed good agreement with the observed temperatures at both stations, except during the later period of the field survey at $\mathrm{C} 1$ where some daily variations were observed in the data. Error statistics for temperature calibrations are shown in Table 3.4. The RMSE ranges from $0.58^{\circ} \mathrm{C}$ at $\mathrm{T} 5$ to $2.28^{\circ} \mathrm{C}$ at $\mathrm{T} 1$, with a mean RMSE of $1.28^{\circ} \mathrm{C}$ for all the stations.

The model calibration for the salinity time series is provided in Figure 3.14 to Figure 3.16. At Stations T1 and T2, which are inside and near Bellingham Bay, the model was capable of simulating the sharp salinity drops during ebb tides. However, the model over-predicted salinities during the flood. Because Station T1 is located right downstream of Squalicum Creek, it is likely that future extension of the model grid to include Squalicum Creek and other potential storm water outfalls may improve the model results. In addition, the Nooksack River plume seems to have a strong influence on salinity distribution at Station T2 (Figure 3.14). At Station T3 which is near the boundary, model results were in good agreement with the data, as the observed data were used as the open boundary conditions. For those stations outside Bellingham Bay (T4 to T7), predicted salinities matched the observed data well (Figure 3.15 and Figure 3.16). There were noticeable reductions in salinities at $\mathrm{T} 3$ and $\mathrm{T} 7$ for the period of $6 / 21 / 2009$ to $6 / 26 / 2009$ and at T6 for the period of 6/12/2009 to 6/17/2009. Because T3 and T7 are at the northern open boundary, there is a possibility that it was influenced by the Fraser River plume. Comparisons of predicted and observed salinities at Station $\mathrm{C} 1$ and $\mathrm{C} 4$ at the bottom of the water column are plotted in Figure 3.16. Both model results and observed data showed high and nearly constant salinity distribution at both stations, indicating that the bottom layer of Bellingham Bay is mainly occupied by saline ocean water from the Rosario Strait. Although C1 is the station closest to the mouth of Nooksack River, it seems unaffected by the Nooksack River plume. Error statistics for salinity calibrations are shown in Table 3.6. The RMSE ranges from $0.49 \mathrm{ppt}$ at $\mathrm{C} 4$ to $3.51 \mathrm{ppt}$ at $\mathrm{T} 2$, with a mean RMSE of 1.91 ppt for all the stations. 

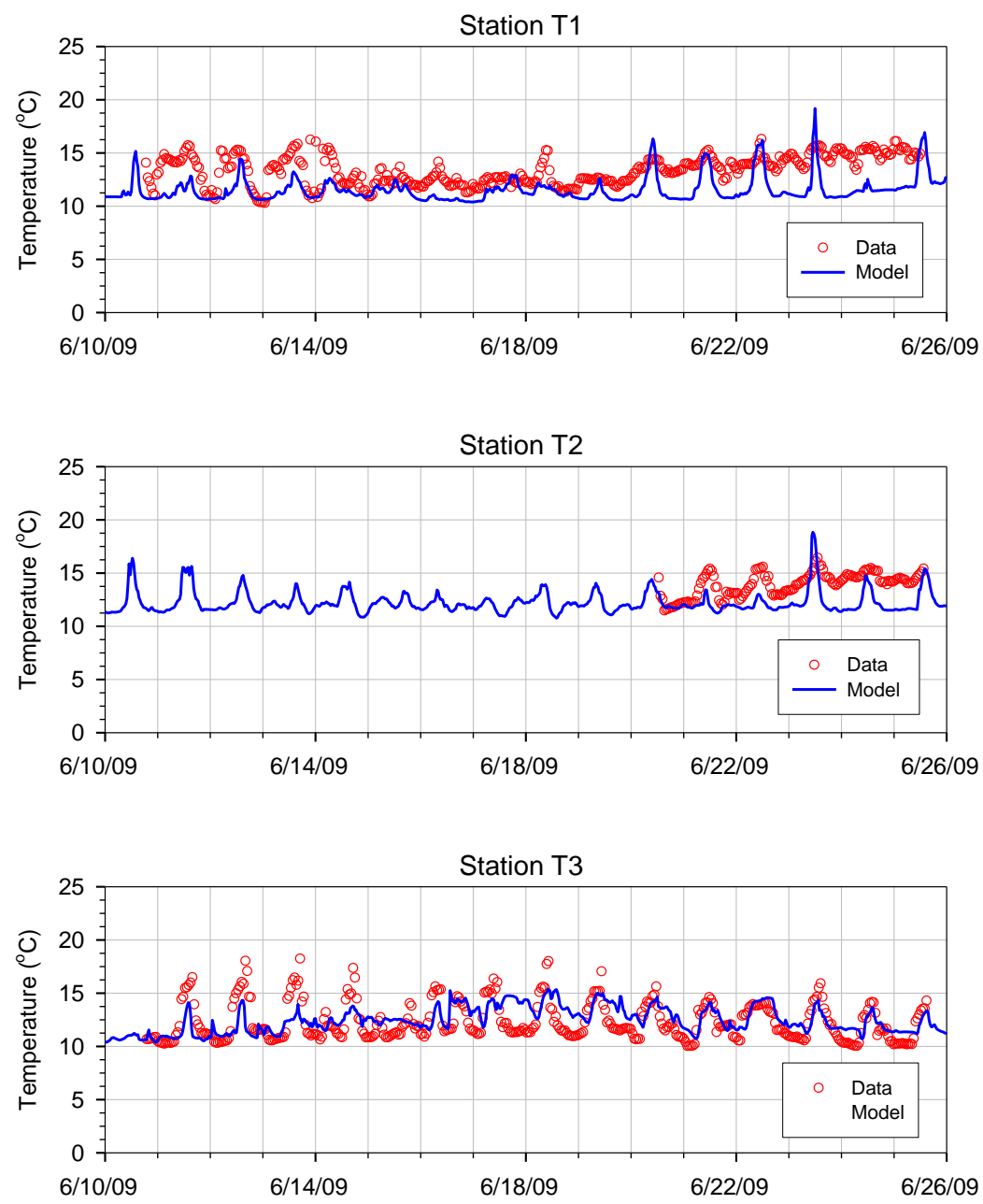

Figure 3.11. Comparisons of Predicted and Observed Water Temperature at Stations T1, T2, and T3 

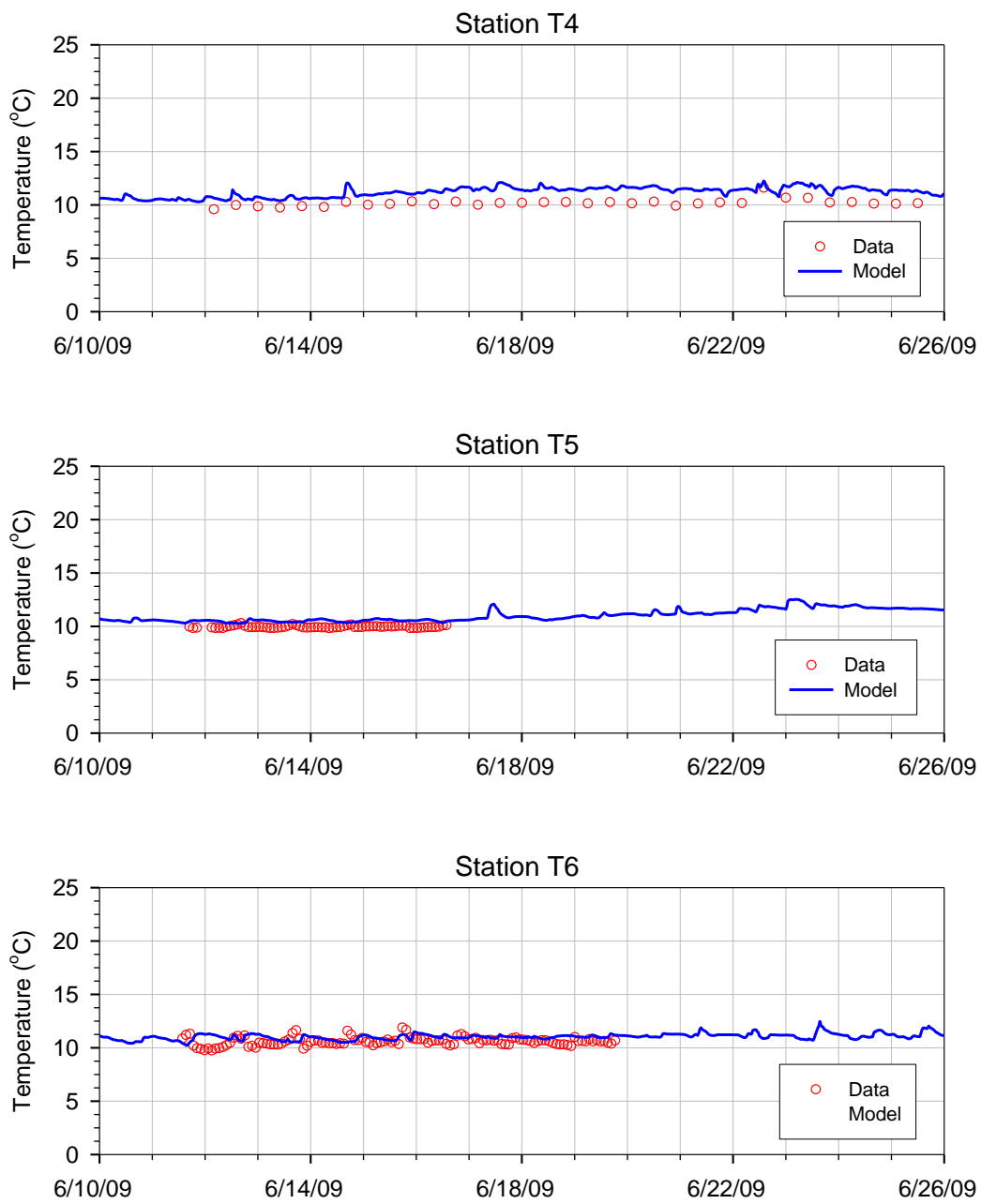

Figure 3.12. Comparisons of Predicted and Observed Water Temperature at Stations T4, T5, and T6 

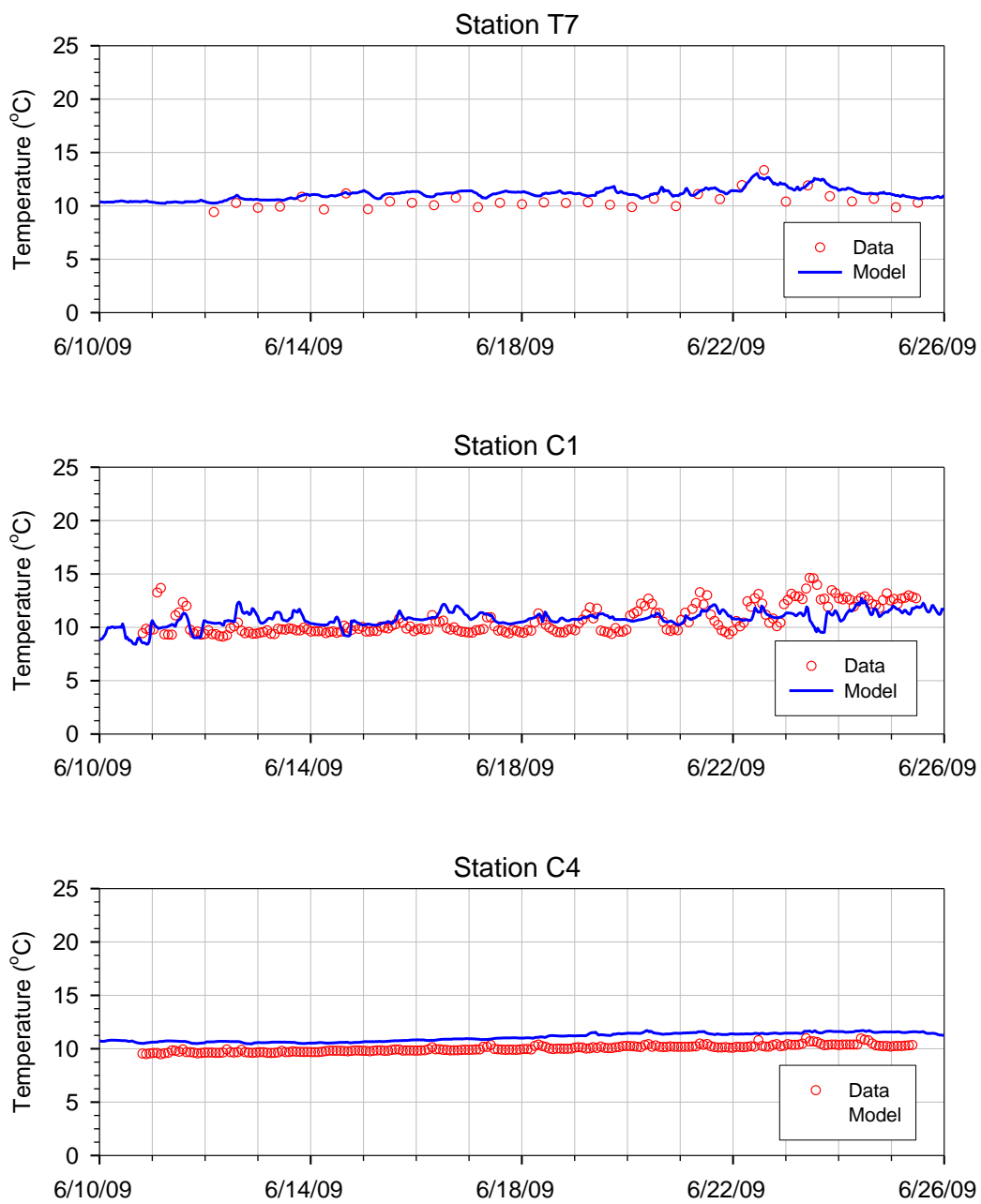

Figure 3.13. Comparisons of Predicted and Observed Water Temperature at Stations T7, C1, and C4

Table 3.4. Model Calibration Error Statistics for Water Temperature Time Series

\begin{tabular}{cccc}
\hline Station & ME $\left({ }^{\circ} \mathrm{C}\right)$ & MAE $\left({ }^{\circ} \mathrm{C}\right)$ & RMSE $\left({ }^{\circ} \mathrm{C}\right)$ \\
\hline $\mathrm{T} 1$ & -1.87 & 1.94 & 2.28 \\
$\mathrm{~T} 2$ & -1.75 & 1.87 & 2.12 \\
$\mathrm{~T} 3$ & 0.25 & 1.25 & 1.56 \\
$\mathrm{~T} 4$ & 1.17 & 1.17 & 1.21 \\
$\mathrm{~T} 5$ & 0.55 & 0.55 & 0.58 \\
$\mathrm{~T} 6$ & 0.37 & 0.51 & 0.62 \\
$\mathrm{~T} 7$ & 0.74 & 0.82 & 0.91 \\
$\mathrm{C} 1$ & 0.16 & 1.04 & 1.19 \\
$\mathrm{C} 4$ & 1.05 & 1.05 & 1.07 \\
\hline Mean & 0.07 & 1.13 & 1.28 \\
\hline
\end{tabular}



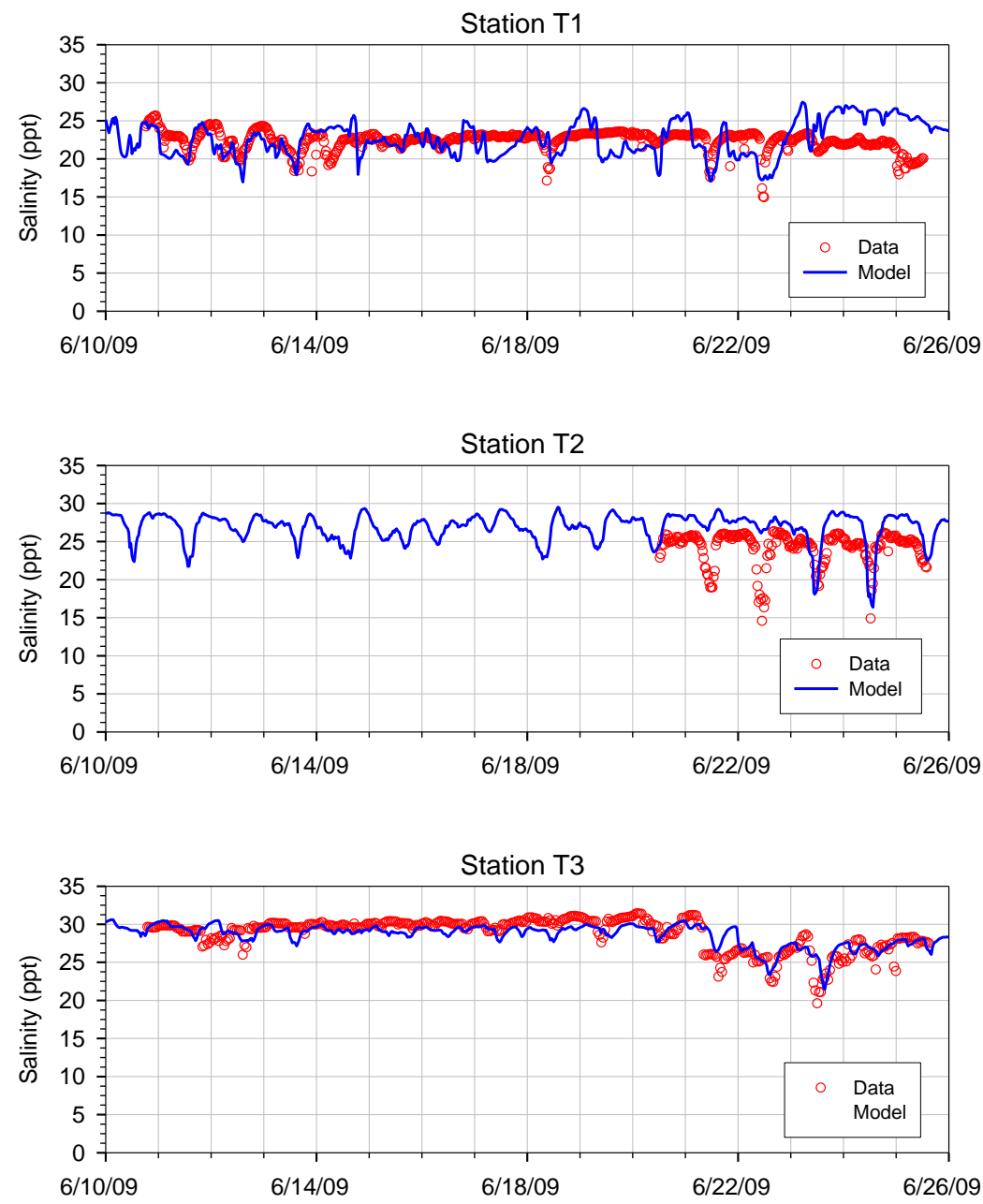

Figure 3.14. Comparisons of Predicted and Observed Salinity at Stations T1, T2, and T3 

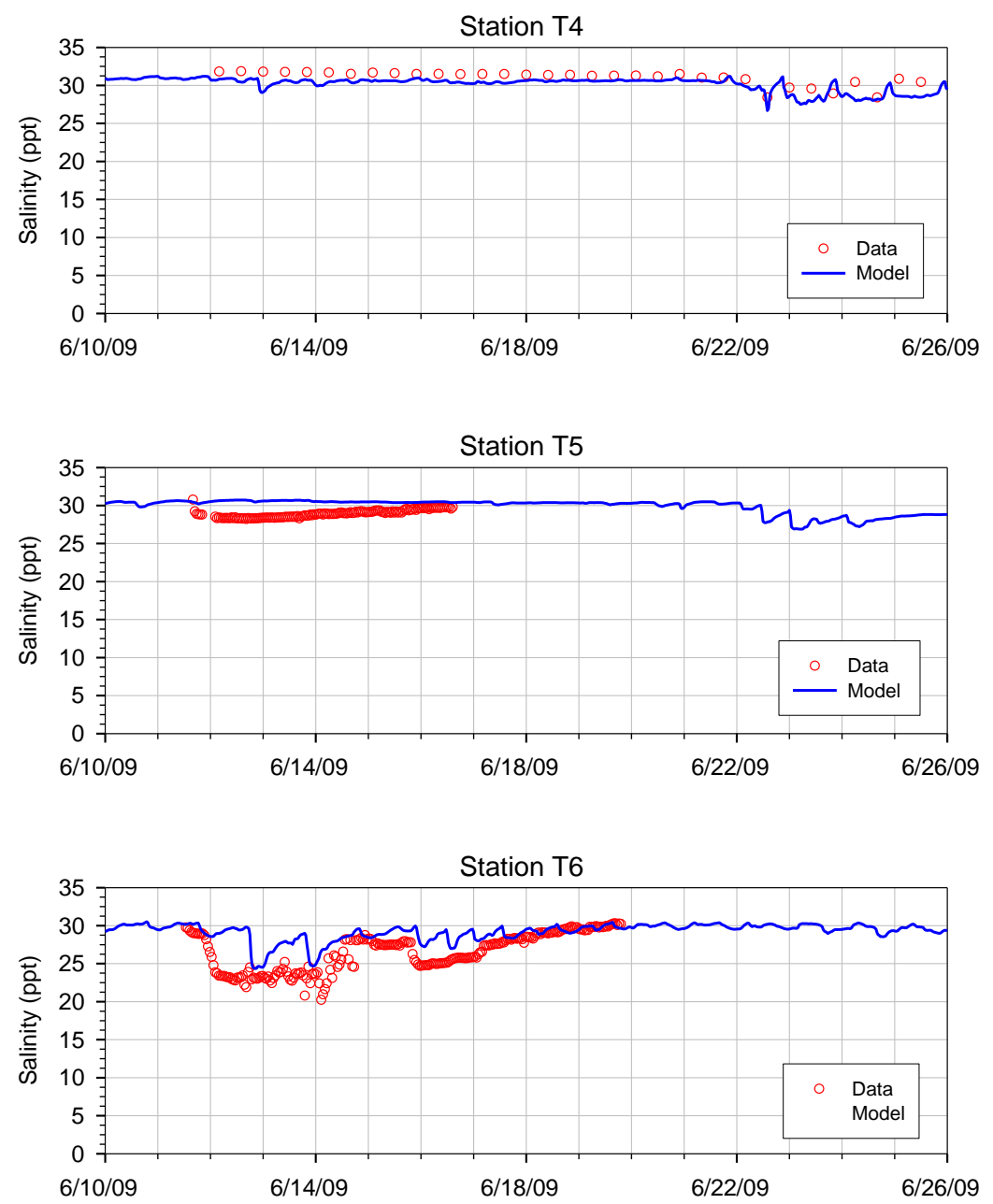

Figure 3.15. Comparisons of Predicted and Observed Salinity at Stations T4, T5, and T6 

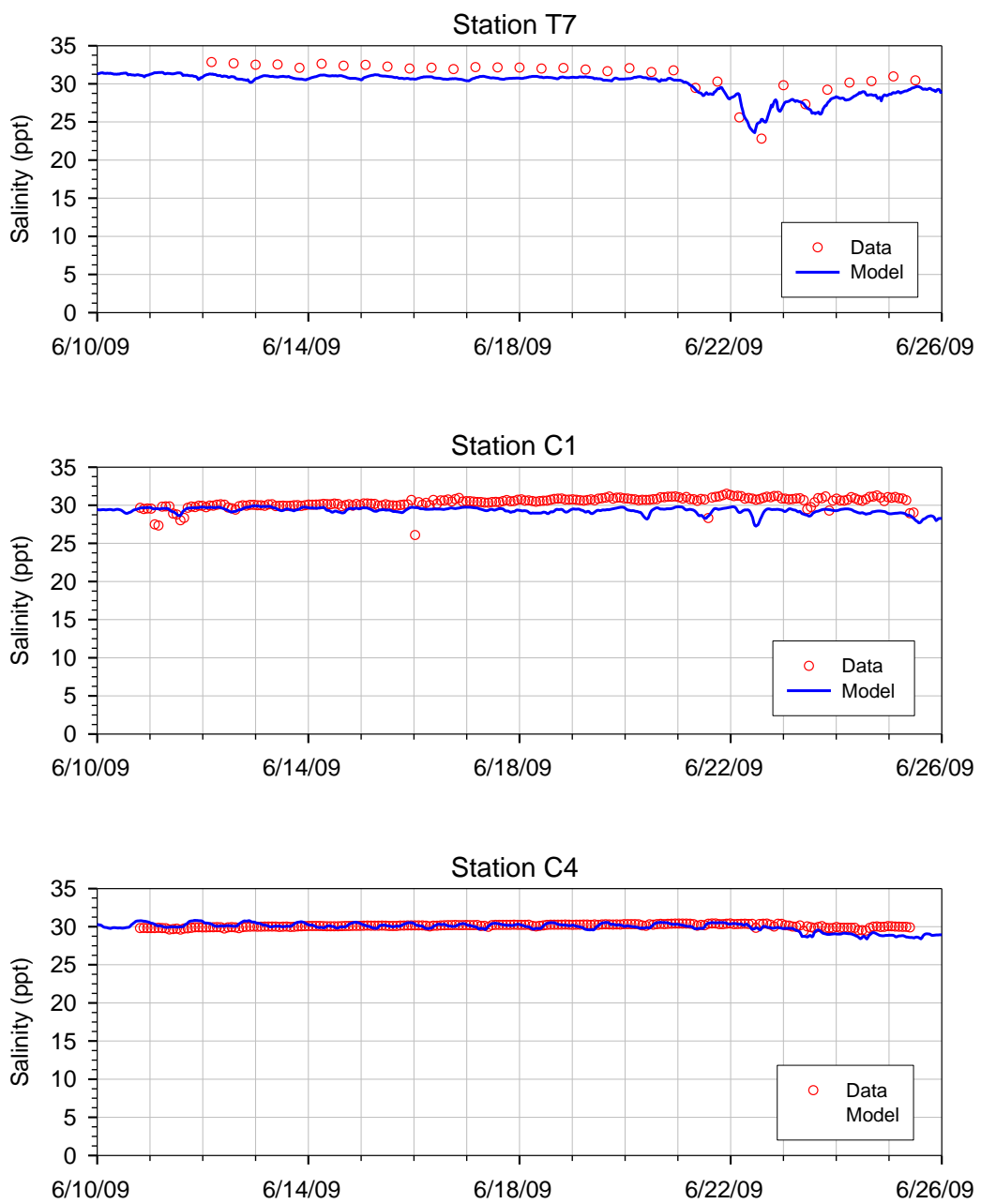

Figure 3.16. Comparisons of Predicted and Observed Salinity at Stations T7, C1, and C4

Table 3.5. Model Calibration Error Statistics for Salinity Time Series

\begin{tabular}{cccc}
\hline Station & ME (ppt) & MAE (ppt) & RMSE (ppt) \\
\hline T1 & 0.45 & 2.34 & 3.01 \\
T2 & 2.73 & 3.06 & 3.51 \\
T3 & -0.17 & 1.06 & 1.38 \\
T4 & -1.02 & 1.12 & 1.26 \\
T5 & 1.61 & 1.61 & 1.70 \\
T6 & 2.16 & 2.23 & 2.95 \\
T7 & -1.12 & 1.45 & 1.56 \\
C1 & -1.01 & 1.14 & 1.31 \\
C4 & -0.10 & 0.36 & 0.49 \\
\hline Mean & 0.39 & 1.60 & 1.91 \\
\hline
\end{tabular}


As part of model calibration, predicted temperature and salinity profiles were also compared to observed profiles collected during the deployment and retrieval of field instruments. Comparisons of predicted and observed temperature profiles are shown in Figure 3.17 and Figure 3.18; and salinity profiles in Figure 3.19 and Figure 3.20. It can be seen that the model is capable of capturing the general patterns of temperature and salinity distribution over the water column. In general, temperature and salinity profiles become more stratified inside the bay, e.g., stations $\mathrm{T} 1, \mathrm{~T} 2, \mathrm{C} 1$ and $\mathrm{C} 2$. In contrast, vertical salinity gradients become weaker at stations away from the river mouth (e.g., Stations T4 and T7). Errors statistics for temperature and salinity profile calibrations are shown in Table 3.7 respectively. The overall mean RMSE for temperature and salinity profiles are $1.50^{\circ} \mathrm{C}$ and $2.00 \mathrm{ppt}$, respectively.

While temperature and salinity calibration can be further improved with the refinement of forcing inputs and model configuration, the level of accuracy for temperature and salinity calibration is considered sufficient in this study to develop a hydrodynamic model to characterize the general circulation patterns and temperature/salinity distributions in Bellingham Bay.
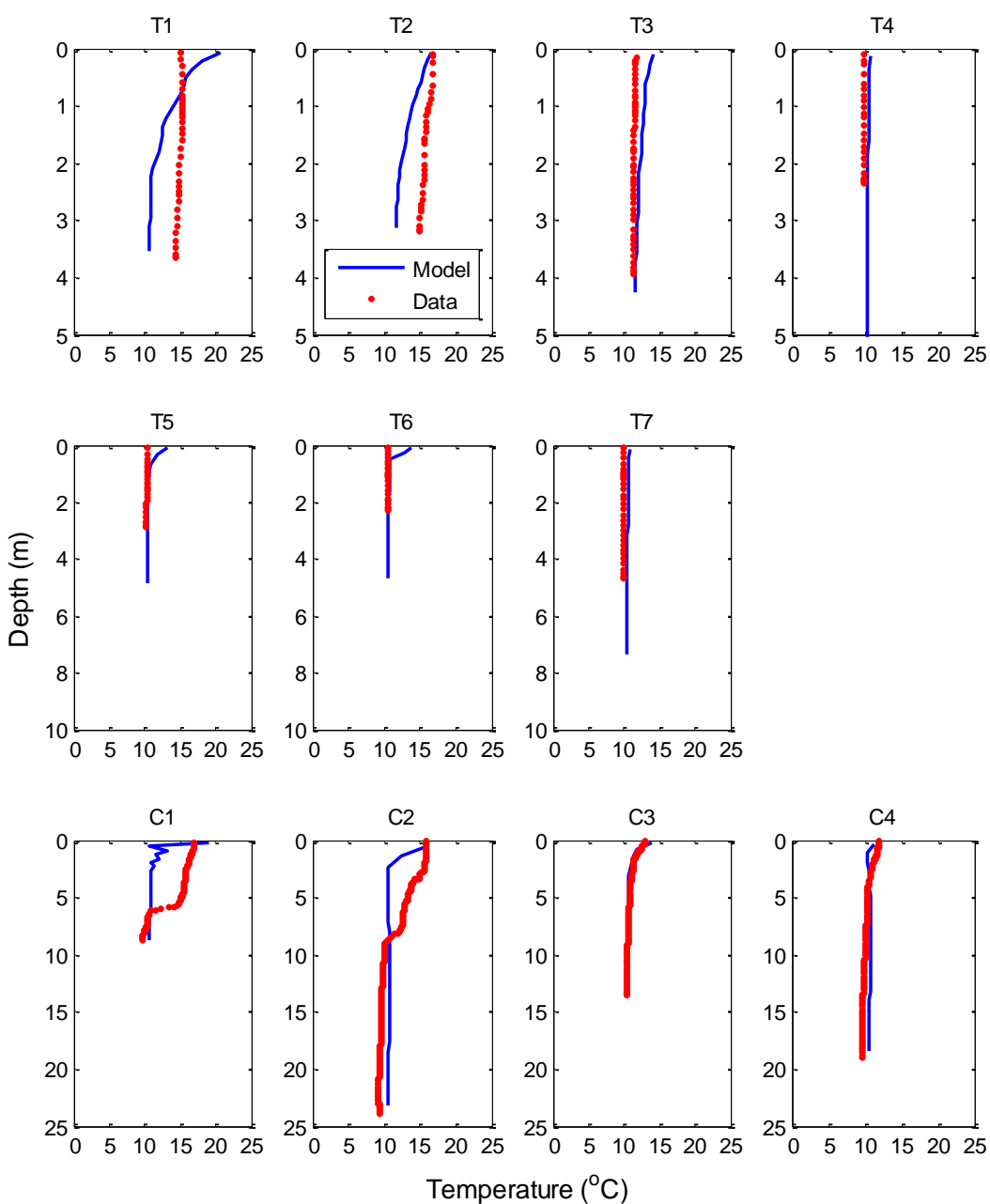

Figure 3.17. Comparisons of Predicted and Observed Water Temperature Vertical Profiles During the Deployment Period on June 10 and 11, 2009 

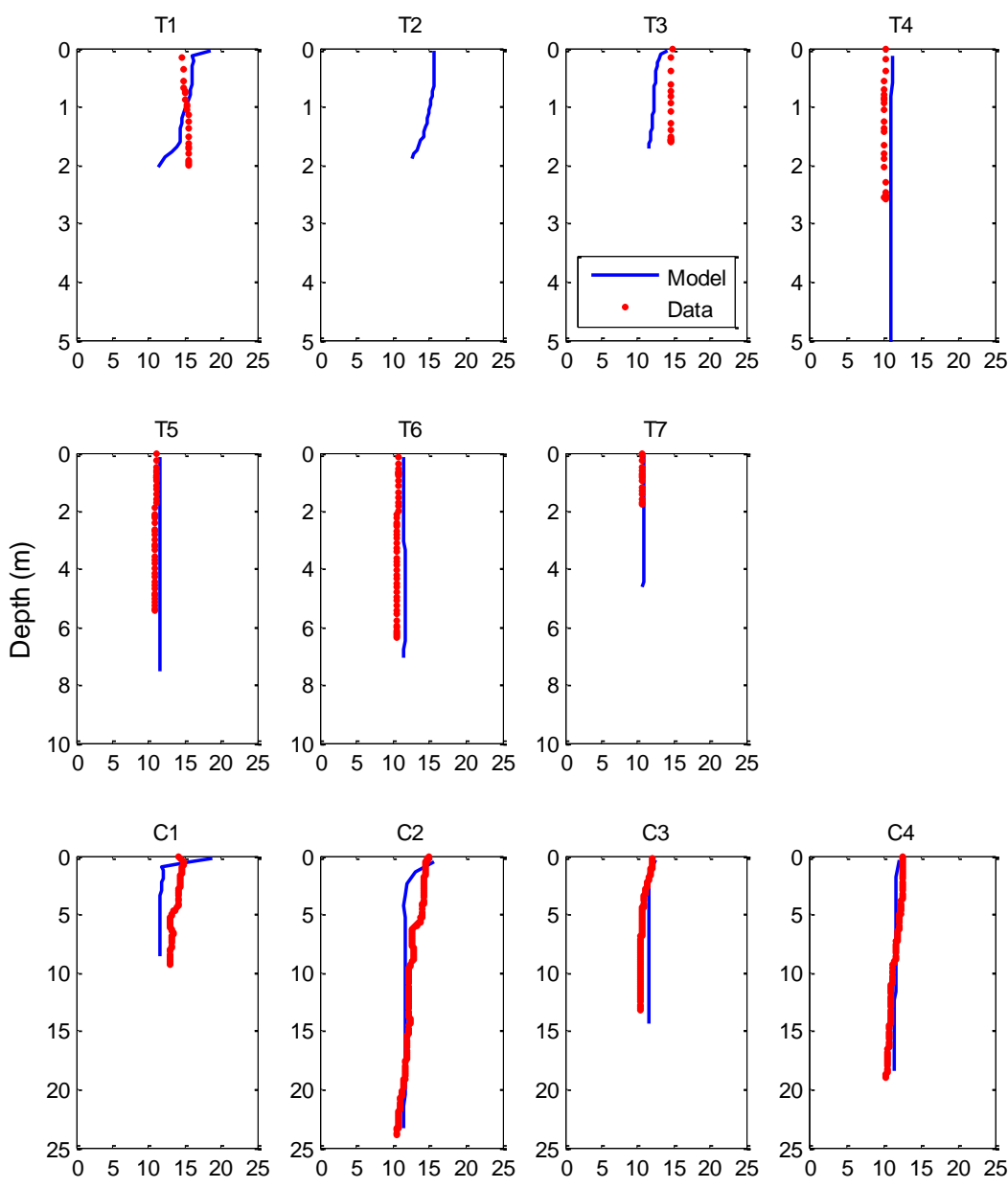

Figure 3.18. Comparisons of Predicted and Observed Water Temperature Vertical Profiles During Retrieval Period on June 25, 2009 
Table 3.6. Model Calibration Error Statistics for Temperature Vertical Profiles

\begin{tabular}{|c|c|c|c|c|}
\hline & Station & $\operatorname{ME}\left({ }^{\circ} \mathrm{C}\right)$ & $\operatorname{MAE}\left({ }^{\circ} \mathrm{C}\right)$ & $\operatorname{RMSE}\left({ }^{\circ} \mathrm{C}\right)$ \\
\hline \multirow{11}{*}{$\begin{array}{l}\text { Deployment } \\
\text { Period }\end{array}$} & $\mathrm{T} 1$ & -2.06 & 2.92 & 3.22 \\
\hline & $\mathrm{T} 2$ & -2.55 & 2.55 & 2.71 \\
\hline & $\mathrm{T} 3$ & 0.92 & 0.92 & 1.11 \\
\hline & $\mathrm{T} 4$ & -2.08 & 2.58 & 3.54 \\
\hline & T5 & 0.66 & 0.67 & 0.92 \\
\hline & T6 & 0.29 & 0.29 & 0.79 \\
\hline & $\mathrm{T} 7$ & 0.64 & 0.64 & 0.65 \\
\hline & $\mathrm{C} 1$ & -2.71 & 3.21 & 3.78 \\
\hline & $\mathrm{C} 2$ & -0.26 & 1.67 & 2.05 \\
\hline & $\mathrm{C} 3$ & -0.04 & 0.23 & 0.30 \\
\hline & $\mathrm{C} 4$ & 0.45 & 0.70 & 0.76 \\
\hline \multirow{11}{*}{$\begin{array}{c}\text { Retrieval } \\
\text { Period }\end{array}$} & $\mathrm{T} 1$ & -0.25 & 1.45 & 1.80 \\
\hline & $\mathrm{T} 2$ & N/A & N/A & N/A \\
\hline & $\mathrm{T} 3$ & -2.33 & 2.33 & 2.39 \\
\hline & $\mathrm{T} 4$ & 0.63 & 0.63 & 0.70 \\
\hline & T5 & 0.67 & 0.67 & 0.67 \\
\hline & T6 & 1.04 & 1.04 & 1.06 \\
\hline & $\mathrm{T} 7$ & 0.09 & 0.11 & 0.15 \\
\hline & $\mathrm{C} 1$ & -1.68 & 2.11 & 2.23 \\
\hline & $\mathrm{C} 2$ & -0.60 & 0.91 & 1.17 \\
\hline & $\mathrm{C} 3$ & 0.84 & 0.85 & 0.92 \\
\hline & $\mathrm{C} 4$ & 0.06 & 0.62 & 0.68 \\
\hline Mean & & -0.39 & 1.29 & 1.50 \\
\hline
\end{tabular}



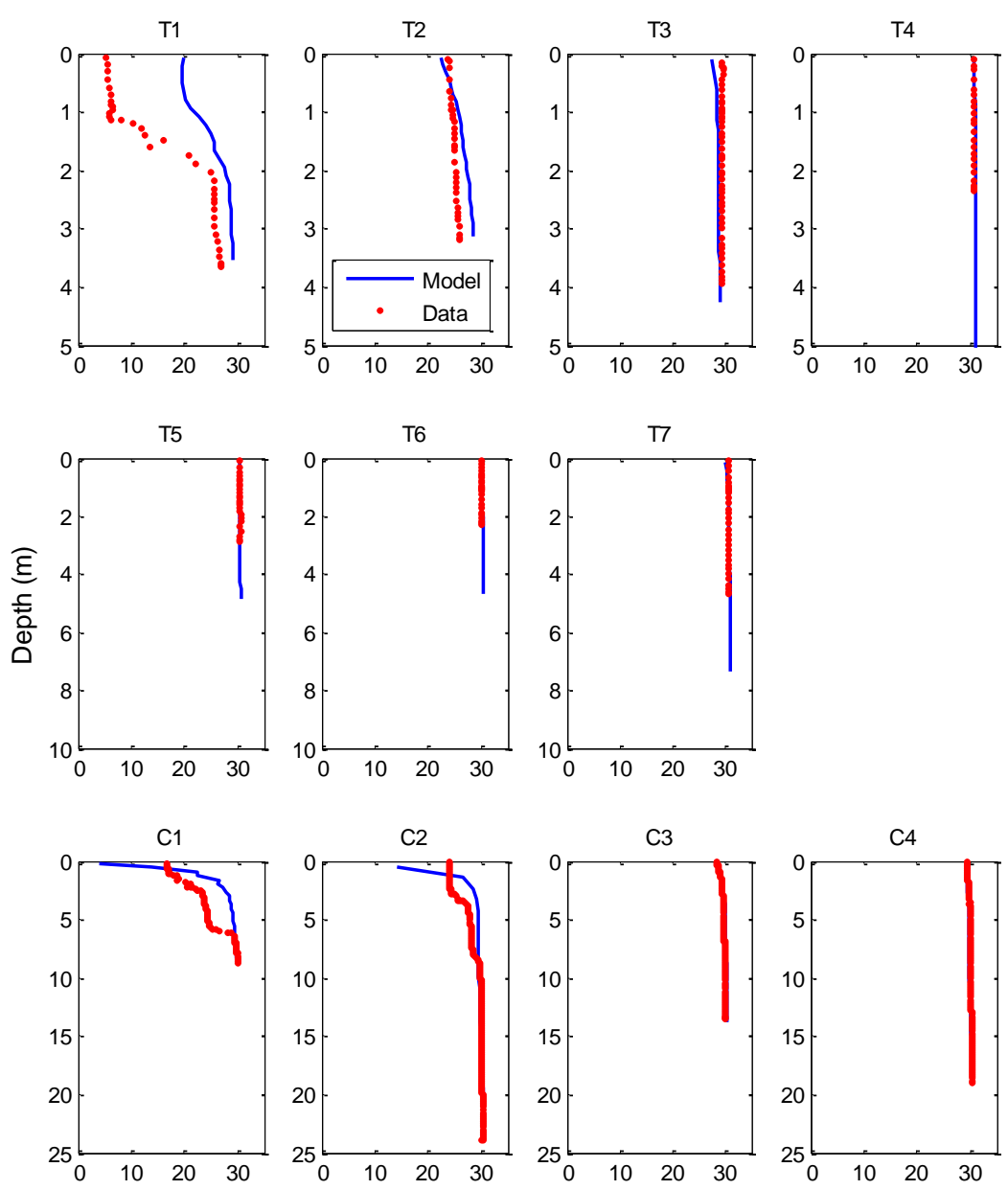

Figure 3.19. Comparisons of Predicted and Observed Salinity Vertical Profiles During Deployment Period on June 10 and 11, 2009 

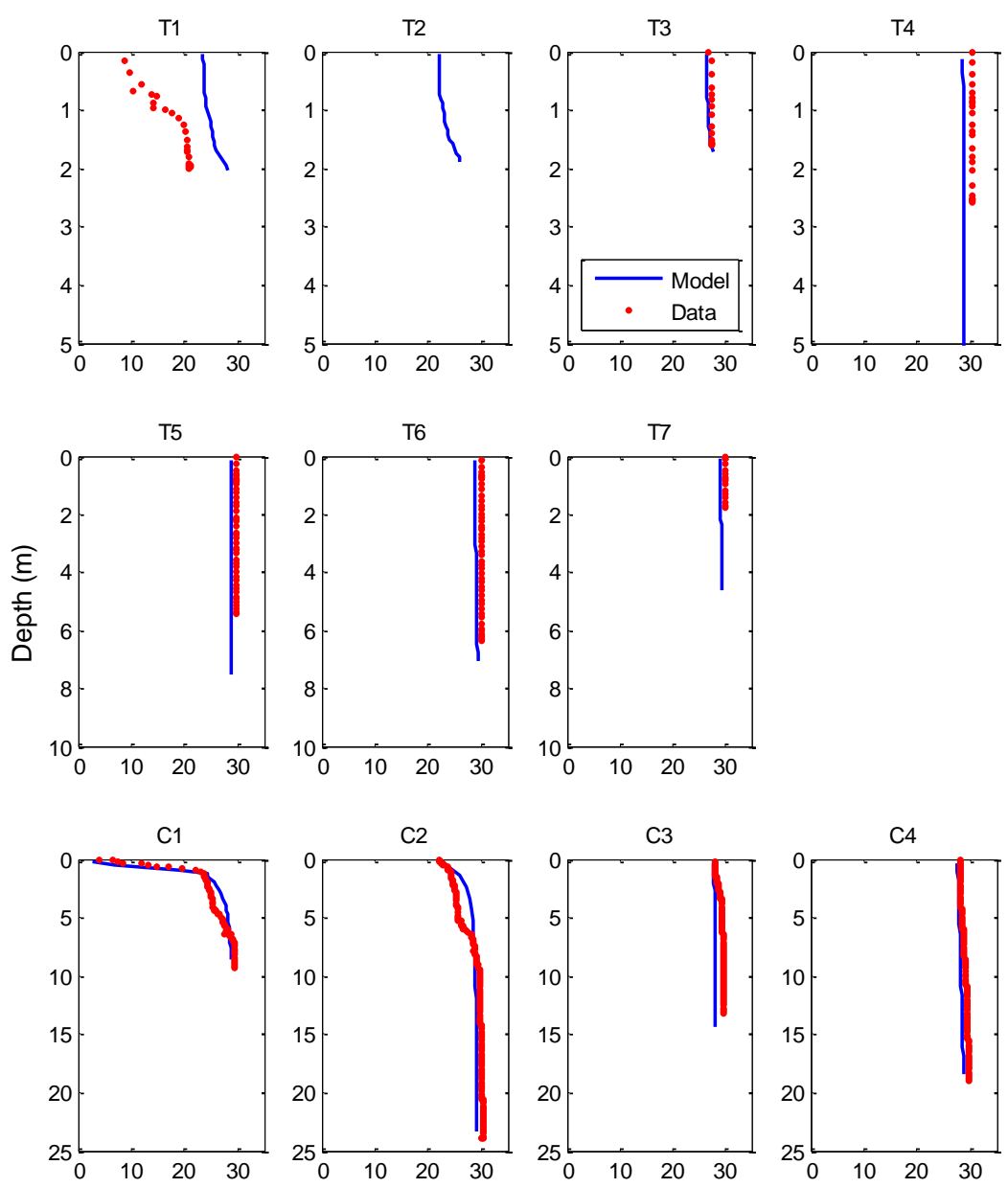

Figure 3.20. Comparisons of Predicted and Observed Salinity Vertical Profiles During Retrieval Period on June 25, 2009 
Table 3.7. Model Calibration Error Statistics for Salinity Vertical Profiles

\begin{tabular}{|c|c|c|c|c|}
\hline & Station & $\mathrm{ME}(\mathrm{ppt})$ & MAE (ppt) & RMSE (ppt) \\
\hline \multirow{11}{*}{$\begin{array}{l}\text { Deployment } \\
\text { Period }\end{array}$} & $\mathrm{T} 1$ & 8.04 & 8.04 & 9.64 \\
\hline & $\mathrm{T} 2$ & 1.43 & 1.67 & 1.84 \\
\hline & $\mathrm{T} 3$ & -0.91 & 0.91 & 0.98 \\
\hline & $\mathrm{T} 4$ & 0.47 & 0.47 & 0.54 \\
\hline & T5 & -0.10 & 0.10 & 0.11 \\
\hline & T6 & -0.02 & 0.10 & 0.12 \\
\hline & $\mathrm{T} 7$ & 0.07 & 0.19 & 0.23 \\
\hline & $\mathrm{C} 1$ & 2.36 & 3.68 & 4.72 \\
\hline & $\mathrm{C} 2$ & 0.21 & 1.16 & 2.38 \\
\hline & $\mathrm{C} 3$ & 0.21 & 0.22 & 0.23 \\
\hline & $\mathrm{C} 4$ & -0.20 & 0.20 & 0.21 \\
\hline \multirow{11}{*}{$\begin{array}{c}\text { Retrieval } \\
\text { Period }\end{array}$} & $\mathrm{T} 1$ & 9.01 & 9.01 & 9.73 \\
\hline & $\mathrm{T} 2$ & N/A & N/A & N/A \\
\hline & T3 & -0.64 & 0.65 & 0.71 \\
\hline & $\mathrm{T} 4$ & -1.27 & 1.27 & 1.31 \\
\hline & T5 & -0.93 & 0.93 & 0.93 \\
\hline & T6 & -1.04 & 1.04 & 1.05 \\
\hline & $\mathrm{T} 7$ & -1.43 & 1.43 & 1.56 \\
\hline & $\mathrm{C} 1$ & 0.13 & 1.57 & 2.12 \\
\hline & $\mathrm{C} 2$ & -0.07 & 1.16 & 1.33 \\
\hline & $\mathrm{C} 3$ & -1.35 & 1.35 & 1.43 \\
\hline & $\mathrm{C} 4$ & -0.78 & 0.78 & 0.82 \\
\hline Mean & & 0.63 & 1.71 & 2.00 \\
\hline
\end{tabular}

\subsection{Hydrodynamics in Bellingham Bay}

With the completion of hydrodynamic model calibration, it may be used to provide detailed hydrodynamic information in temporal and spatial scales in Bellingham Bay. We selected surface velocity and salinity as the example to illustrate their spatial distribution in Bellingham Bay during different tidal stages.

Figure 3.21 shows the surface velocity distribution during ebb tide at 6/24/2009 9:30 AM during spring tide (see inset for the reference of tidal phase). Water flows into the model domain from the northwest open boundary and leaves the model domain via the south open boundary. The strongest current (with magnitude $>3 \mathrm{~m} / \mathrm{s}$ ) occurs in the Rosario Strait and Bellingham Channel (Figure 1.1). The water inside Bellingham and adjacent Samish and Padilla Bays tends to ebb out the system through 
channels around Guemes Island. Inside Bellingham Bay, the velocity is small in general except in the river channels of the Nooksack River.

Figure 3.22 shows the surface velocity distribution during low tide at 6/24/2009 12:00 PM. Compared to previous ebb stage, the overall current magnitude decreases substantially, especially in the deep channels. Water inside Bellingham Bay continues flowing out of the system, as can be seen from the velocity in the middle portion of the Bay. In contrast, water inside Samish and Padilla Bays reaches the stagnant point.

Figure 3.23 shows the surface velocity distribution during the flood tide at 6/24/2009 5:00 PM. Compared to the velocity pattern during ebb tide shown in Figure 3.21, water flows into the model domain from the south open boundary and leaves via the northwest open boundary. It can be also seen that tides propagate into Bellingham Bay, mainly through the waterway south of Lummi Island and Sinclair Island from Bellingham Channel. However, a portion of the water is diverted into Samish Bay by Eliza Island. Again, compared to currents in the water bodies outside Bellingham Bay, currents inside Bellingham Bay are weaker.

Figure 3.24 shows the surface velocity distribution during high tide at 6/24/2009 8:30 PM. In contrast to the velocity pattern at flood tide, the velocity field is complicated and does not show a dominant flow pattern because water inside the model domain reaches the stagnant state, and tidal currents are at the reverse stage.

In Section 3.3.2, both model results and field observations indicate that currents at stations $(\mathrm{C} 1$ and C2) inside Bellingham Bay are much weaker than stations (C3 and C4) located in the channel between Lummi Island and Peninsula. At Station C2 in the middle of Bellingham Bay, velocities in both directions (East and North) are on the order of $0.1 \mathrm{~m} / \mathrm{s}$. The 2-D plots of current velocity also demonstrate that strongest currents tend to occur in the channels outside Bellingham Bay. During both flood and ebb, most ocean water tends to bypass Bellingham Bay. This is possibly due to the existence of multiple islands at the mouth of Bellingham Bay. One may expect that velocity magnitudes inside Bellingham Bay could be much restricted.

Figure 3.25 and Figure 3.26 show the distributions of surface salinity during low tide at $6 / 24 / 2009$ 12:00 PM and high tide at 6/24/2009 8:30 PM, respectively. The effect of the Nooksack River plume on salinity can be clearly seen at both tidal stages. During low tide (Figure 3.25), the front of the river plume intrudes south to the middle of Bellingham Bay. The effect of the freshwater plume in Lummi Bay can also be seen during low tide. Large tide flats in the Nooksack and Lummi river deltas play an important role in circulations near the region of estuarine mouths. The wetting and drying process in the tide flats is simulated in the hydrodynamic model in this study. The tide-flat feature during low tide can be clearly seen in Figure 3.25. For instance, the Nooksack River delta is largely exposed during the low tide. For Padilla Bay, more than half area of the Bay becomes dry during low tide in spring tide while during high tide (Figure 3.26), the river plume is pushed northward by ocean water and leaves Bellingham Bay through the channel between Lummi Island and Lummi Peninsula. However, the impact of the Nooksack River on salinity outside Bellingham Bay seems to be minimal. This is mainly attributed to the strong tidal exchanges outside Bellingham Bay. As for salinity inside Samish and Padilla Bays, it is primarily controlled by ocean water salinity because the river inflows into Samish Bay and Padilla Bay are small. 
In addition, the shape of the river plume serves as a useful indicator of the spatial distribution of riverderived substances (e.g., nutrients) inside Bellingham Bay. The calibrated hydrodynamic model can be used to quantify their physical retention time in Bellingham Bay in the future.

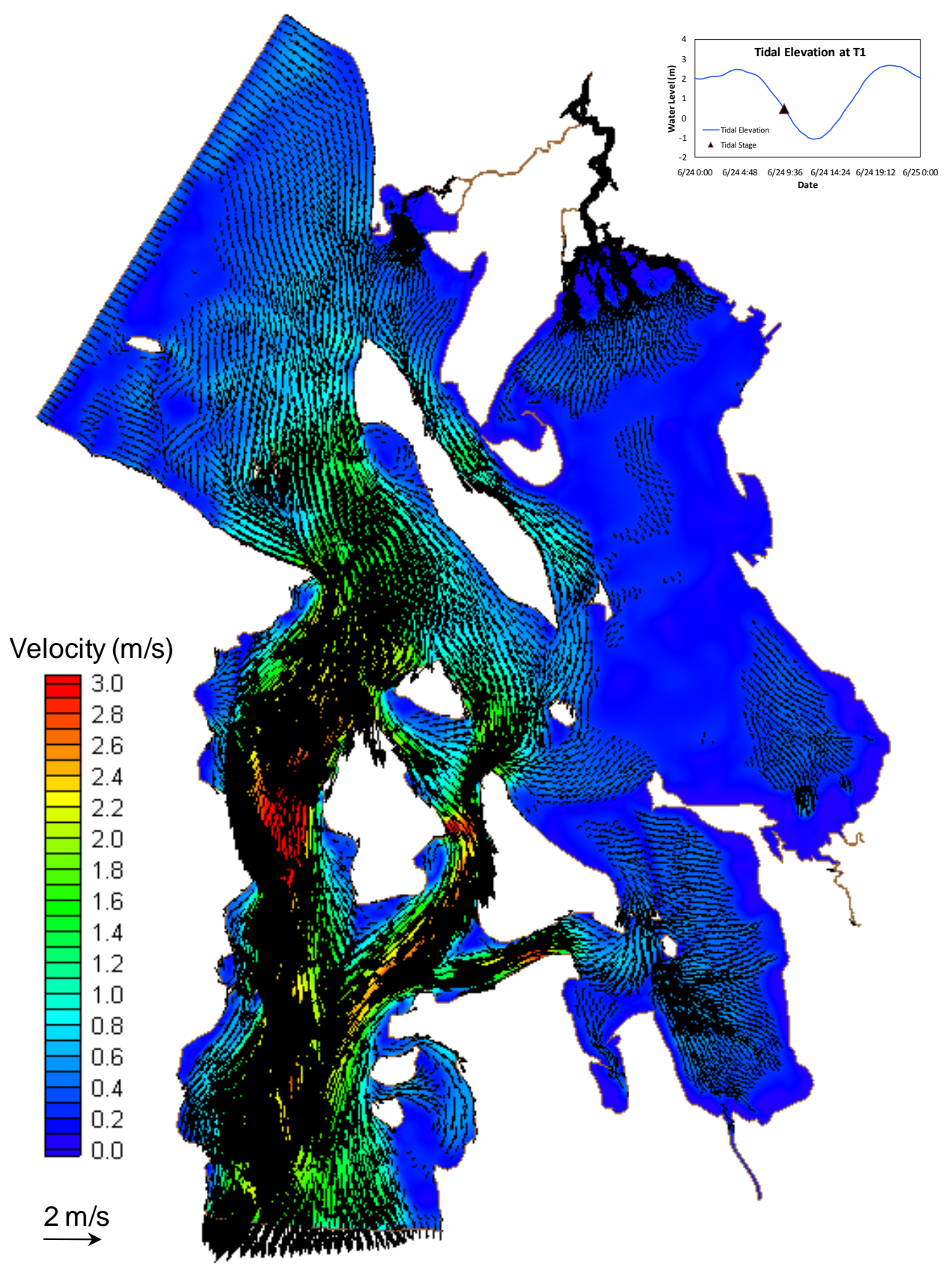

Figure 3.21. Snapshot of Surface Velocity During Ebb (6/24/2009 9:30 AM) 


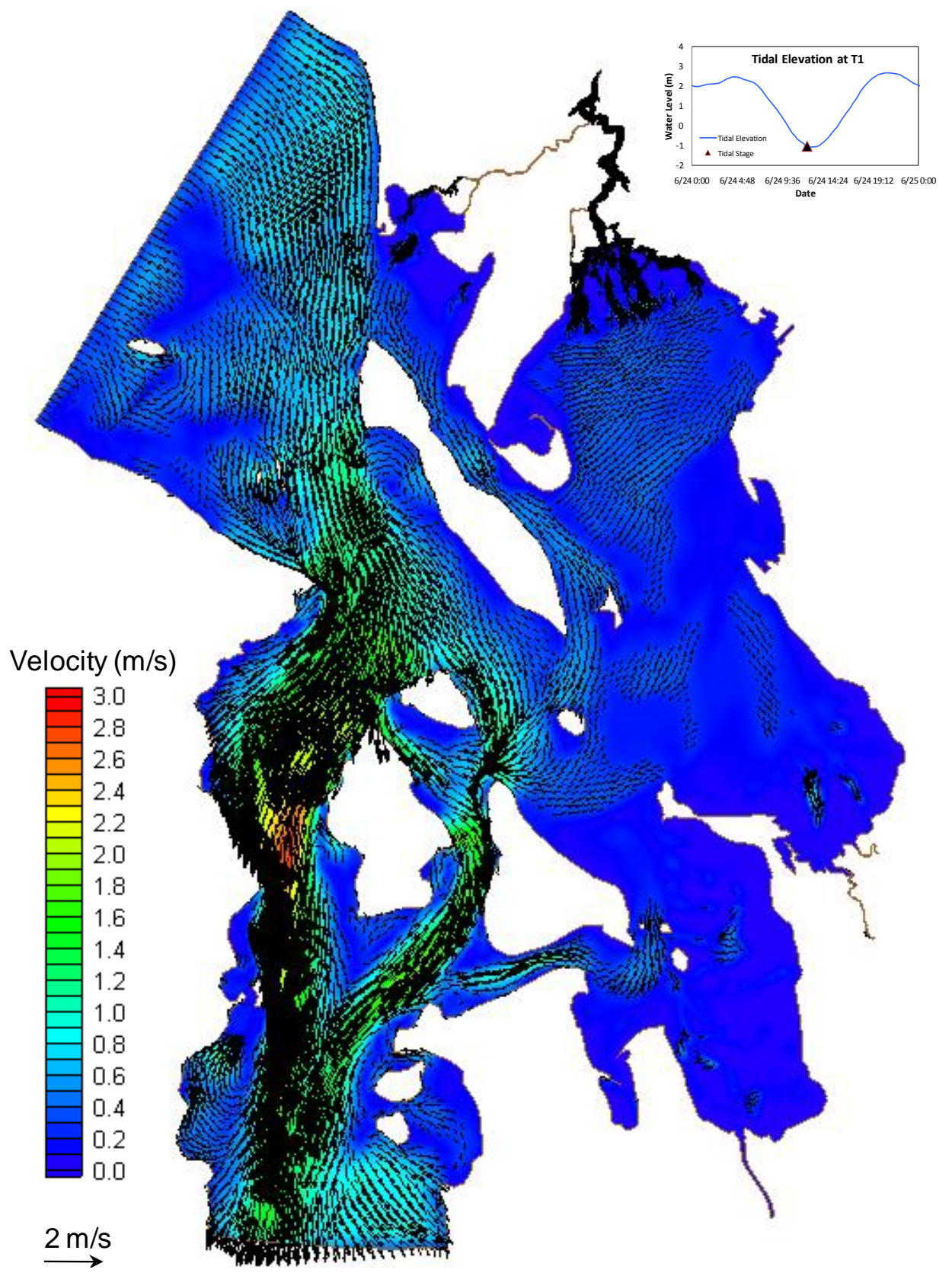

Figure 3.22. A Snapshot of Surface Velocity During Low Tide (6/24/2009 12:00 PM) 


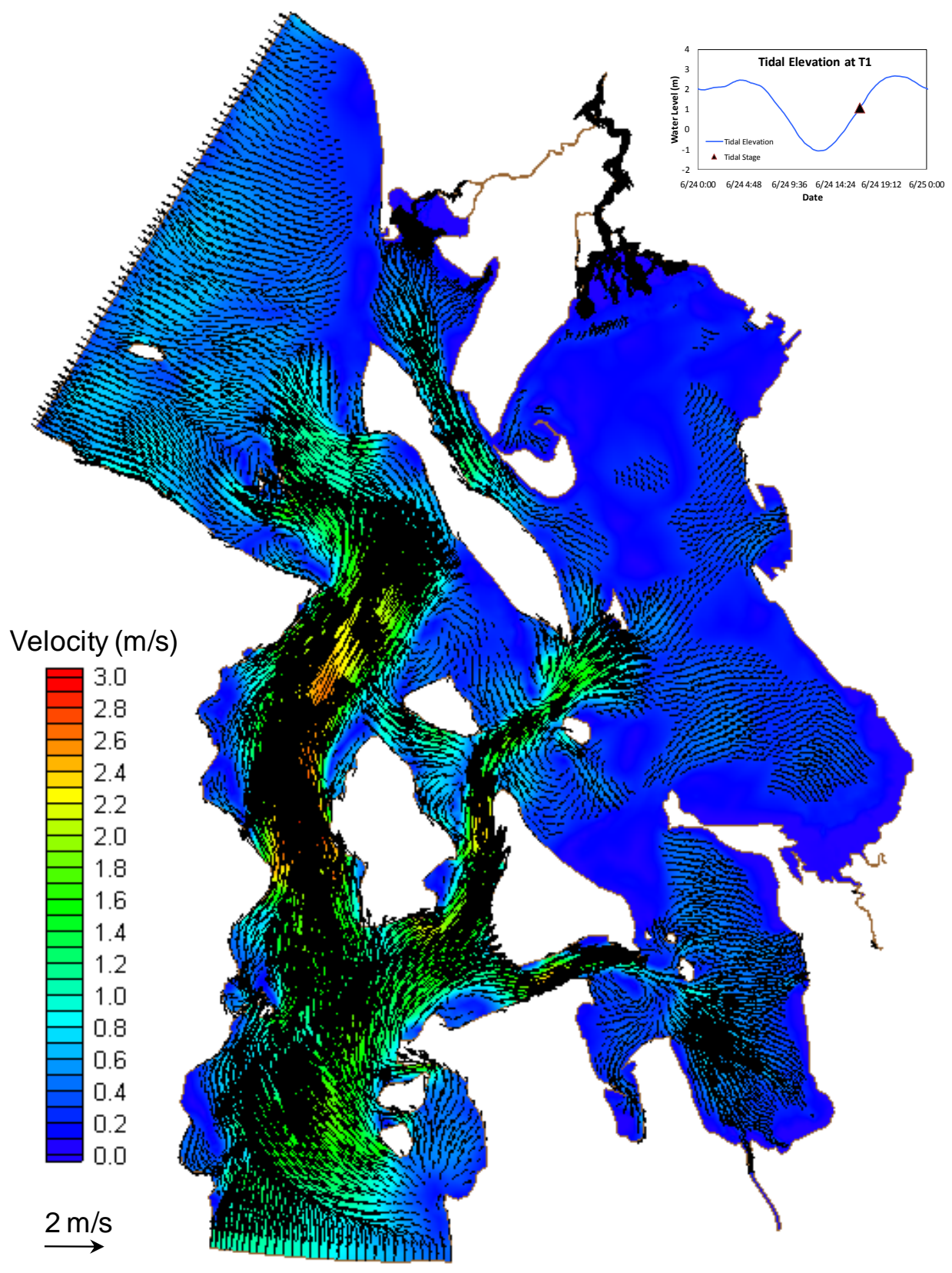

Figure 3.23. A Snapshot of Surface Velocity During Flood (6/24/2009 5:00 PM) 


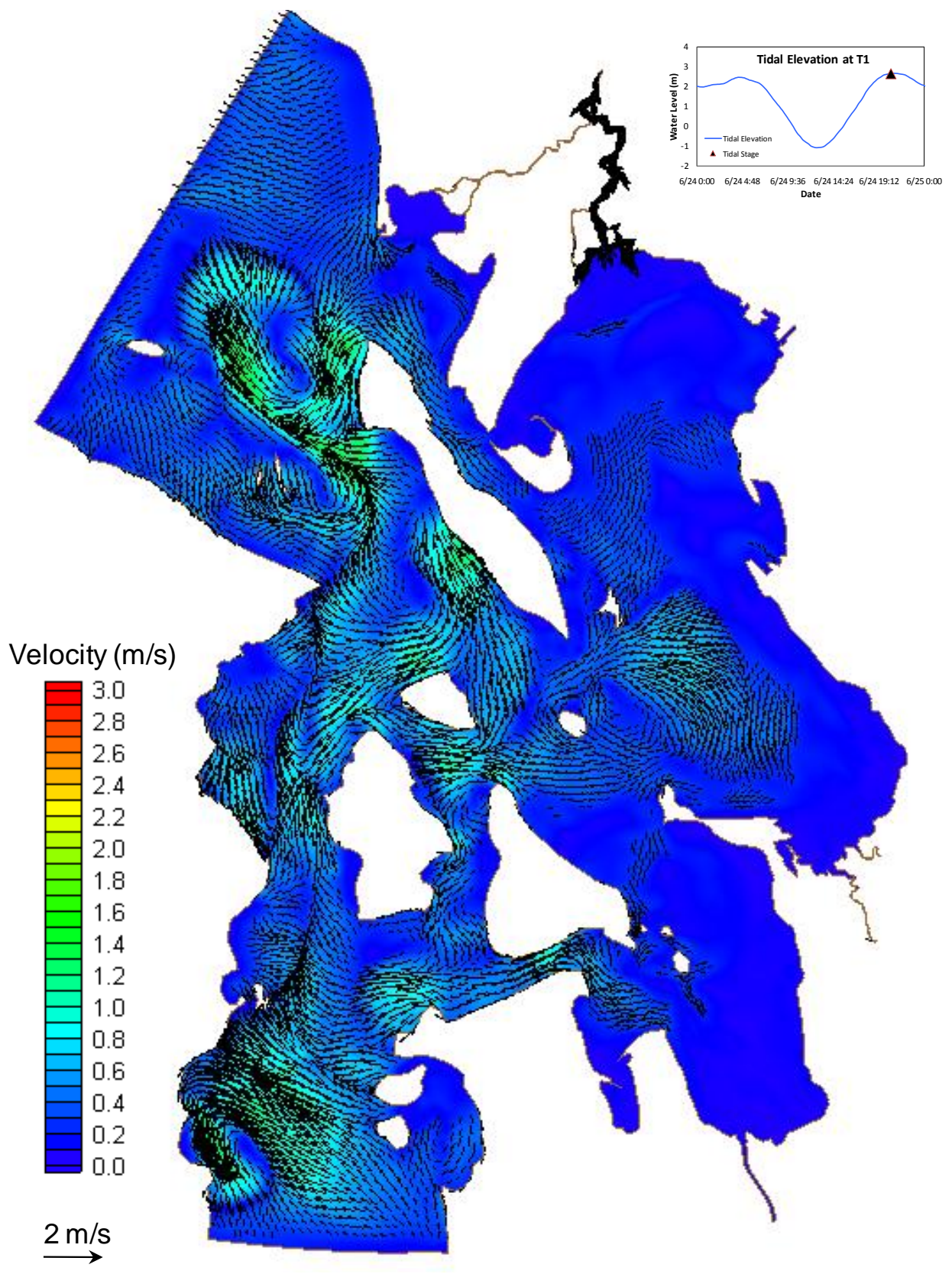

Figure 3.24. A Snapshot of Surface Velocity During High Tide (6/24/2009 8:30 PM) 


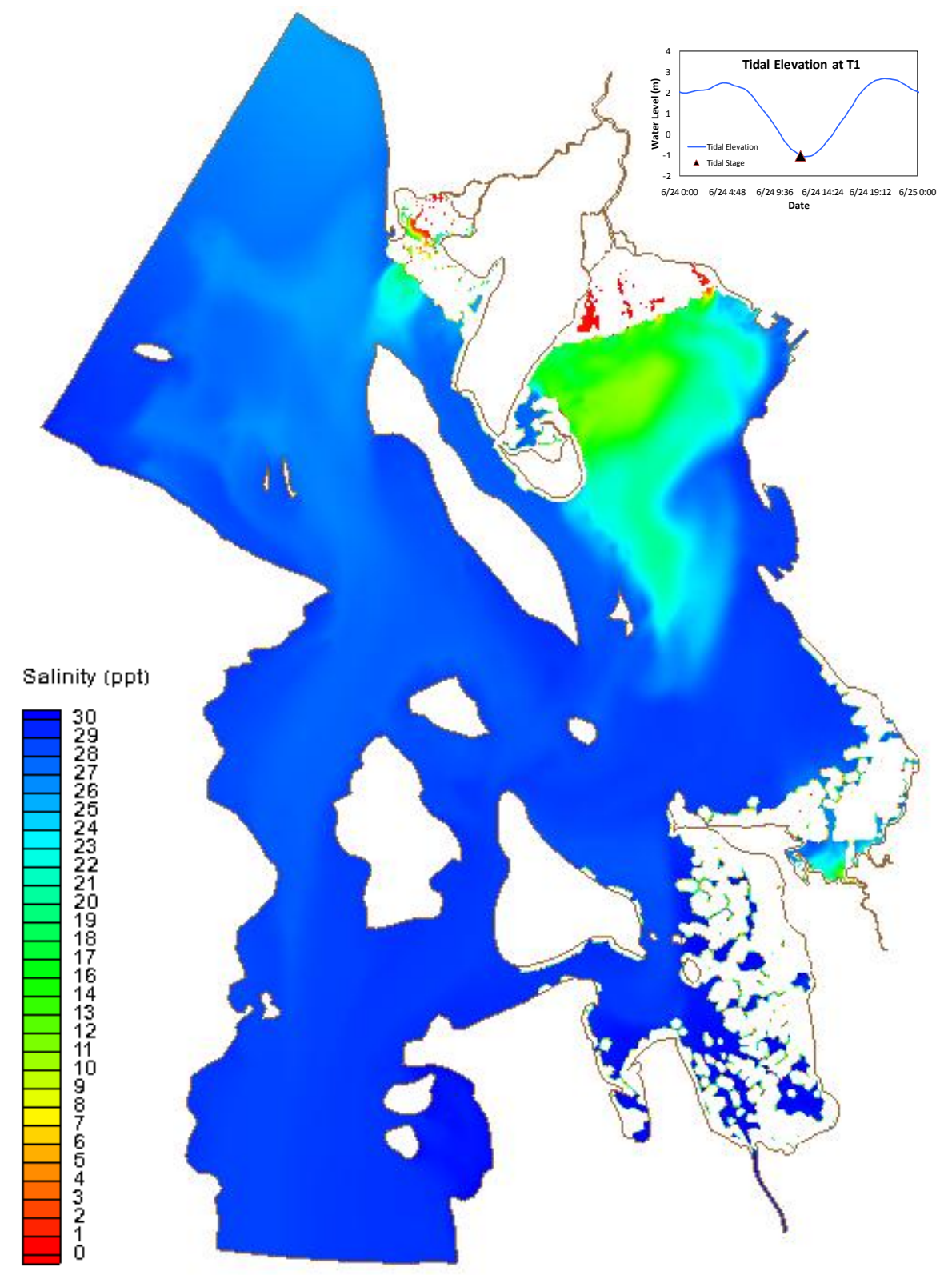

Figure 3.25. A Snapshot of Surface Salinity During Low Tide (6/24/2009 12:00 PM). The dried mudflat (while area) can be seen at the upper portions of Bellingham Bay. 


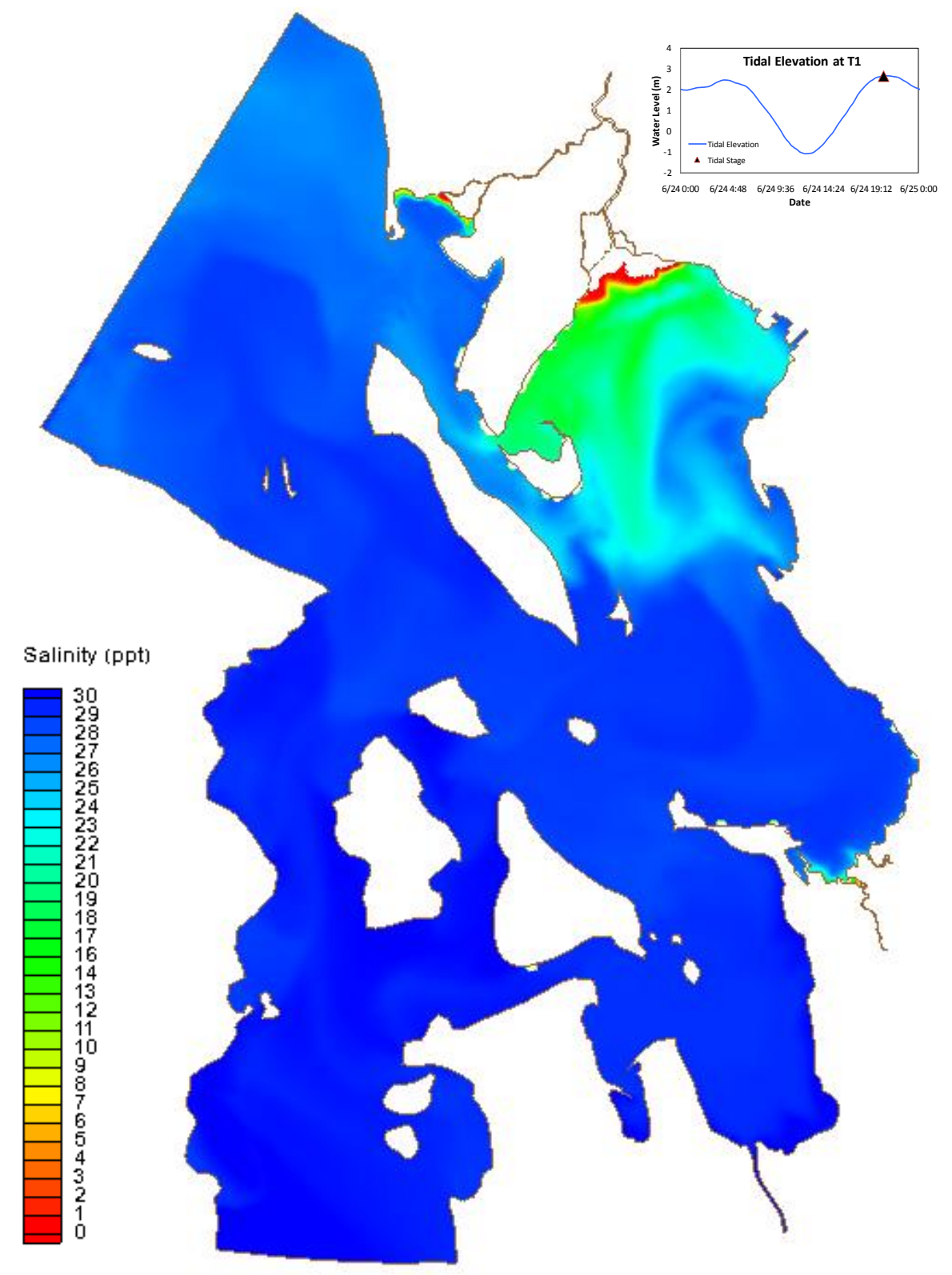

Figure 3.26. A Snapshot of Surface Salinity During High Tide (6/24/2009 8:30 PM)

\subsection{Linkage to GNOME}

The Bellingham Bay hydrodynamic model solution was linked to GNOME, for particle trajectory simulations. GNOME is a publicly available oil spill trajectory model that simulates oil movement due to winds, currents, tides, and spreading. It was developed by NOAA's Hazardous Materials Response Division (HAZMAT) and is used to calculate both the "best guess" (exact) trajectory of a spill and the larger "minimum regret" trajectory by including the potential uncertainty in the hydrodynamic forcing (NOAA 2002). "Best guess" stands for the numerical solution for particle trajectory calculated by GNOME based on exact current and wind input. In comparison, the "uncertainty" solution includes the 
potential uncertainty embedded in the current and wind input. An example of the model application is provided in Figure 3.27 and Figure 3.28. Figure 3.27 showed the initial release locations of particles in the center of Bellingham Bay at June 10, 2009 12:00 AM. Figure 3.28 shows the spatial distribution of particles after 5 days of initial release at June 15, 2009 12:00 AM.

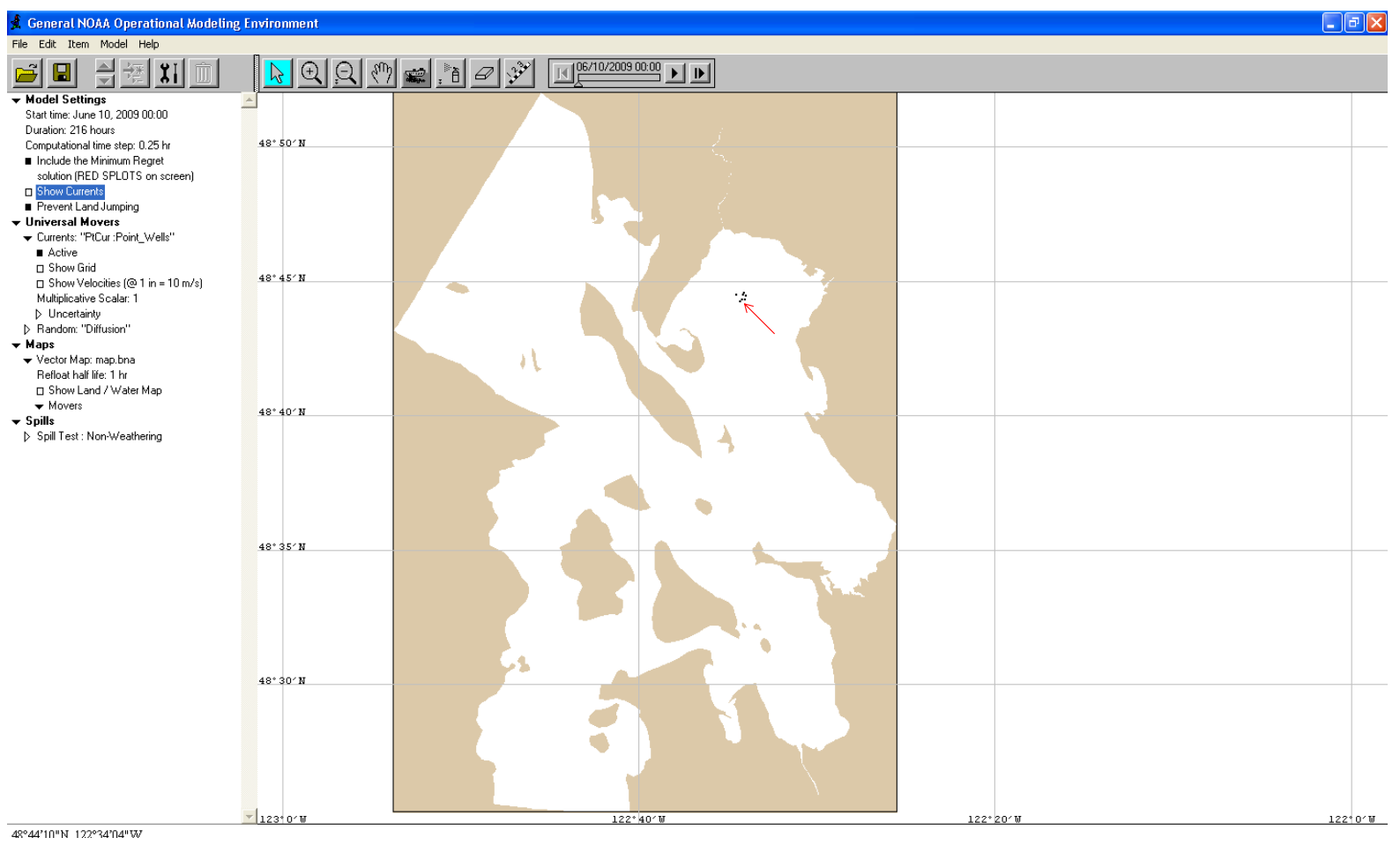

Figure 3.27. Initial Distribution of Released Particles (pointed by arrow) in Bellingham Bay 


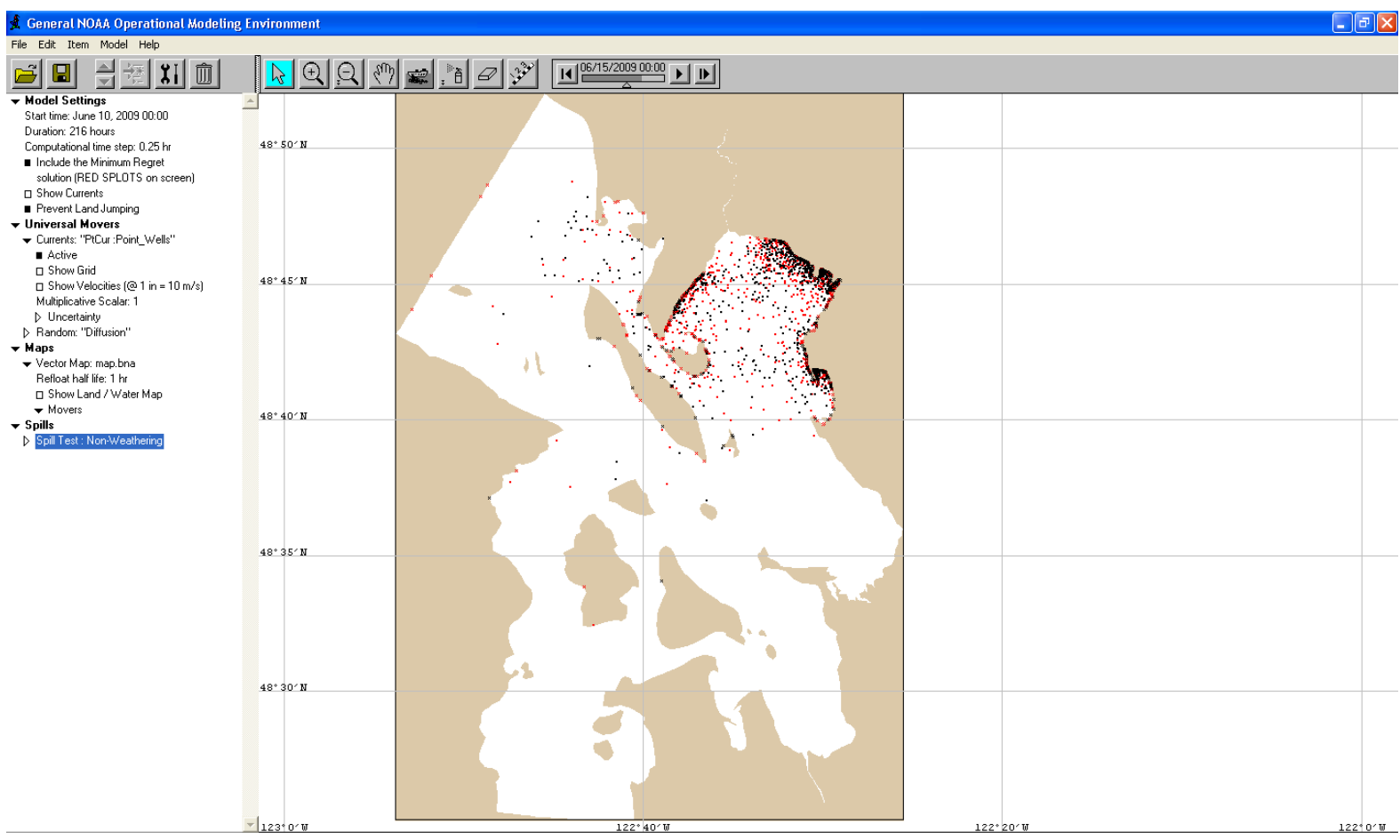

Figure 3.28. A Snapshot of Particle Distribution After 5 Days Simulation (black dots denote the "best guess" trajectory as truly calculated by the hydrodynamic model solutions while the red dots denote the larger "minimum regret" trajectory for the same spill when uncertainty is accounted in GNOME calculations) 



\subsection{Summary}

In this study, a hydrodynamic and transport model for Bellingham Bay and adjacent coastal waters was developed using the coastal ocean circulation model FVCOM that uses unstructured grids and finite volumes. The model simulates tides and currents, temperature, and salinity in Bellingham Bay in a threedimensional domain. The model was calibrated against oceanographic field data for the period of $6 / 10 / 2009$ to $6 / 25 / 2009$, which were collected specifically for the purpose of model development and calibration. The model development and calibration efforts are summarized as follows:

- The model was developed based on PNNL's high-resolution Puget Sound and Northwest Straits circulation and transport model. A sub-model grid for Bellingham Bay and adjacent coastal waters was extracted from the Puget Sound model and refined in the Bellingham Bay region using bathymetric LIDAR and river channel cross-section data.

- The model was applied using tides, river inflows, and meteorological forcing. A tidal open boundary condition was specified by XTide predictions. Temperature and salinity open boundary conditions were specified based on observed data. Meteorological forcing (wind and net heat flux) was obtained from NOAA real observations and NCEP NARR outputs.

- The model was applied in a parallelized mode with 48 cores using a time step of 2.5 seconds. It took 18 hours cpu time to complete 26 days simulation.

- The model was successfully calibrated using the following datasets collected during the field survey:

○ Times series of water surface elevation, temperature, and salinity

○ Time series of velocity at surface, middle, and bottom layers

○ Temperature and salinity profiles during instrument deployment and retrieval.

Averaged error statistics of model calibration for water surface elevation, velocity, temperature, and salinity at all stations (including time series and profiles) are provided in Table 4.1.

- The predicted tidal elevations and velocities matched reasonably well with observed data. The model was also able to reproduce the stratifications inside Bellingham Bay.

- Wetting and drying processes in tide flats in Bellingham Bay, Samish Bay, and Padilla Bay were successfully simulated.

- Both model results and observed data indicated that while water surface elevations inside Bellingham Bay are highly correlated to tides, velocities inside the bay may not be dominated by tidal forcing, and local factors such as wind and freshwater inflows could play an important role on the circulation.

- The Bellingham Bay model solution was successfully linked to NOAA oil-spill trajectory prediction model, GNOME.

A summary of model calibration statistics is provided below. As more field data become available, further improvement in accuracy may be possible with further refinement of model grids and additional analysis of model parameters. 
Table 4.1. Summary of Model Calibration Error Statistics

\begin{tabular}{ccccc}
\hline & $\begin{array}{c}\text { Water Level } \\
(\mathrm{m})\end{array}$ & $\begin{array}{c}\text { Velocity } \\
(\mathrm{m} / \mathrm{s})\end{array}$ & $\begin{array}{c}\text { Temperature } \\
\left({ }^{\circ} \mathrm{C}\right)\end{array}$ & $\begin{array}{c}\text { Salinity } \\
(\mathrm{ppt})\end{array}$ \\
\hline ME & 0.04 & 0.03 & 0.07 & 0.39 \\
MAE & 0.08 & 0.08 & 1.13 & 1.60 \\
RMSE & 0.11 & 0.10 & 1.28 & 1.91 \\
\hline
\end{tabular}

$(\mathrm{ME}=$ mean error, $\mathrm{MAE}=$ mean absolute error, $\mathrm{RMSE}=$ root mean square error $)$ 


\subsection{References}

Aoki K and A Isobe. 2007. "Application of Finite Volume Coastal Ocean Model to Hindcasting the Wind-Induced Sea-Level Variation in Fukuoka Bay.” J. Oceanography 63(2):333-339.

Blumberg A and G Mellor. 1987. "A description of a three-dimensional coastal ocean circulation model." In: Three-Dimensional Coastal Ocean Models. NS Heaps (Ed.), 1-16, American Geophysical Union, Washington, DC.

Chen C and M. Rawson. 2005. "An ecosystem management model system for the Satilla River Estuary, Georgia.” In: Oceans, 2005. Proceedings of MTS/IEEE, Vol. 1, pp. 622-632.

Chen C, H Liu, and RC Beardsley. 2003. "An Unstructured, Finite-Volume, Three-Dimensional, Primitive Equation Ocean Model: Application to Coastal Ocean and Estuaries." J. Atm. \& Oceanic Tech. 20:159-186.

Chen C, P Xue, P Ding, RC Beardsley, Q Xu, X Mao, G Gao, J Qi, C Li, H Lin, G Cowles, and M Shi. 2008. "Physical Mechanisms for the Offshore Detachment of the Chanjiang Diluted Water in the East China Sea." J. Geophys. Res., 113, C02002, doi: 10.1029/2006JC003994.

Finlayson DP, RA Haugerud, H Greenberg, and MG Logsdon. 2000. "Puget Sound Digital Elevation Model." University of Washington. Accessed on November 10, 2009 at: http://students.washington.edu/dfinlays/pugetsound/.

Flater D. 1996. “A Brief Introduction to XTide.” Linux Journal 32:51-57.

Galperin, B, L Kantha, S Hassid, and A Rosati. 1988. "A quasi-equilibrium turbulent energy model for geophysical flows." J. Atmos. Sci. 45:55-62.

Hamrick J. 1992. A three-dimensional environmental fluid dynamics computer code: theoretical and computational aspects. Special Report in Applied Marine Science and Ocean Engineering (SPAM-SOE) No. 317, Virginia Institute of Marine Science, Gloucester Point, Virginia.

Hart Crowser, Inc. 2009. Field Report - Bellingham Bay Oceanographic Data Collection. Bellingham, Washington.

Khangaonkar T and Z Yang. 2010. "A High Resolution Hydrodynamic Model of Puget Sound to Support Nearshore Restoration Feasibility Analysis and Design.” Ecological Restoration (in press).

Kantha, L and C Clayson. 1994. “An improved mixed layer model for geophysical applications.” J. Geophys. Res. 99:25235-25266.

Mellor G and T Yamada. 1982. "Development of a turbulence closure model for geophysical fluid problem" Rev. Geophys. Space. Phys. 20:851-875.

Mellor G and A Blumberg. 2004. "Wave breaking and ocean surface layer thermal response." J. Phys. Oceanogr. 34:693-698. 
Mesinger F, G DiMego, E Kalnay, K Mitchell, P Shafran, W Ebisuzaki, D Jovic, J Woollen, E Roger, E Herbery, M Ek, Y Fan, R Grumbline, W Higgins, H Li, Y Lin, G Manikin, D Parrish, and W. Shi. 2006. "North American regional reanalysis." Bulletin of the American Meteorological Society 87:343-360.

NOAA - National Oceanic and Atmospheric Administration. 2002. GNOME User's Manual. General NOAA Oil Modeling Environment.

NOAA - National Oceanic and Atmospheric Administration. 2009. Meteorological data at Cherry Point, Washington (Station ID: 9449424). Accessed October 30, 2009, at http://tidesandcurrents.noaa.gov/.

PSLC - Puget Sound Lidar Consortium. 2005. Lidar Bare Earth DEM [computer file]. Lummi Nooksack River. Accessed on November 10, 2009 at http://pugetsoundlidar.ess.washington.edu/.

Weisberg RH and L Zheng. 2006. "Circulation of Tampa Bay driven by buoyancy, tides, and winds, as simulated using a finite volume coastal ocean model.” J. Geophys. Res., 111, C01005, doi:10.1029/2005JC003067.

Yang Z and T Khangaonkar. 2007. Development of a Hydrodynamic Model of Puget Sound and Validation and Application for the Northwest Straits. PNNL-17161, Pacific Northwest National Laboratory, Richland, Washington.

Yang Z and T Khangaonkar. 2008. "Modeling Tidal Circulation and Stratification in Skagit River Estuary Using an Unstructured Grid Ocean Model.” Ocean Modelling, doi: 10.1016/j.ocemod.2008.07.004.

Yang Z, T Khangaonkar, M Calvi, and K Nelson. 2009a. Simulation of Cumulative Effects of Nearshore Restoration Projects on Estuarine Hydrodynamics. Ecol. Model. doi: 10.1016/j.ecolmodel.2008.12.006.

Yang Z, T Khangaonkar, R Labiosa, and T Kim. 2009b. Puget Sound Dissolved Oxygen Modeling Study: Development of an Intermediate-Scale Hydrodynamic Model. PNNL-18484, Pacific Northwest National Laboratory, Richland, Washington.

Yang Z, KL Sobocinski, D Heatwole, T Khangaonkar, R Thom, and R Fuller. 2010. "Hydrodynamic and Ecological Assessment of Nearshore Restoration: A Modeling Study." Ecol. Model.

doi:10.1016/j.ecolmodel.2009.07.011.

Zhao L, C Chen, and G Cowles. 2006. "Tidal Flushing and Eddy Formation in Mount Hope Bay and Narragansett Bay: An Application of FVCOM.” J. Geophys. Res., 111, C10015, doi:10.1029/2005JC003135.

Zheng L, C Chen, and H Liu. 2003. "A Modeling Study of the Satilla River Estuary, Georgia. Part I: Flooding/Drying Process and Water Exchange over the Salt Marsh-Estuary-Shelf Complex." Estuaries 26(3):651-669. 



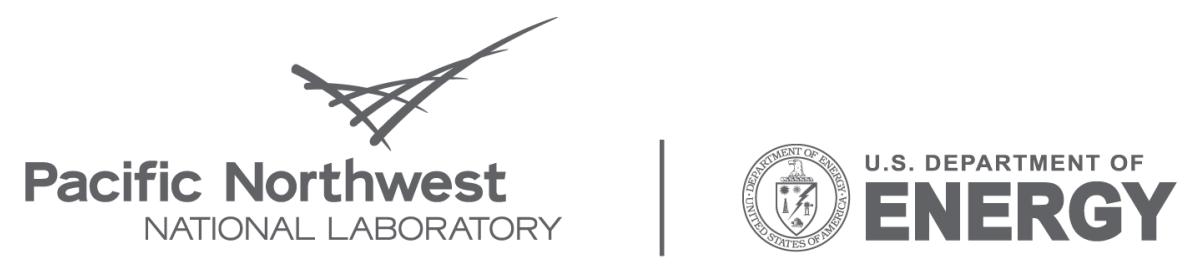

Proudly Operated by Battelle Since 1965

902 Battelle Boulevard

P.O. Box 999

Richland, WA 99352

1-888-375-PNNL (7665)

www.pnl.gov 